ADVANCED STEEL CONSTRUCTION

\section{An International Journal}

Volume 7 Number 2

June 2011

CONTENTS

Technical Papers

Establishment and Application of Cable-sliding Criterion Equation

Zhihua Chen, Hongbo Liu, Xiaodun Wang and Ting Zhou

Behavior of Lightweight Aggregate Concrete Filled Steel Tubular Slender Columns under

Axial Compression

Zhongqiu Fu, Bohai Ji, Lei Lv and Wenjie Zhou

Genetic Programming Based Modeling of Shear Capacity of Composite Beams with Profiled Steel Sheeting

M.A. Köroğlu, A. Köken, M.H. Arslan and A. Cevik

Hysteretic Performance of Connections to Gangue CFST Column with

Ring Stiffeners under Low Reversed Cyclic Loading

Guochang Li, Wei Sun and Roberto T. Leon

The Application of a HHT Based Ultrasonic Detecting Method in Quality Assessment of CFST Fuxiang Ye, Xiaoxiong Zha and Hongxin Wang

Effect of Dampers on Seismic Demand of Short Period Structures in Deep Cohesionless Sites N.S. Armouti

Copyright (ㄷ) 2011 by

The Hong Kong Institute of Steel Construction

Website: $h$ ttp://www.hkisc.org

ISSN 1816-112X

Science Citation Index Expanded, Materials Science Citation Index and ISI Alerting

Cover: Hong Kong Design Institute

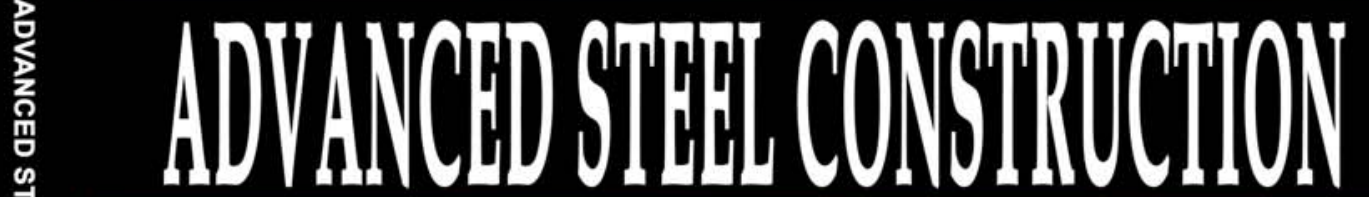

an International Journal ISSN 1816-112X

Volume 7 Number 2

June 2011

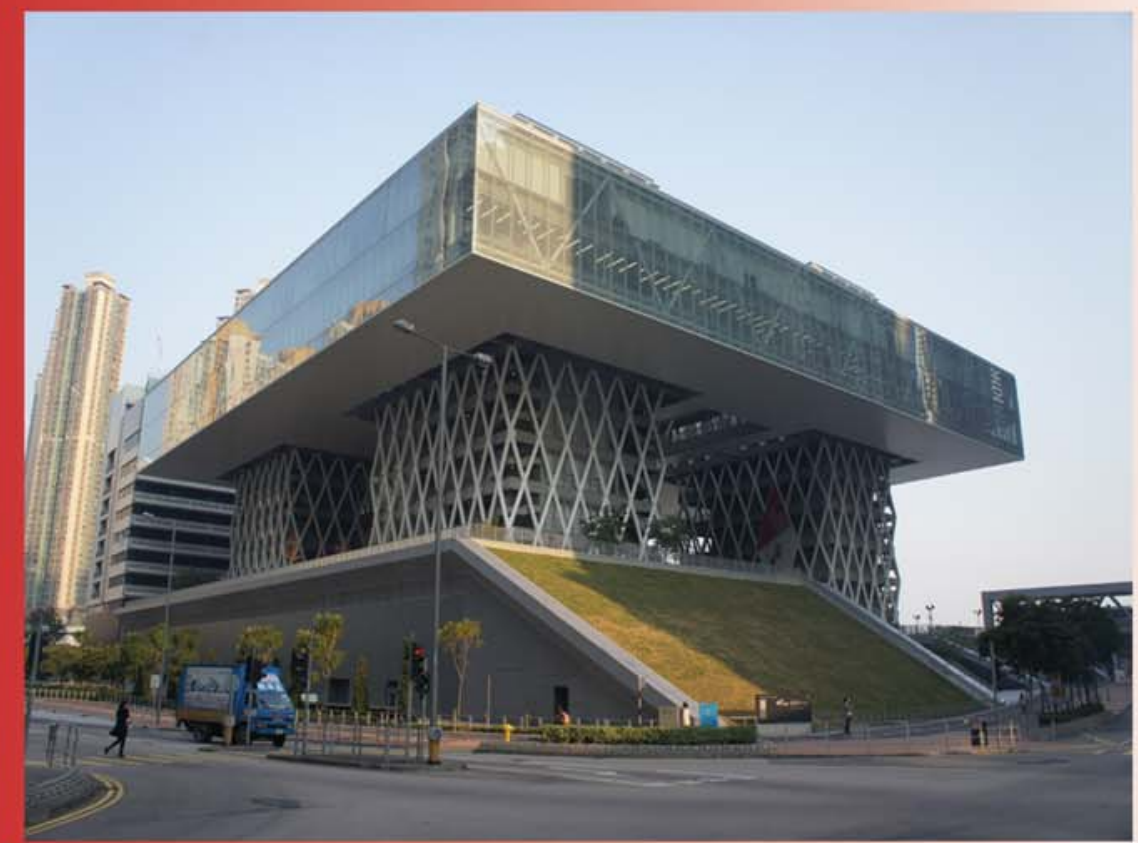

Editors-in-Chief

S.L. Chan, The Hong Kong Polytechnic University, Hong Kong

W.F. Chen, University of Hawaii at Manoa, USA

R. Zandonini, Trento University, Italy 


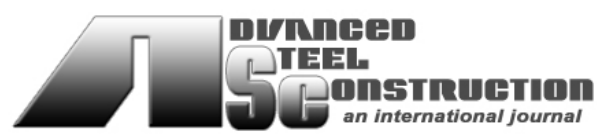

ISSN 1816-112X

Science Citation Index Expanded, Materials Science Citation Index and ISI Alerting

\section{EDITORS-IN-CHIEF}

Asian Pacific, African and organizing Editor

S.L. Chan

The Hong Kong Polyt. Univ., Hong Kong

\section{American Editor \\ W.F. Chen \\ Univ. of Hawaii at Manoa, USA}

\section{European Editor}

R. Zandonini

Trento Univ., Italy

\section{INTERNATIONAL} EDITORIAL BOARD

F.G. Albermani

The Univ. of Queensland, Australia

I. Burgess

Univ. of Sheffield, UK

F.S.K. Bijlaard

Delft Univ. of Technology, The Netherlands

R. Bjorhovde

The Bjorhovde Group, USA

M.A. Bradford

The Univ. of New South Wales, Australia

D. Camotim

Technical Univ. of Lisbon, Portugal

C.M. Chan

Hong Kong Uni v. of Science \& Technolog Hong Kong

T.H.T. Chan

Queensland Univ. of Technology, Australia

S.P. Chiew

Nanyang Technological Univ., Singapore

W.K. Chow

The Hong Kong Polyt. Univ., Hong Kong

K.F. Chung

The Hong Kong Polyt. Univ., Hong Kong

G.G. Deierlein

Stanford Univ., California, USA

\section{Advanced Steel \\ Construction an international journal}

L. Dezi

Univ. of Ancona, Italy

D. Dubina

The Politehnica Univ. of Tim

Romania

R. Greiner

Technical Univ. of Graz, Austria

L.H. Han

Tsinghua Univ. China

G.W.M. Ho

Ove Arup \& Pa rtners Hong Kon g Ltd., Hong Kong

B.A. Izzuddin

Imperial College of Science, Technology

and Medicine, UK

J.P. Jaspart

Univ. of Liege, Belgium

S. A. Jayachandran

IIT Madras, Chennai, India

S. Kitipornchai

City Univ. of Hong Kong, Hong Kong

D. Lam

Univ. of Bradford, UK

G.Q. Li

Tongji Univ., China

J.Y.R. Liew

National Univ. of Singapore, Singapore

E.M. Lui

Syracuse Univ., USA

Y.L. Mo

Univ. of Houston, USA

J.P. Muzeau

y, CUST, Clermont Ferrand, France

D.A. Nethercot

Imperial College of Science, Technology and Medicine, UK

Y.Q. Ni

The Hong Kong Polyt. Univ., Hong Kong

D.J. Oehlers

The Univ. of Adelaide, Australia

K. Rasmussen

The Univ. of Sydney, Australia

J.M. Rotter

The Univ. of Edinburgh, UK
C. Scawthorn

Scawthorn Porter Associates, USA

P. Schaumann

osoara, Univ. of Hannover, Germany

G.P. Shu

Southeast Univ. China

J.G. Teng

The Hong Kong Polyt. Univ., Hong Kong

G.S. Tong

Zhejiang Univ., China

K.C. Tsai

National Taiwan Univ., Taiwan

C.M. Uang

Univ. of California, USA

B. Uy

University of Western Sydney

M. Veljkovic

Univ. of Lulea, Sweden

F. Wald

Czech Technical Univ. in Prague, Czech

Y.C. Wang

The Univ. of Manchester, UK

Y.L. Xu

The Hong Kong Polyt. Univ., Hong Kong

D. White

Georgia Institute of Technology, USA

E. Yamaguchi

Kyushu Institute of Technology, Japan

Y.B. Yang

National Taiwan Univ., Taiwan

Y.Y.Yang

China Academy of Building Research,

Beijing, China

B. Young

The Univ. of Hong Kong, Hong Kong

X.L. Zhao

Monash Univ., Australia

Z.H. Zhou

Alpha Consultant Ltd., Hong Kong 



\begin{tabular}{ll}
\hline \hline & General Information \\
& Advanced Steel Construction, an international journal \\
\hline \hline Aims and scope
\end{tabular}

\section{Aims and scope}

The International Journal of Advanced Steel Construction provides a platform for the publication and rapid dissemination of ori ginal and up-to-date research and tec hnological developments in steel c onstruction, design and anal ysis. Scope of research $p$ apers published in this journal includes but is not limite $d$ to theor etical and expe rimental research on elements, assemblages, sy stems, material, design philosophy and codification, standards, fabrication, projects of innov ative nature an d computer tech niques. The journal is specifically $t$ ailored to channel the e xchange of tec hnological know-ho $w$ bet ween $r$ esearchers an d practitioners. Contributions from all aspects related to the recent developments of advanced steel construction are welcome.

\section{Instructions to authors}

Submission of the manuscript. Authors may submit double-spaced manuscripts preferably in MS Word by emailing to one of the chief editors as follows for arrangement of review. Alternatively papers can be submitted on a diskette to one of the chief editors.

Asian Pacific, African and organizing editor : Professor S.L. Chan, Email: ceslchan@polyu.edu.hk

American editor:

European editor:

Professor S.L. Chan, Email: ceslchan@polyu.edu

Professor R. Zandonini, Email: riccardo_zandonini@ing.unitn.it

All manuscripts submitted to the journal are recommended to accompany with a li st of four potential reviewers suggested by the author(s). This list should include the complete name, add ress, telephone and fax num bers, em ail address, and at least five keywords that identify the expertise of each reviewer. This scheme will improve the process of review.

Style of manuscript

General. Author(s) should provide full postal and email addresses and fax number for correspondence. The manuscript including abstract, keywords, references, figures and tables should be in English with pages numbered and typed with double line spacing on single side of A4 or letter-sized paper. The front page of the article should contain:

a) a short title (reflecting the content of the paper);

b) all the name(s) and postal and email addresses of author(s) specifying the author to whom correspondence and proofs should be sent;

c) an abstract of $100-200$ words; and

d) 5 to 8 keywords.

The paper must contain an introduction and a conclusion. The length of paper should not exceed 25 journal pages (approximately 15,000 words equivalents).

Tables and figures. Tables and figures including photographs should be typed, numbered consecutively in Arabic numerals and with short titles. They should be referred in the text as Figure 1, Table 2, etc. Originally drawn figures and photographs should be provided in a form suitable for photographic reproduction and reduction in the journal.

Mathematical expressions and units. The Systeme Internationale (SI) should be followed whenever possible. The numbers identifying the displayed mathematical expression should be referred to in the text as Eq. (1), Eq. (2).

References. References to published literature should be referred in the text, in the order of citation with Arabic numerals, by the last name(s) of the author(s) (e.g. Zandonini and Zanon [3]) or if more than three authors (e.g. Zandonini et al. [4]). References should be in English $w$ ith occasional allow ance of 1-2 e xceptional referenc es in local lang uages and $r$ eflect the curren $t$ state-of-technology. Journal titles should be abbreviated in the style of the Word List of Scientific Periodicals. References should be cited in the following style $[1,2,3]$.

Journal: [1] Chen, W.F. and Kishi, N., "Semi- rigid Steel Beam-to-column Connections, Data Base and Modellin g", Journal of Structural Engineering, ASCE, 1989, Vol. 115, No. 1, pp. 105-119.

Book: [2] Chan, S.L. and Chui, P.P.T., "Non-linear Static and Cyclic Analysis of Semi-rigid Steel Frames", Elsevier Science, 2000.

Proceedings: [3] Zandonini, R. a nd Zanon, P., "Experimental Analy sis of S teel Beams with Semi -rigid Joint s", Proceedings of International Conference on Advances in Steel Structures, Hong Kong, 1996, Vol. 1, pp. 356-364.

Proofs. Proof will be sent to the c orresponding author to correct an y typesetting errors. Alternations to the original manuscript at this stage will not be accepted. Proofs should be returned within 48 hours of receipt by Express Mail, Fax or Email.

Copyright. Submission of an article to "Advanced Steel Construction" implies that it presents the original and unpublished work, and not under consideration for publication nor published elsewhere. On acceptance of a manuscript submitted, the copyright thereof is transferred to the publisher $b y$ the Transfer of $C$ opyright Agreement and upon $t$ he acceptance of publication for the $p$ apers, the corresponding author must sign the form for Transfer of Copyright.

Permission. Quoting from this journal is granted provided that the customary acknowledgement is given to the source.

Page charge and Reprints. There will be no page charges if the length of paper is within the limit of 25 journal pages. A total of 30 free offprints will be supplied free of charge to the corresponding author. Purchasing orders for additional offprints can be made on order forms which will be sent to the authors. These instructions can be obtained at the Hong Kong Institute of Steel Construction, Journal website: http://www.hkisc.org

The International Journal of Advanced Steel Construction is published quarterly by non-profit making learnt society, The Hong Kong Institute of Steel Construction, c/o Department of Civil \& Structural Engineering, The Hong Kong Polytechnic University, Hung Hom, Kowloon, Hong Kong.

Disclaimer. No responsibility is assumed for a ny injury and / or damage to per sons or property as a matter of products liability, negligence or otherwise, or from any use or operation of any methods, products, instructions or ideas contained in the material herein.

Subscription inquiries and change of address. Address all subscription inquiries and correspondence to Member Records, IJASC. Notify an address change as soon as possible. All communications should include both old and new addresses with zip codes and be accompanied by a mailing label from a recent issue. Allow six weeks for all changes to become effective.

The Hong Kong Institute of Steel Construction

HKISC

c/o Department of Civil and Structural Engineering,

The Hong Kong Polytechnic University,

Hunghom, Kowloon, Hong Kong, China.

Tel: 852- 27666047 Fax: 852- 23346389

Email: ces/chan@polyu.edu.hk Website: http://www.hkisc.org/

ISSN 1816-112X

Science Citation Index Expanded, Materials Science Citation Index and ISI Alerting

Copyright $\odot 2011$ by:

The Hong Kong Institute of Steel Construction. 



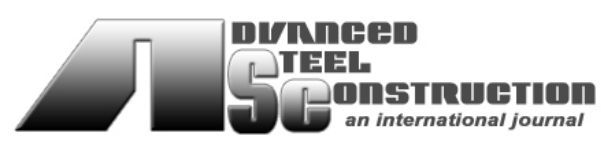

ISSN 1816-112X

Science Citation Index Expanded, Materials Science Citation Index and ISI Alerting

\section{EDITORS-IN-CHIEF}

Asian Pacific, African and organizing Editor

S.L. Chan

The Hong Kong Polyt. Univ., Hong Kong

Email: ceslchan@polyu.edu.hk

\section{American Editor}

W.F. Chen

Univ. of Hawaii at Manoa, USA

Email:waifah@hawaii.edu

\section{European Editor}

R. Zandonini

Trento Univ., Italy

Email: riccardo.zandonini@ing.unitn.it

\section{Advanced Steel \\ Construction an international journal}

VOLUME 7 NUMBER 2

JUNE 2011

Technical Papers

Establishment and Application of Cable-sliding Criterion

Equation

Zhihua Chen, Hongbo Liu, Xiaodun Wang and Ting Zhou

Behavior of Lightweight Aggregate Concrete Filled Steel Tubular

Slender Columns under Axial Compression

Zhongqiu Fu, Bohai Ji, Lei Lv and Wenjie Zhou

Genetic Programming Based Modeling of Shear Capacity of

Composite Beams with Profiled Steel Sheeting

M.A. Köroğlu, A. Köken, M.H. Arslan and A. Çevik

Hysteretic Performance of Connections to Gangue CFST Column with Ring Stiffeners under Low Reversed Cyclic Loading

Guochang Li, Wei Sun and Roberto T. Leon

The Application of a HHT Based Ultrasonic Detecting Method in Quality Assessment of CFST

Fuxiang Ye, Xiaoxiong Zha and Hongxin Wang

Effect of Dampers on Seismic Demand of Short Period Structures in Deep Cohesionless Sites

N.S. Armouti 



\title{
ESTABLISHMENT AND APPLICATION OF CABLE-SLIDING CRITERION EQUATION
}

\author{
Zhihua Chen ${ }^{1,2}$, Hongbo Liu ${ }^{1, *}$ Xiaodun Wang ${ }^{1}$ and Ting Zhou ${ }^{1}$ \\ ${ }^{1}$ Department of Civil Engineering, Tianjin University, Tianjin 300072, China \\ ${ }^{2}$ Tianjin Key Laboratory of Civil Engineering Structure \& New Materials, \\ Tianjin University, Tianjin 300072, China \\ *(Corresponding author: E-mail: hb_liu2008@163.com)
}

Received: 15 May 2010; Revised: 20 September 2010; Accepted: 23 October 2010

\begin{abstract}
Based on thermal expansion theory, cable-sliding criterion equations are derived for the static analysis of cable-pulley systems. The friction between cable and pulley is considered in the equations. The cable-sliding criterion equations can govern the sliding motion between cable and pulley. In terms of the governing equations, a few program codes can be easily implemented using the APDL language of ANSYS software. The implemented program is further adopted in the following three examples: the structural behavior of a suspen-dome structure with sliding cable-strut joints; the constructional process of a suspen-dome structure with sliding cable-strut joints and the design of a tree structure. The analytical results show that the cable-sliding criterion equations are effective in describing the sliding motion between cable and pulley.
\end{abstract}

Keywords: Cable-pulley systems; sliding; friction; suspen-dome structure; tree structure

\section{INTRODUCTION}

Pulley-cable systems have considerable advantages in the field of engineering, such as structural simplicity, compactness, low friction, absorbing shock and transferring forces. They have been widely employed in cars, cranes, robots, etc.. Furthermore, pulley cable systems are also introduced to spatial structures, such as pre-stressed space truss [1], suspen-dome structure with sliding cable-strut joints [2]. In addition, it has been applied in some structural design processes, e.g., the form finding analysis of tree structure [3].

For the modeling of cable passing through a pulley, Aufaure [4, 5], Zhou [6] and Ju [7] proposed different finite element models to study the deformation and dynamic behavior of structures. The pulley cable systems are included in their study with the assumption of the equal tensions in the cable segments at two sides of a pulley. However, friction exists between cables and the pulley surface $[8,9]$, which results in different tension values at two side of a pulley. The similar frictional effects have been investigated on rigging slings in a heavy lift system [10-12].

In the finite element models, sliding cable elements are often adopted to investigate the mechanical behavior of structures with pulley-cable systems. However, a large number of program codes are needed in terms of complicated mathematical theory and finite element theory. Therefore, this method is not widely applied in practice. This limitation motivates the study on the cable-sliding criterion equations in this paper. The equations are based on thermal expansion theory to describe the pulley-cable system. In terms of the equations, only a few program codes are needed using APDL language in ANSYS software. The derived equations are easily understood and applied in practice. 


\section{PULLEY-CABLE SYSTEM SIMULATION IN ANSYS}

In general, sliding cable elements are not available in commercial finite element (FE) software packages. However, structures including pulley-cable systems have to be modeled by establishing the sliding cable elements in analysis. The establishment of the elements is considerably difficult in the current commercial FE software packages. In order to overcome the difficulty, thermal expansion theory is adopted in this paper. The basic idea of the theory is that a virtual temperature-increased load is introduced in one-side cable of a pulley, and a virtual temperature-decreased load is applied in another side cable of a pulley. Subsequently, a nonlinear finite element analysis can be conducted using the commercial FE software packages. The modeling of the cable passing through pulleys is achieved. The following is the general procedure to analyze the pulley-cable system in ANSYS:

1) A finite element model is firstly established in ANSYS. Two-node LINK10 elements are adopted to simulate the cable member in pulley-cable systems without considering the sliding behavior between two sides of a pulley.

2) A nonlinear FE analysis is further conducted to obtain the tensions of all cable elements.

3) If the tensions of both side cables of a pulley are not in equilibrium, the cable may slide around the pulley. The sliding lengths around each pulley can be obtained by solving the cable-sliding criterion equations which are to be introduced in the following section. According to these sliding lengths around each pulley, the virtual temperature of both sides of each pulley can be evaluated using thermal expansion theory.

4) After that, a virtual temperature is applied to the corresponding cable element. A re-analysis on the pulley-cable system is fulfilled to obtain the tensions of all cable elements.

5) Finally, the tensions of both sides of pulleys are verified. If they are in equilibrium, the analysis is completed. If not, Step 3 through Step 5 are repeated until the equilibrium is achieved.

\section{CABLE-SLIDING CRITERION EQUATIONS}

Thermal expansion theory is employed to investigate the cable-pulley system. The critical issue is to accurately obtain the sliding length of cables passing through a pulley. The cable-sliding criterion equations are derived for solving the sliding length of cables passing through a pulley.

\subsection{Relationship of the Tensions at Two Sides of a Pulley}

Figure 1 shows the tensions in the two cables around a pulley with slip. The inertial effect of the pulley is neglected. The relationship between the tensions at two sides on the edge of slipping is given by Euler's equation as [13]:

$T_{2}=\alpha T_{1}$

Where the tension ratio $\alpha$ is given as:

$\alpha=e^{\mu \theta}$, 
Where $\mu$ is the friction coefficient and $\theta$ is the contact angle as shown in Figure 1. Eq. 1 will be applied to build the relationship between the tensions in the two adjacent cable elements in cable-pulley systems.

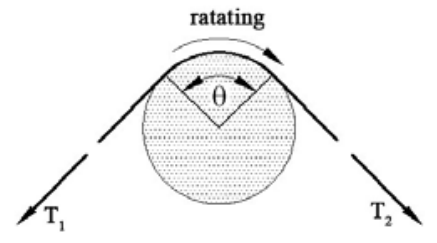

Figure 1. Cable Passing Through a Pulley

\subsection{Cable-sliding Criterion Equations for Pulley-cable Systems}

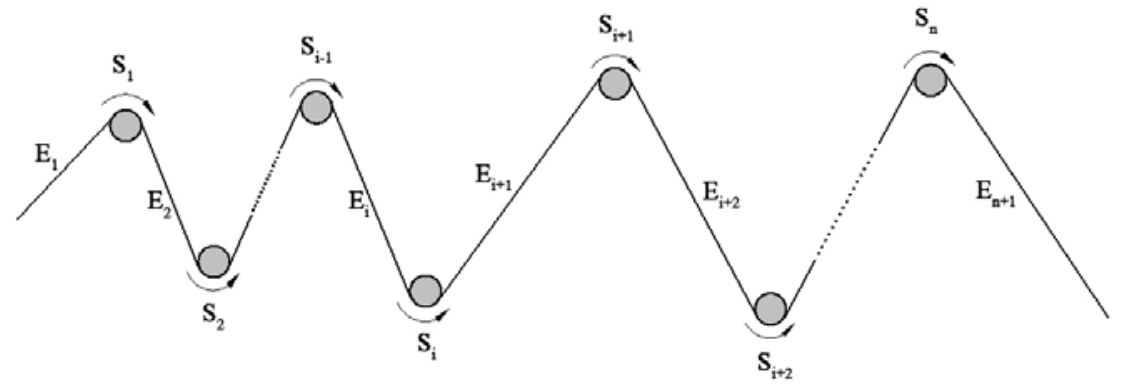

Figure 2. Pulley Cable Systems

Figure 2 gives the diagram for deriving the cable-sliding criterion equations. Symbol $S_{i}(i=1,2, \cdots, n)$ denotes pulley number, and $E_{i}(i=1,2, \cdots, n+1)$ denotes cable element number. It is well known that if the force $F_{i}$ (internal force in cable i) of both sides of a pulley are not in equilibrium, the cable will slide around the pulley until it reaches equilibrium. Based on the deformed model, the force equilibrium equations at each pulley can be obtained as follows.

For Pulley 1 in Figure 2, the force equilibrium is given in Eq. 3a

$$
\frac{x_{1}-\lambda x_{n}}{l_{1}} E A_{1}+F_{1}=\left(\frac{x_{2}-x_{1}}{l_{2}} E A_{2}+F_{2}\right) \alpha \text {. }
$$

For Pulley $i(i=2,3, \cdots, n-1)$, the force equilibrium is presented in Eq. 3b

$$
\frac{x_{i}-x_{i-1}}{l_{i}} E A_{i}+F_{i}=\left(\frac{x_{i+1}-x_{i}}{l_{i+1}} E A_{i+1}+F_{i+1}\right) \alpha .
$$

For Pulley $n$, the force equilibrium is expressed in Eq. 3c

$$
\frac{x_{n}-x_{n-1}}{l_{n}} E A_{n}+F_{n}=\left(\frac{\lambda x_{1}-x_{n}}{l_{n+1}} E A_{n+1}+F_{n+1}\right) \alpha \text {. }
$$

Rearranging the force equilibrium Eqs. 3a to 3c, the following equations can be obtained

$$
\left[\frac{E A_{1}}{l_{1}}+\frac{E A_{2} \alpha}{l_{2}}\right] x_{1}-\left[\frac{E A_{2} \alpha}{l_{2}}\right] x_{2}-\left[\frac{\lambda E A_{1}}{l_{1}}\right] x_{n}=\alpha F_{2}-F_{1}
$$




$$
\begin{aligned}
& {\left[-\frac{E A_{i}}{l_{i}}\right] x_{i-1}+\left[\frac{E A_{i}}{l_{i}}+\frac{E A_{i+1} \alpha}{l_{i+1}}\right] x_{i}-\left[\frac{E A_{i+1} \alpha}{l_{i+1}}\right] x_{i+1}=\alpha F_{i+1}-F_{i}} \\
& {\left[-\frac{\lambda E A_{n+1} \alpha}{l_{n+1}}\right] x_{1}+\left[-\frac{E A_{n}}{l_{n}}\right] x_{n-1}+\left[\frac{E A_{n}}{l_{n}}+\frac{E A_{n+1} \alpha}{l_{n+1}}\right] x_{n}=\alpha F_{n+1}-F_{n}}
\end{aligned}
$$

where $\quad x_{i}=$ sliding length of the cable at Pulley $i(i=1,2, \cdots, n)$.

$\lambda=$ type number of the cable-pulley system. If the cable-pulley system is open-loop, $\lambda=0$; If the cable-pulley system is closed-loop, $\lambda=1$.

$A_{i}=$ the section area of cable element $i(i=1,2, \cdots, n, n+1)$.

$E=$ the elastic modulus of a cable element.

Eqs. 4 are the cable-sliding criterion equations, and the sliding length $x_{i}$ of cable at Pulley $i$ can be obtained by solving Eqs. 4. Then the length variation value of each cable element can be evaluated by the following equations, respectively:

$$
\begin{aligned}
& \text { for } \lambda=0 \quad\left(x_{1}\right),\left(x_{2}-x_{1}\right), \ldots,\left(x_{i}-x_{i-1}\right), \ldots,\left(x_{n}-x_{n-1}\right),\left(-x_{n}\right) \\
& \text { for } \lambda=1 \quad\left(x_{1}-x_{n}\right),\left(x_{2}-x_{1}\right), \ldots,\left(x_{i}-x_{i-1}\right), \ldots,\left(x_{n}-x_{n-1}\right)
\end{aligned}
$$

Moreover,

$$
\begin{aligned}
& \text { for } \lambda=0 \quad\left(x_{1}\right)+\left(x_{2}-x_{1}\right)+\ldots+\left(x_{i}-x_{i-1}\right)+\ldots+\left(x_{n}-x_{n-1}\right)+\left(-x_{n}\right)=0 \\
& \text { for } \lambda=1 \quad\left(x_{1}\left(-x_{n}\right)\right)+\left(x_{2}-x_{1}\right)+\ldots+\left(x_{i}-x_{i-1}\right)+\ldots+\left(x_{n}-x_{n-1}\right)=0
\end{aligned}
$$

Therefore, it is verified that the sliding length $x_{i}$ of the cable at pulley $i$ is obtained by solving the cable-sliding criterion equations. The equations satisfy the compatibility requirement of displacement. In other words, the original length is not changed. The virtual temperature loads of each cable element can be calculated in terms of Eqs. 7.

For cable element 1: $\quad-\alpha_{T} \Delta T_{1} L_{1}=\Delta L_{1}=x_{1}-\lambda x_{n}$

For cable element $i=2 \sim n: \quad-\alpha_{T} \Delta T_{i} L_{i}=\Delta L_{i}=x_{i}-x_{i-1}$

For cable element $n+1: \quad-\alpha_{T} \Delta T_{n+1} L_{n+1}=\Delta L_{n+1}=\lambda x_{1}-x_{n}$

The cable sliding around a pulley can be realized by applying these virtual temperature loads on all cable elements. For the cable-pulley systems in Figure 2, the structural analysis of all fixed pulleys can be done in one iteration using the proposed cable-sliding criterion equations. Only a few iterations are needed if the pulleys are movable. In a word, the cable-sliding criterion equations provide an easy way for the structural analysis of cable-pulley systems. The results are accurate with rapid convergence. Therefore, the cable-sliding criterion equations can be widely applied in practice. 


\section{MULTI-LINE PULLEY-CABLE SYSTEMS}

In the case of single cable-pulley systems, e.g., crane structures, beam string structures, cable-sliding criterion equations easily fulfill the task with well convergence. However, when multi-line cable-pulley systems are considered, such as suspen-dome structures, additional factors have to be considered as follows

1) In multi-line cable-pulley systems (e.g., suspen-dome structures with several single cable-pulley systems), the interference among each single cable pulley systems is very remarkable. For this type of systems, the convergence rate of cable-sliding criterion equations is slow and some solutions even disconverge in some cases.

2) Geometric nonlinearity of multi-cable pulley system is usually significant, which results in the slow convergence rate of the cable-sliding criterion equations.

In order to solve the above two problems, the following measures are adopted:

1) For the first problem, it can be solved by evaluating the virtual temperature firstly and applying the obtained virtual temperature to the corresponding cable pulley system one by one.

2) For the second problem, the solution process is divided into several steps. In each step, the amplification factor of the obtained virtual temperature is adopted according to different precision in each step.

As an illustrative example, the solution process of cable-sliding criterion equations is given in details for suspen-dome structure. The suspen-dome structure is a multi-cable pulley system.

1) A FE model is established using universal elements BEAM188, LINK8, and LINK10 in the commercial software package ANSYS. The assumption is made that the cable cannot slide around pulley;

2) A nonlinear analysis is conducted with the FE model. Both the material nonlinearity and geometric nonlinearity are considered;

3) Before the analysis, a precision error_ 1 is preliminarily set for the first step of the analysis (two steps are set in this example as well as two precisions);

4) The inner force $F_{i}^{j}$ of each cable element is obtained, where $i$ denote the cable number and $j$ denote the number of cable pulley system;

5) The unbalanced force at each pulley is evaluated. If the $M A X\left(\left|\Delta F_{i}\right|\right) \leq$ error_1, the current iteration of cable sliding is completed and then the computation goes to Step (7), or else the computation continues by Step (6);

$\Delta F_{i}=\left|F_{i+1}-\alpha F_{i}\right|$

6) If $\operatorname{MAX}\left(\left|\Delta F_{i}\right|\right) \geq$ error_ 1 , cable will slide around pulley until the system reach equilibrium. Using the proposed cable-sliding criterion equations, the virtual temperatures of each cable element are calculated and applied to the corresponding cable element to realize cable sliding around pulleys. It is noted that in order to obtain a well convergence, the virtual temperature of each 
cable pulley system are calculated and applied to the corresponding cable element one by one by an amplification factor $\varphi$. In other words, the virtual temperature of the first cable pulley system are calculated and applied firstly by multiplying amplification factor $\varphi$ and then for second cable pulley system, third cable pulley system ... and then return to step (4). In addition, the factor $\varphi$ can be taken to 1.0 2.0 by experience;

7) The second step iteration is carried out and set precision as control error _ 2 . Because two steps were set, error_ 2 must be an allowable value for practical purpose (if number of step is more than two, the control precision of last step must be allowable in practice). According to the analysis method in the first step, a structural analysis is carried out. It is noted that the amplification factor $\varphi$ of virtual temperature must be 1 in the last step iteration.

\section{VERIFICATION}

In this section, a static analysis of a continuous cable passing two pulleys is conducted to verify the proposed cable-sliding criterion equation. The system is shown in Figure 3. One end of the cable is connected to a winch with a pulling force of $80 \mathrm{kN}$. The other end is connected to a structure member or a payload. The force and displacement boundary conditions are also indicated in Figure 3. The diameter and Yong's modulus of the cables are assumed to be $26 \mathrm{~mm}$ and $50 \mathrm{kN} / \mathrm{mm}^{2}$, respectively. The example is the same as that in Ref. [10].

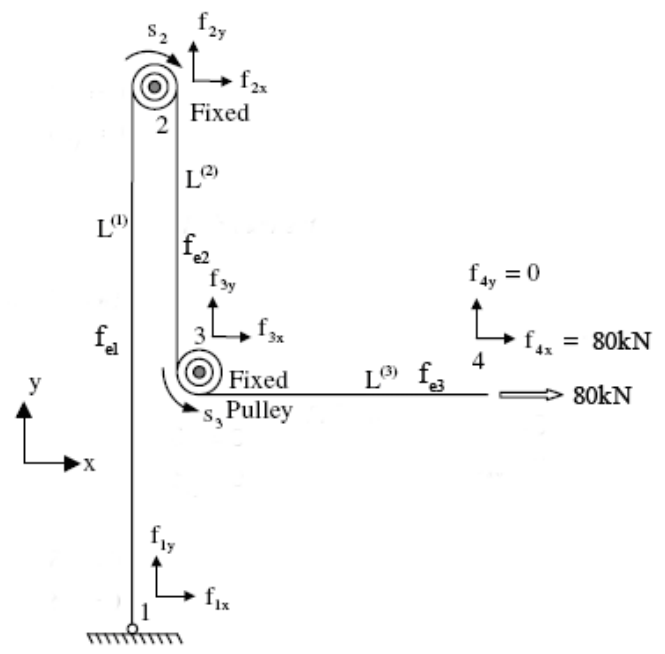

Figure 3. A Continuous Cables Passing through Two Fixed Pulleys

Result 1 in Table 1 is given by the proposed method in this paper and Result 2 is evaluated by the formulae presented in Ref. [10]. Comparisons show that the results of the proposed method agree well with the results given by Ref. [10]. Therefore, the proposed method is effective to analyze the cable pulley system by using the cable-sliding criterion equations.

Table 1. Summary of the Analysis Results

\begin{tabular}{|c|c|c|c|c|c|c|}
\hline Item & $\mathrm{F}_{1 \mathrm{y}}$ & $\mathrm{F}_{2 \mathrm{y}}$ & $\mathrm{F}_{3 \mathrm{y}}$ & $\mathrm{S}_{1}$ & $\mathrm{~S}_{2}$ & $\delta$ \\
\hline Result 1 & $19.47 \mathrm{kN}$ & $69.41 \mathrm{kN}$ & $49.94 \mathrm{kN}$ & $3.67 \mathrm{~mm}$ & $9.31 \mathrm{~mm}$ & $15.34 \mathrm{~mm}$ \\
\hline Result 2 & $19.47 \mathrm{kN}$ & $69.42 \mathrm{kN}$ & $49.95 \mathrm{kN}$ & $3.67 \mathrm{~mm}$ & $9.31 \mathrm{~mm}$ & $15.34 \mathrm{~mm}$ \\
\hline Error & 0 & 0.01 & 0.02 & 0 & 0 & 0 \\
\hline
\end{tabular}




\section{NUMERICAL EXAMPLES AND DISCUSSIONS}

\subsection{Example 1: Behaviors of Suspen-dome Structure with Sliding Cable-strut Joints}

Suspen-dome structure is a pre-stressed spatial structure. It has higher stiffness than that of single layer lattice shell. Also, the construction of suspen-dome structure is more convenient than that of cable dome. Suspen-dome structure has been widely applied as roof structures in many buildings, such as Hikarigaoka dome and Fureai dome in Japan, Badminton Gymnasium for 2008 Beijing Olympic Games in China, and Jinan Olympic sports center's gymnasium for the $200911^{\text {th }}$ National Olympic Games in China [14].

In the design of suspen-dome structure, a critical issue is the choice on the type of cable-strut joints. In practice, two kinds of cable-strut joints are usually considered. One is non-sliding cable-strut joint as shown in Figure 4, and the other is sliding cable-strut joint as shown in Figure 5. If the first type is adopted, the two adjacent hoop cables are independent and the hoop cables cannot slide around joints. Comparatively, if the second type is adopted, each circumference hoop cable is a continuous cable and the hoop cable can slide around joints. Due to the convenience and low cost of the second type, the continuous cable sliding around joints are preferred in most structures.

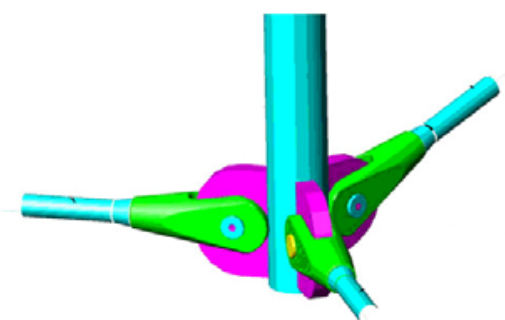

Figure 4. Non-sliding Cable-strut Joint

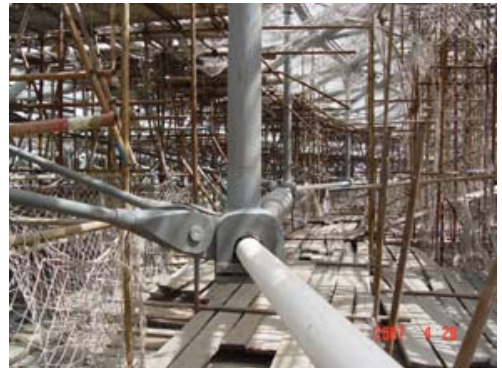

Figure 5. Sliding Cable-strut Joint

In addition, a previous reference reports that the suspen-dome structure with sliding cable-strut joint can carry the asymmetric loads more efficiently than the suspen-dome with non-sliding cable-strut joint does [2]. In contrast, we propose that the suspen-dome structure with non-sliding cable-strut joint is better than the suspen-dome structure with sliding cable-strut joint under asymmetric loads. Our reason is illustrated in Figure 6 . Forces $F_{i}$ and $F_{j}$ denote concentrated vertical forces applied at node I and $\mathrm{J}$, and $F_{i}>F_{j}$.

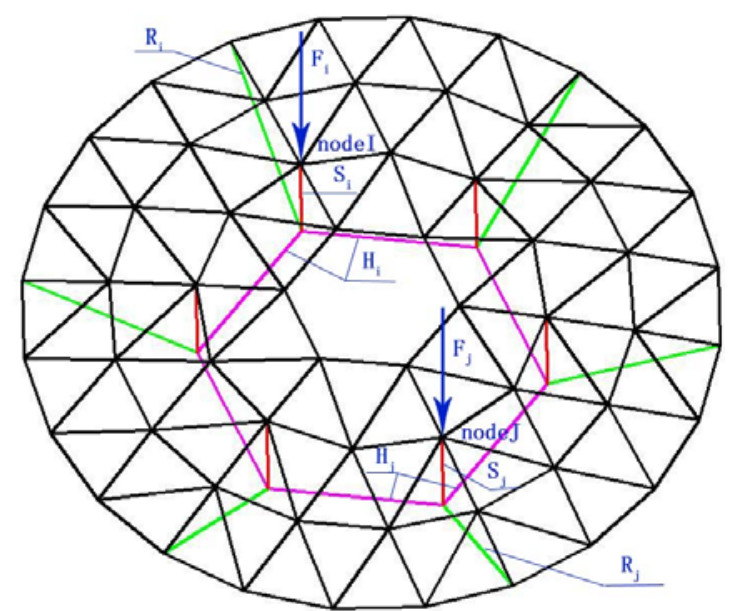

black line: single layer lattice shell; red line: struts; green line: radial bars; pink line: cables 
Assuming that the hoop cable cannot slide around cable-strut joints, it is obvious that the vertical displacement of Node I and the inner forces of the neighboring members connected to Node I are larger than those of Node J. If the hoop cable can slide around cable-strut joints with free-friction, the cable will slide around cable-strut joints until the cable forces in cable element are in equilibrium. Compared with the former case, the inner force of the hoop cable element below Node I will decrease and the inner force of hoop cable element below Node $\mathrm{J}$ will increase when the hoop cable can slide around cable-strut joint with free-friction. Subsequently, in one hand, the vertical displacement of Node I, the inner force and moment of members connected to Node I will increase until being in equilibrium; in the other hand, the vertical displacement of Node $\mathrm{J}$, the inner force and moment of member connected to Node $\mathrm{J}$ will decrease until being in equilibrium. Therefore, the maximum inner force and maximum node displacement of the suspen-dome structure is much larger when the hoop cable can slide around cable-strut joint with free-friction.

The following example further confirms our opinion. Here, Chiping Gymnasium is analyzed, whose roof is a suspen-dome system. The schematic view of the structural system is shown in Figure 7. Detailed information about this structure can refer to Ref. [15]. Due to the existence of arches and solar radiation action, the loads of the suspen-dome system is very non-uniform. In this analysis, the friction is not considered such that the tension ratio $\alpha$ in Eqns. (4) is equal to 1.

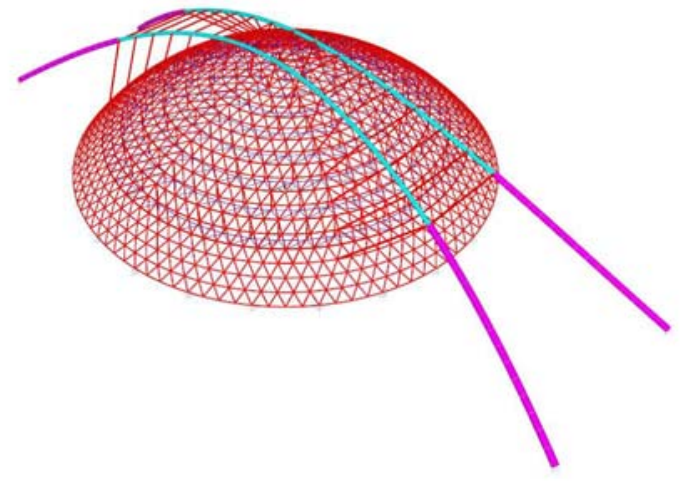

Figure 7. A Schematic View of Structural System of Chiping Gymnasium

Table 2 presents maximum values, minimum values, average values, deviations between maximum value and average value as well as deviations between minimum value and average value. Case 1 gives the results when the hoop cable cannot slide around cable-strut joint and Case 2 gives results when the hoop cable can slide around cable-strut joint with free-friction. Table 2 shows that the inner force in each hoop cable is very non-uniform, especially for $1 \sim 4$ hoop cables and the maximum deviation can reach 190\% for Cable Group 1.

Table 2. Distribution of Cable Force when Hoop Cable is Noncontinuous

\begin{tabular}{|l|l|c|c|c|c|c|c|c|}
\hline \multicolumn{2}{|c|}{ Cable groups } & 1 & 2 & 3 & 4 & 5 & 6 & 7 \\
\hline \multirow{4}{*}{ Case 1 } & Minimum force $(\mathrm{kN})$ & 0.53 & 14.76 & 53.15 & 322.70 & 584.29 & 1075.82 & 1851.65 \\
\cline { 2 - 9 } & Maximum force $(\mathrm{kN})$ & 198.02 & 111.15 & 193.72 & 447.76 & 698.86 & 1165.11 & 2085.72 \\
\cline { 2 - 9 } & Average force $(\mathrm{kN})$ & 68.23 & 57.84 & 130.98 & 392.80 & 644.45 & 1117.72 & 1976.50 \\
\cline { 2 - 9 } & Maximum deviation (\%) & 190 & 92 & 59 & 18 & 9 & 4 & 6 \\
\hline Case 2 & Cable force & 74.27 & 65.97 & 140.89 & 393.09 & 648.09 & 1112.60 & 1920.20 \\
\hline
\end{tabular}

Note: Cable group 1 is outmost hoop cables, and Cable group 7 is the innermost hoop cables

The distribution of maximum equivalent stress for both Case 1 and Case 2 are given in Table 3 . From Table 3, the maximum equivalent stress of Case 2 is larger than that of Case 1, which shows the mechanical behavior of Case1 is better than that of Case 2. Compared with the maximum equivalent stress of $129 \mathrm{MPa}$ and the maximum node displacement of $68 \mathrm{~mm}$ of Case 1, the 
corresponding values of Case 2 are 230MPa (77\% increased) and $135 \mathrm{~mm}$ (96\% increased), respectively. Therefore, The suspen-dome of with non-sliding cable-strut joint is better in mechanical behavior when the structure carries asymmetric loads.

Table 3. Distribution of Equivalent Stress of Each Suspen-dome Member with Stacked Arch Model

\begin{tabular}{|l|c|c|c|c|c|}
\hline & $0 \sim 50(\mathrm{MPa})$ & $50 \sim 100(\mathrm{MPa})$ & $100 \sim 150(\mathrm{MPa})$ & $150 \sim 200(\mathrm{MPa})$ & $\geq 200(\mathrm{MPa})$ \\
\hline Case 1 & 3134 & 1049 & 41 & - & - \\
\hline Case 2 & 2639 & 1244 & 233 & 48 & 60 \\
\hline
\end{tabular}

\subsection{Example 2: Numerical Simulation on the Pre-stressing Construction Process of Suspen-dome Structure}

A finite element model of a suspen-dome structure is established to study the effect of friction between cables and cable-struts during the pre-stressing construction. This suspen-dome structure is with a span of $35.4 \mathrm{~m}$ and a rise of $4.6 \mathrm{~m}$. Steel pipes of $\phi 133 \mathrm{~mm} \times 6 \mathrm{~mm}$ are used as the principal members of the upper single layer shell, and steel pipes of $\phi 89 \mathrm{~mm} \times 4 \mathrm{~mm}$ are used as vertical struts. One radial cable $(6 \times 19 \phi 18.5)$ and one hoop cable $(6 \times 19 \phi 24.5)$ are arranged in the bottom of the structure. The elastic modulus of steel pipes and cables are $2.1 \times 10^{5} \mathrm{~N} / \mathrm{mm}^{2}$ and $1.8 \times 10^{5} \mathrm{~N} / \mathrm{mm}^{2}$, respectively. The boundary conditions are that the vertical and tangential displacements are restricted with unrestricted radial displacement. The pre-stresses of hoop cables are uniformly set as $100 \mathrm{kN}$. The finite element model is shown in Figure 8.

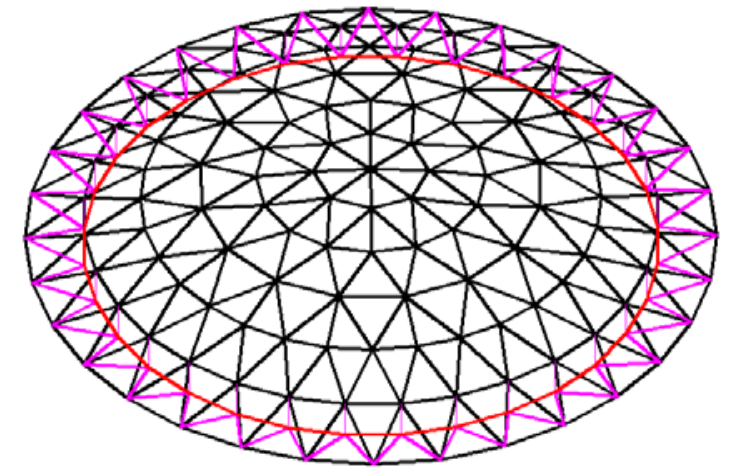

Figure 8. Finite Element Model of Suspen-dome of Tianbao Center

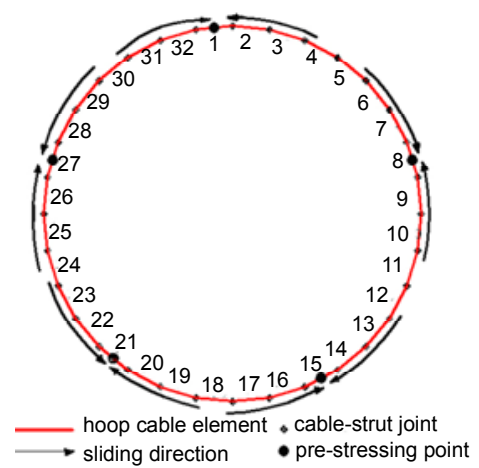

Figure 9. Schematic Diagram for Sliding Direction and Number of Cable Element

The coefficient of friction between cables and cable-struts is assumed as $0.4[16,17]$. In terms of the shape of cable-strut joint, the tension ratio $\alpha$ for hoop cables at cable-strut joint is 1.08. The five pre-stressing points for the hoop cable system are set as shown in Figure 9. Because only one hoop cable is adopted in the structure, the pre-tensioning control value is $100 \mathrm{kN}$ if the friction between cable and joints is not considered. 
In order to study the effect of friction, the numerical analysis is carried out using the proposed cable-sliding criterion equations. Firstly, the FE model (Figure 8) is established using the node coordinates of the zero state geometry obtained from the modified cyclic iteration and initial length control methods [18]. Secondly, the effect of friction is considered and the numerical simulation analysis of the construction procedure is carried out using the same cable-sliding criterion equations. The maximum inner force, minimum inner force, deviation between calculated force and design force are obtained from the FE analysis and they are $79.5 \mathrm{kN}, 100 \mathrm{kN}$, and $20.48 \%$, respectively. The average pre-stress loss is $6.83 \%$ for each cable-strut joints in the hoop cable system, which agrees well with the experiment results of the Badminton Gymnasium of 2008 Beijing Olympic Games [16, 17]. The deviations between calculated force and design force are shown in Figure 10 and it can be concluded that the friction has a significant effect on the pre-stressing construction.

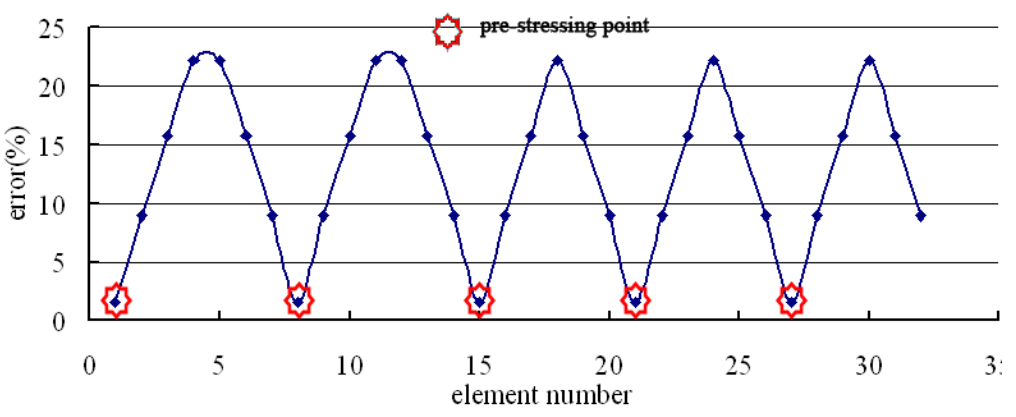

Figure10. Deviations for Each Hoop Cable Element

\subsection{Example 3: Design of Tree Structure}

Tree structures provide an efficient way to transfer large surface loads to a single point on the ground. They have been widely used in architecture and structure. The branches of the tree are arranged so that only tension and compression forces exist under the applied loads, which results in smaller member cross-sectional areas and a minimal amount of materials. Additionally, hanging models are the traditional method to determine the equilibrium shape of tree structures. A hanging model of the tree structure is created with flexible threads or chains. The thread or chain is suspended and secured together at certain points (branching nodes) so that it can rotate freely at the intersection. The equilibrium shape resulting in purely axial forces can be found because the thread or chain is capable of supporting only tension forces.

The traditional method can obtain the optimal shape of tree structures, but the procedure needs much time. Therefore, a computational algorithm, which can obtain the best shape of tree structure with a little time, is desired. The proposed cable-sliding criterion equations can provide such an algorithm because it can simulate the sliding of chain passing nodes. To show the cable-sliding criterion equations are applied in the design of tree structure, an example is designed.

The initial form is shown in Figure 11, and Node 1, Node 2 and Node 3 are sliding nodes. In other words, Line1 and Line 2 can rotate freely at the Node 1; Line3 and Line 4 can rotate freely at the Node 2; Line5 and Nine 6 can rotate freely at Node 3. Using the traditional method, the initial form of tree structures is built using threads and all nodes are fixed using thumbtacks as shown in Figure 12. Then thumbtacks at Node 1, Node 2 and Node 3 are removed and Line 1 and Line 2, Line 3 and Line 4, and Line 5 and Line 6 can rotate freely at Node 2, Node 3 and Node 4, respectively. Meanwhile, Node 4 is moved along the vertical direction until all threads are tightened. The final shape of the tree structure is shown in Figure 13 and it is the optimum shape of the tree structure obtained from the traditional method. 


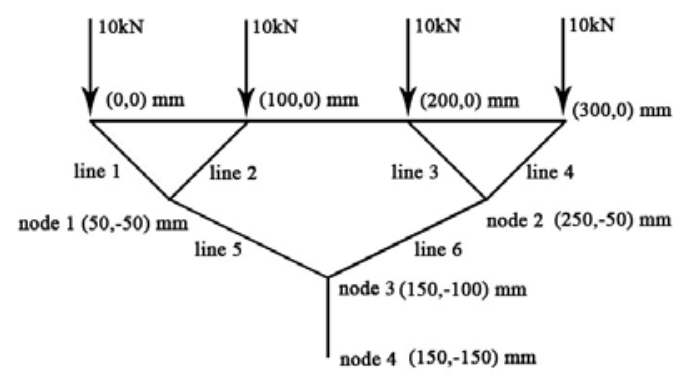

Figure 11. Initial Shape of Tree Structure

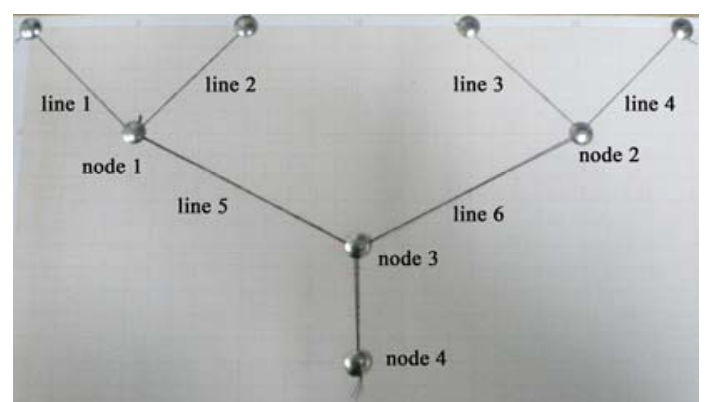

Figure 12. Initial Shape of Tree Structure of Traditional Method

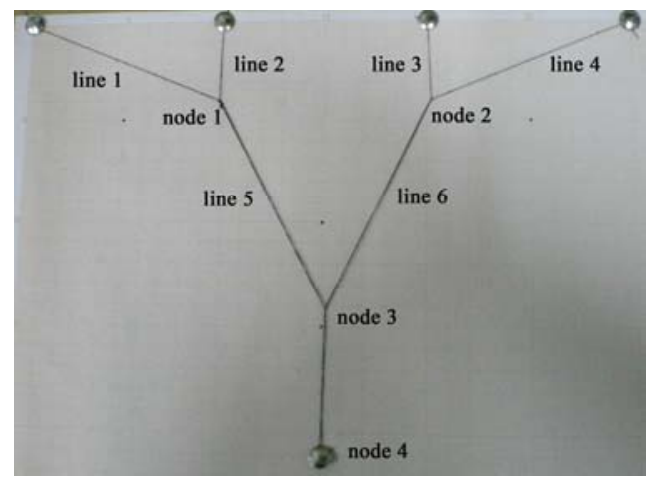

Figure 13. Best Shape of Tree Structure from Traditional Method

Using the proposed cable-sliding criterion equations (4) in this paper, the process of the traditional method is simulated and the result is shown in Figure 14. Compared with the optimum shape obtained from the traditional method as it shown in Figure 13, the optimum shape obtained using cable-sliding criterion equations is well consistent and therefore, cable-sliding criterion equations can be used to determine the optimum shape of tree structure.

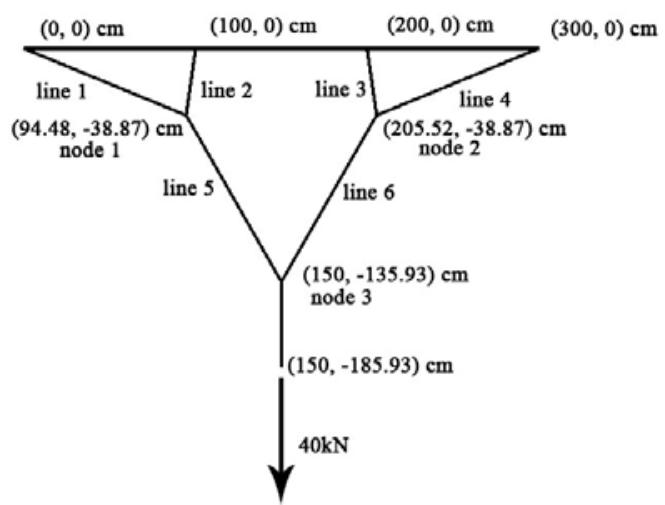

Figure 14. Best Shape of Tree Structure from FEM Analysis 


\section{CONCLUSIONS}

A group of cable-sliding criterion equations for simulating a cable passing through multiple pulleys is proposed in this paper. The proposed method is firstly evaluated by a simple cable system with three fixed pulleys. The obtained results satisfy the static equilibrium and deformation compatibility conditions of the structural system and basic engineering principles. Then the cable-sliding criterion equations are further applied to three practical engineering systems: a suspen-dome structure with stacked arches, a constructional numerical simulation of suspen-dome structure and a tree structure design.

Numerical analysis for a suspen-dome structure with stacked arches shows that the suspen-dome structure with non-sliding cable-strut joints is better than the suspen-dome with sliding cable-strut joint under asymmetric loads. Therefore, the non-sliding cable-strut joint is proposed for the future suspen-dome design.

Numerical simulation of the construction process of a suspen-dome structure shows that the friction between hoop cables and cable-strut joints has a significant effect on the pre-stressing construction. Therefore, some additional measures are suggested, such as to amplify the pre-tensioning control value of loop cables, to increase the pre-stressing points and to decrease the coefficient of friction between cable and cable-strut joint.

A design example of a tree structure shows that the cable-sliding criterion equations serve as a useful tool for designing spatial tree structures.

\section{ACKNOWLEDGEMENTS}

This work is sponsored by the Committee of National Natural Science Foundation of China (Grant No.: 50778122) and the Program for New Century Excellent Talents in University of Ministry of Education in China (Grant No.: NCET-06-0228).

\section{REFERENCES}

[1] Han, Q.H., Yuan, Z.H., Ying, M. and Liu, X.L. "Numerical Analysis and Experimental Study of Prestressed Diagonal-on-Square Composite Space Truss”, Advanced in Structural Engineering, 2005, Vol. 8, No. 4, pp. 397-410.

[2] Cui, X.Q. and Guo, Y.L., "Influence of Sliding Cable Joint on Mechanical Behavior of Suspen-dome Structures”, International Journal of Space Structure, 2004, Vol. 19, No. 3, pp.149-154.

[3] Hunt, J., Haase, W., Sobek, W., “A Design Tool for Spatial Tree Structures”, Journal of the International Association for Shell and Spatial Structures, 2009, Vol. 50, No. 1, pp. 3-10.

[4] Aufaure, M., "A Three-node Cable Element Ensuring the Continuity of the Horizontal Tension: A Clamp Cable Element”, Computers \& Structures, 2000, Vol. 74, No. 2, pp.243-252.

[5] Aufaure, M., “A Finite Element of Cable Passing through a Pulley”, Computers \& Structures, 1993, Vol. 46, No. 5, pp. 807-812.

[6] Zhou, B., Accorsi, M.L. and Leonard, J.W., "Finite Element Formulation for Modeling Sliding Cable Elements”, Computers and Structures, 2004, Vol. 82, No. 2, pp. 271-280. 
[7] Ju, F., and Choo, Y.S., "Dynamic Analysis of Tower Cranes”, Journal of Engineering Mechanics, 2005, Vol. 131, No. 1, pp. 88-96.

[8] Ravikumar, M. and Chattopadhyay, A., "Integral Analysis of Conveyor Pulley using Finite Element Method”, Computers \& Structures, 1999, Vol. 71, No. 3, pp. 303-332.

[9] Singru, P.M. and Modak, J.P., "Computer Simulation of the Dynamic and Vibration Response of a Belt Drive Pulley”, Journal of Sound and Vibration, 2001, Vol. 242, No. 2, pp. 277-293.

[10] Lee, K.H., Choo, Y.S. and Ju, F., "Finite Element Modeling of Frictional Slip in Heavy Lift Sling Systems”, Computers and Structures, 2003, Vol. 81, No. 2, pp. 673-690.

[11] Ju, F., and Choo, Y.S., "Super Element Approach to Cable Passing through Multiple Pulleys”, International Journal of Solids and Structures, 2005, Vol. 42, No. 3, pp. 533-547.

[12] Wei, J.D., "Friction Sliding Cable Element for Structural Analysis of Prestressed Steel Truss”, Chinese Journal of Computational Mechanics, 2006, Vol. 23, No. 6, pp. 800-806 (in Chinese).

[13] Beer, F.B. and Johnston, E.R., "Vector Mechanical for Engineers: Statics”, McGraw-Hill, New York, 1996.

[14] Zhang, Z.H., Cao, Q.S., Dong, S.L. and Fu, X.Y., "Structural Design of a Practical Suspendome”, Journal of Advanced Steel Construction, 2008, Vol. 4, No. 4, pp. 323-340.

[15] Chen, Z.H., Yan, X.Y. and Liu, H.B., "Large-span Hybrid Structure of Suspen-dome with Stacked Arch in Chiping Gymnasium”, Building Structures, 2009, Vol. 39, No. 7, pp.18-20 (in Chinese).

[16] Wang, S., Zhang, G.J. and Zhang, A.L., et al., "The Prestress Loss Analysis of Cable-strut Joint of the Badminton Gymnasium for 2008 Olympic Games,” Journal of Building Structures, 2007, Vol. 28, No. 6, pp. 39-44 (in Chinese).

[17] Zhang, A.L., Liu, X.Q. and Wang, D.M., et al., "Health Monitoring of the Prestressing Suspend-dome of the Badminton Gymnasium for 2008 Olympic Games”, Journal of Building Structures, 2007, Vol. 28, No. 6, pp. 93-99 (in Chinese).

[18] Lv, F.H. and Shen, Z.Y., "Control of Erection of Hybridized Space Structure using the Modified Cyclic Iteration and Initial Length Control Methods”, Journal of Building Structures, 2005, Vol. 26, No. 3, pp. 92-97 (in Chinese). 


\title{
BEHAVIOR OF LIGHTWEIGHT AGGREGATE CONCRETE FILLED STEEL TUBULAR SLENDER COLUMNS UNDER AXIAL COMPRESSION
}

\author{
Fu Zhong-qiu ${ }^{1}$, Ji Bo-hai ${ }^{2, *}$, Lv Lei $^{3}$ and Zhou Wen-jie ${ }^{3}$ \\ ${ }^{1}$ PhD Candidate, College of Civil and Transportation Engineering \\ Hohai University, Xikang Road 1\#, Nanjing, Jiangsu, P.R. China 210098 \\ ${ }^{2}$ Professor, College of Civil and Transportation Engineering \\ Hohai University, Xikang Road 1\#, Nanjing, Jiangsu, P.R. China 210098 \\ ${ }^{3}$ M.E., College of Civil and Transportation Engineering \\ Hohai University, Xikang Road 1\#, Nanjing, Jiangsu, P.R. China 210098 \\ *(Corresponding author: E-mail: hhbhji@163.com)
}

Received: 11 July 2010; Revised: 28 September 2010; Accepted: 23 November 2010

\begin{abstract}
Based on axially compressive tests on 6 short columns and 27 slender columns of lightweight aggregate concrete filled steel tube (LACFST), macroscopic deformation characters, axial force-longitudinal strain curves, failure mode and failure mechanism are studied. The results are also compared with these of the normal concrete filled steel tube. The test results demonstrated that slenderness ratio is the main influence factor to the behavior of LACFST long columns under axial load. The greater the slenderness ratio is, the lower the ultimate bearing capacity and stability coefficient of the specimen are, and the performances of core concrete affect the stability behavior of lightweight aggregate concrete and normal concrete filled steel tube long columns. The stability coefficient of specimens is determined by the peak strain of concrete and unrelated to the peak strength of concrete. The stability coefficient increases when the peak strain of concrete increasing. Comparison results show that calculation formula in Europe code EC4 (1996) can be applied to calculate the bearing capacity of LACFST columns under axially compressive load.
\end{abstract}

Keywords: Lightweight aggregate concrete filled steel tube; axial compressed test; slenderness ratio; stability coefficient; bearing capacity

\section{INTRODUCTION}

Modern structure requires high strength and light materials. Concrete filled steel tube (CFST) exploits the advantages of the steel tensile properties and concrete compressive properties. The concrete can delay the local buckling of steel pipe, and steel tube confined concrete increase its compressive strength. Compare to concrete structures, component section of CFST is smaller which greatly reduces self-weight and have good seismic performance [1]. And the construction is simple without complicated pre-stress tensioning. Currently, the properties of CFST had been studied by many researchers [2, 3, 4], and norms were made in different countries [5]. It is used in building and bridge structures $[6,7,8]$.

Lightweight aggregate concrete (LAC) has advantages of higher strength/weight ratio, thermal insulation and fire resistance characteristics, without alkali-aggregate reaction [9]. LAC is about $20 \%$ to $30 \%$ lighter than normal concrete. Its thermal conductivity is about $12 \%$ to $33 \%$ of the normal one. At the same time, it is an environmentally and friendly material. Existing research shows that lightweight concrete also has good mechanical properties [10]. But Compare to normal concrete, LAC has a lower elastic modulus and higher brittleness. If lightweight aggregate concrete is used to fill steel tube, it forms lightweight aggregate concrete filled steel tube (LACFST). Because of the restraint of steel, the strength and brittleness can be improved. And using LACFST in structural can reduce weight. Especially in the long span bridge and high-rise building structures, the application of LACFST can reduce the cost. 
Lightweight aggregate concrete is one of the future development directions of concrete application. This provides application possibility of LACFST in future. Japan has successfully used LACFST in "Shinkansen" project (high-speed railway bridge) [11]. But according to the published literature [12], it shows that the study about the performance of LACFST is still in a primary stage. In this study results of the axial compression test of 33 short and slender LACFST specimens are presented, and the performance of LACFST slender columns is discussed.

\section{EXPERIMENTAL INVESTIGATIONS}

\subsection{Materials}

The coarse aggregate of the lightweight aggregate concrete used in the test is shale ceramic with physical and mechanical properties as follows: Lightweight aggregate of bulk density is $814 \mathrm{~kg} / \mathrm{m}^{3}$, cylindrical compressive strength is $8.5 \mathrm{MPa}$ and water absorption ratio is $6 \%$ an hour. Two different types of concrete using ordinary Portland cement and washed river sand were used in casting the specimens. The concrete mixture and material properties are shown in Table 1.

Table 1. Mixture of LAC Concrete $\left(\mathrm{kg} / \mathrm{m}^{3}\right)$ and Material Properties

\begin{tabular}{ccccccccc}
\hline $\begin{array}{c}\text { Cubic } \\
\text { strength } \\
f_{c u}(\mathrm{MPa})\end{array}$ & $\begin{array}{c}\text { Prism } \\
\text { strength } f_{c k} \\
(\mathrm{MPa})\end{array}$ & Cement & Haydite & Sand & $\begin{array}{c}\text { Mineral } \\
\text { powder }\end{array}$ & Water & $\begin{array}{c}\text { Water } \\
\text { reducer }\end{array}$ & $\begin{array}{c}\text { Elastic } \\
\text { Modulus(GPa) }\end{array}$ \\
\hline 34.3 & 25.6 & 460 & 670 & 650 & 0 & 203 & 0 & 19.5 \\
47.6 & 39.3 & 450 & 650 & 650 & 50 & 125 & 6.8 & 29.6 \\
\hline
\end{tabular}

According to the relevant Chinese standards, compression tests were carried out on a number of Standard cubes $([150 \times 150 \times 150] \mathrm{mm})$ to determine the concrete grade, and prisms $([150 \times 150 \times$ $300] \mathrm{mm})$ in order to determine the 28-days compressive strength $\left(f_{c k}\right)$ and elastic modulus $\left(E_{c}\right)$ of the unconfined concrete.

Straight welded steel tube Q235 was used in the test. According to Chinese standard "Metallic materials at ambient temperature tensile test method" (GB/T228-2002) (2002) [13], tension tests on a group of three coupons were conducted to determine the tensile strength, where the thickness of each section of steel tube made into the interception of the standard specimen. The tension coupons were cut from the steel tube. The dimensions of the coupon are shown in Figure 1.

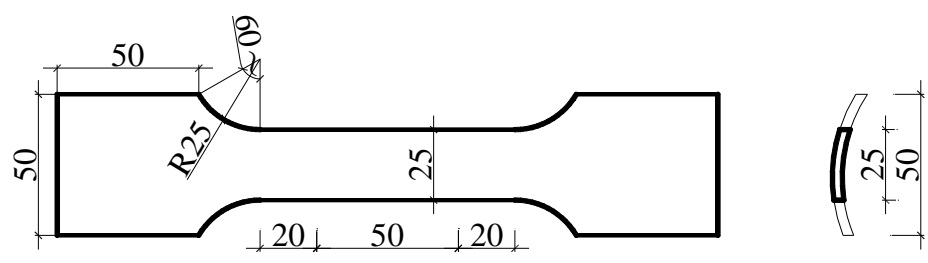

Figure1. Dimensions of the Tensile Coupons (mm)

Before tensile test, the ends of the specimen were compressed flatten to ensure it can be clamped and forced uniformly. Strain gauges were pasted on both sides of the coupon to measure the strain. The strain was collected by TS3890 pseudo-dynamic strain instrument in the whole process. From the relationship of stress and strain, the material properties are shown in Table 2. 
Table 2. Material Properties of Steel

\begin{tabular}{ccccc}
\hline $\begin{array}{c}\text { Thickness } \\
t(\mathrm{~mm})\end{array}$ & $\begin{array}{c}\text { Yield } \\
\text { strength } \\
f_{y}(\mathrm{MPa})\end{array}$ & $\begin{array}{c}\text { Poisson's ratio } \\
v_{s}\end{array}$ & $\begin{array}{c}\text { Ultimate } \\
\text { strength } \\
f_{u}(\mathrm{MPa})\end{array}$ & $\begin{array}{c}\text { Elastic Modulus } \\
E_{s}(\mathrm{MPa})\end{array}$ \\
\hline 2.5 & 298.92 & 0.273 & 352 & $2.01 \times 10^{5}$ \\
3.5 & 316.45 & 0.289 & 370 & $2.09 \times 10^{5}$ \\
\hline
\end{tabular}

\section{$2.2 \quad$ Specimens}

Different slenderness ratio and concrete strength were considered. Two ends of the steel tubes were flat. Before pouring concrete, each column was welded with a $10 \mathrm{~mm}$ thick circular plate on one side. Its center is the same with the geometric center of the steel tube. The LAC was filled in layers; each layer was $500 \mathrm{~mm}$ vibrated manually to ensure its density, and cured by natural conditions. Surface hollows due to concrete shrinkage were filled up with grout to confirm the specimen side smoothness. The parameters of LACFT specimens are given in Tables 3 together with the results to be discussed later.

\subsection{Test Instruments and Procedure}

The details of the test instruments are shown in Figure 2. The experiment was performed in the structural engineering laboratory of Hohai University. Hydraulic jack was implemented to apply loads on the specimens. Pressure sensor and resistance strain gauges were installed to measure loads and strains respectively. At the two ends of the specimens, column joint utilized to simulate the hinged boundary conditions.

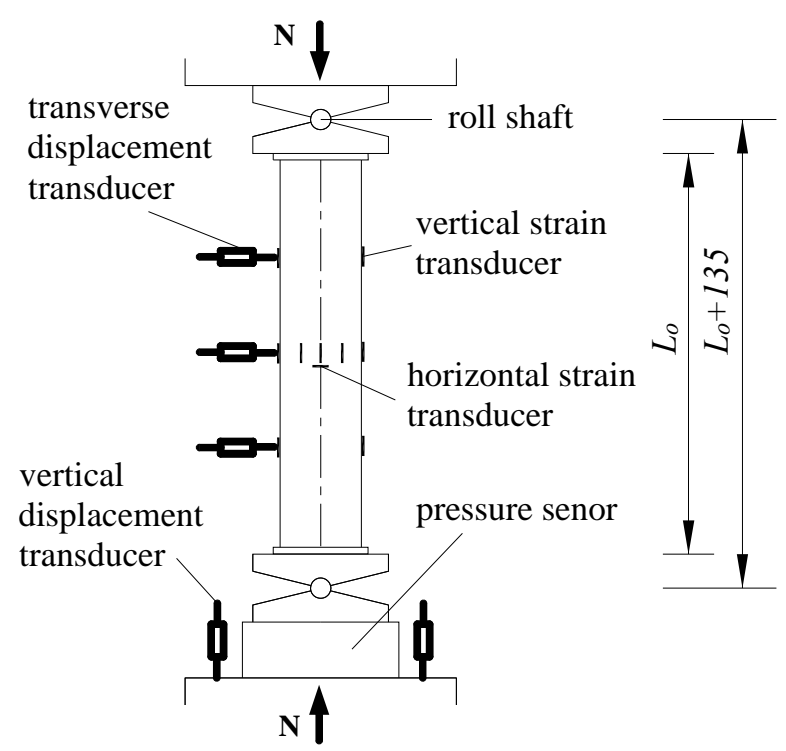

Figure 2. Loading and Measurement System 
Table 3. Detail of the Test Specimens

\begin{tabular}{|c|c|c|c|c|c|c|c|c|c|}
\hline \multirow{2}{*}{ Specimens } & \multicolumn{3}{|c|}{ Pipe size (mm) } & \multirow{2}{*}{$\lambda$} & \multirow{2}{*}{$\begin{array}{c}f_{c k} \\
(\mathrm{MPa})\end{array}$} & \multirow{2}{*}{$\begin{array}{c}f_{y} \\
(\mathrm{MPa})\end{array}$} & \multirow{2}{*}{$\xi$} & \multirow{2}{*}{$N_{u}(\mathrm{kN})$} & \multirow{2}{*}{$\varphi=N_{u} / N_{o}$} \\
\hline & $D$ & $t$ & $L_{0}$ & & & & & & \\
\hline SC1-3-a & 165 & 2.5 & 495 & 12 & 25.6 & 298.92 & 0.74 & 948.57 & 1.0229 \\
\hline SC1-3-b & 165 & 2.5 & 495 & 12 & 25.6 & 298.92 & 0.74 & 896.19 & 0.9665 \\
\hline SC1-3- c & 165 & 2.5 & 495 & 12 & 25.6 & 298.92 & 0.74 & 937.14 & 1.0106 \\
\hline SC1-7-a & 165 & 2.5 & 1155 & 31.2 & 25.6 & 298.92 & 0.74 & 793.33 & 0.8555 \\
\hline SC1-7-b & 165 & 2.5 & 1155 & 31.2 & 25.6 & 298.92 & 0.74 & 753.33 & 0.8124 \\
\hline SC1-10-a & 165 & 2.5 & 1650 & 43.2 & 25.6 & 298.92 & 0.74 & 798.10 & 0.8607 \\
\hline SC1-10-b & 165 & 2.5 & 1650 & 43.2 & 25.6 & 298.92 & 0.74 & 713.33 & 0.7693 \\
\hline SC1-10-C & 165 & 2.5 & 1650 & 43.2 & 25.6 & 298.92 & 0.74 & 736.19 & 0.7939 \\
\hline SC2-3-b & 114 & 3.5 & 342 & 12 & 39.3 & 316.45 & 1.09 & 879.00 & 0.9903 \\
\hline SC2-3-c & 114 & 3.5 & 342 & 12 & 39.3 & 316.45 & 1.09 & 896.19 & 1.0097 \\
\hline SC2-7-a & 114 & 3.5 & 798 & 32.8 & 39.3 & 316.45 & 1.09 & 799.05 & 0.9002 \\
\hline SC2-7-b & 114 & 3.5 & 798 & 32.8 & 39.3 & 316.45 & 1.09 & 698.10 & 0.7865 \\
\hline SC2-10-a & 114 & 3.5 & 1140 & 44.8 & 39.3 & 316.45 & 1.09 & 797.14 & 0.8981 \\
\hline SC2-10-C & 114 & 3.5 & 1140 & 44.8 & 39.3 & 316.45 & 1.09 & 800.00 & 0.9013 \\
\hline SC2-14-a & 114 & 3.5 & 1596 & 60.8 & 39.3 & 316.45 & 1.09 & 824.76 & 0.9292 \\
\hline SC2-14-b & 114 & 3.5 & 1596 & 60.8 & 39.3 & 316.45 & 1.09 & 770.48 & 0.8681 \\
\hline SC3-3-a & 114 & 3.5 & 342 & 12 & 25.6 & 316.45 & 1.67 & 746.67 & 1.0056 \\
\hline SC3-3-b & 114 & 3.5 & 342 & 12 & 25.6 & 316.45 & 1.67 & 712.38 & 0.9594 \\
\hline SC3-3-c & 114 & 3.5 & 342 & 12 & 25.6 & 316.45 & 1.67 & 768.57 & 1.0351 \\
\hline SC3-7-a & 114 & 3.5 & 798 & 32.8 & 25.6 & 316.45 & 1.67 & 584.76 & 0.7875 \\
\hline SC3-7-b & 114 & 3.5 & 798 & 32.8 & 25.6 & 316.45 & 1.67 & 643.81 & 0.8670 \\
\hline SC3-7-c & 114 & 3.5 & 798 & 32.8 & 25.6 & 316.45 & 1.67 & 652.38 & 0.8786 \\
\hline SC3-10-a & 114 & 3.5 & 1140 & 44.8 & 25.6 & 316.45 & 1.67 & 603.81 & 0.8132 \\
\hline SC3-10-b & 114 & 3.5 & 1140 & 44.8 & 25.6 & 316.45 & 1.67 & 598.10 & 0.8055 \\
\hline SC3-10-c & 114 & 3.5 & 1140 & 44.8 & 25.6 & 316.45 & 1.67 & 581.90 & 0.7837 \\
\hline SC3-14-a & 114 & 3.5 & 1596 & 60.8 & 25.6 & 316.45 & 1.67 & 548.57 & 0.7388 \\
\hline SC3-14-b & 114 & 3.5 & 1596 & 60.8 & 25.6 & 316.45 & 1.67 & 541.90 & 0.7298 \\
\hline SC3-14-C & 114 & 3.5 & 1596 & 60.8 & 25.6 & 316.45 & 1.67 & 529.52 & 0.7131 \\
\hline
\end{tabular}

Note: $1 . \quad D$ is the external diameter, $t$ is the thickness, $L_{0}$ is the length of specimen, and calculation length is $L=L_{0}+135$;

2. $f_{c k}$ is Prism strength of concrete, $f_{y}$ is the yield strength of steel;

3. $\xi$ is Confinement coefficient, $\xi=A_{s} f_{y} /\left(A_{c} f_{c k}\right)$, here $A_{s}$ is the area of steel, $A_{c}$ is the area of concrete;

4. $\quad N_{u}$ is test ultimate load, $N_{0}$ is test ultimate load of short column;

5. $\lambda$ is the slenderness ratio, $\lambda=4 L / D ; \varphi$ is stability factor, $\varphi=N_{u} / N_{o}$.

For the accuracy of the specimen's deformation measurements, eight strain gauges were set at the mid-length of the column to record strain's values. Three displacement transducers were installed in the bending plane, the top and the bottom gauges were at distance of one fourth the height of each column from the top and the bottom, respectively, and the third displacement transducers was positioned at the mid-height of each column to measure the lateral deformation. In order to measure the portrait deformation two displacements transducers were set up. All these transducers were connected to computer data acquisition system to record their values in the whole test phases. 
The specimens were loaded at rate of $1 / 10$ of the predicted ultimate load in the elastic phase and at loading rate of $1 / 15$ of the predicted ultimate load in the column yielding phase. Each load was maintained 2-3 minutes to enable the full deformation development. When approaching the predicted ultimate load, the load was added slowly.

\section{DISCUSSIONS OF TEST RESULTS}

\subsection{Failure Process}

Figure 3 shows the failure mode of two groups specimens. Figure 4 shows part of the load $N-$ midpoint deflection $f$ curves. The specimens are all destroyed because of excessive lateral deformation. At the beginning, the deflection of the specimen increases slowly as the load increases. When it was close to the ultimate bearing capacity, the lateral deformation enlarged quickly. After reaching the maximum value, the load began to decrease. With higher slenderness ratio of the specimen, the load decreased and the lateral deflection increased faster. Coupled local global buckling was also observed on some of small slenderness ratio specimens at ends and middle part (Figure 3(a)).

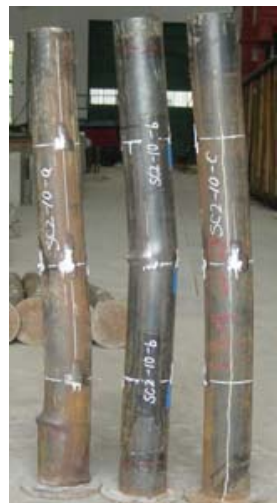

(a) SC2-10

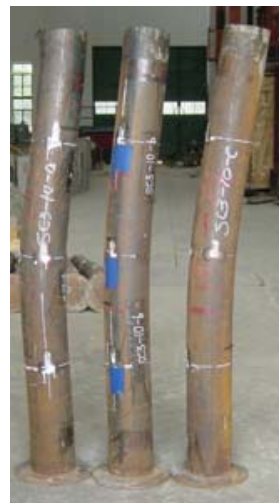

(b) SC3-10

Figure 3. Failure specimens

From Figure 4, the lateral deflection developed gradually at the beginning of the loading process. After a period of elastic deformation, the curves go into plastic stage, and approaches to the ultimate load. Then the load decreases as the lateral deflection increases. The larger the slenderness ratio is, the quicker the decreasing speed of load is. The lateral deflection of some specimens increases at the begging of the test. Because it is hard to make sure that the load was axial exactly, and the material is uneven, the specimens were imperfection initially. But some of the specimens also appeared perfect axial compression state (Figure 4 (a)).

Load $(N)$ - middle point strain $\left(\varepsilon_{s}\right)$ curves were shown in Figure 5. It reflects the changing process of lateral deflection when loading. Tensile one is the circumferential strain, and the compressive one is the longitudinal strain. Line a and $b$ represents the strain curve of two points at different side of roll shaft. Point a is the lateral side of flexural specimen, and point $b$ is the medial side of flexural specimen. The strain $\varepsilon_{s}$, including longitudinal strain and circumferential strain, was measured by resistance strain gauge externally bonded on the steel tube. At the beginning, the cross sections were compressed and the both sides strain were similar. With the load growth and the lateral deformation development, the differences of the strain on both sides increased until it reached the ultimate load. Because of the significant deformation, the larger slenderness ratio specimens damaged with one side subjected to tension and another side subjected to compression. 


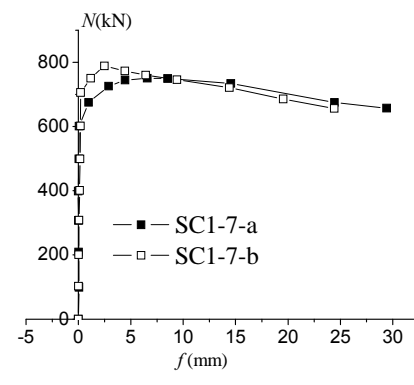

(a)

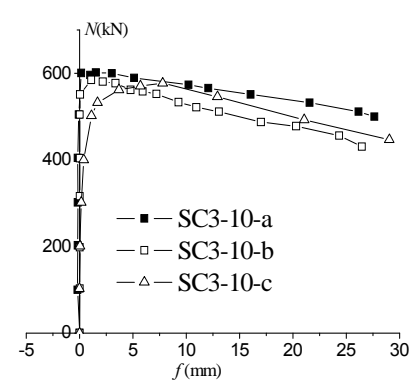

(d)

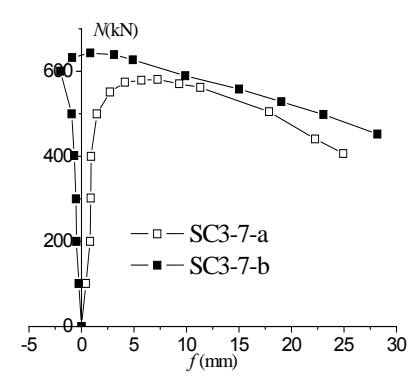

(b)

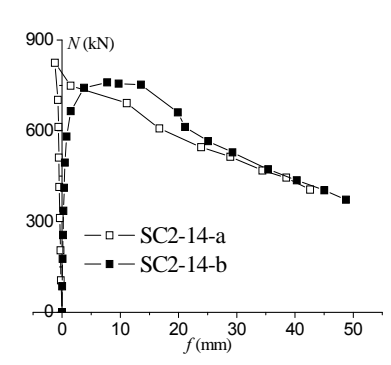

(e)

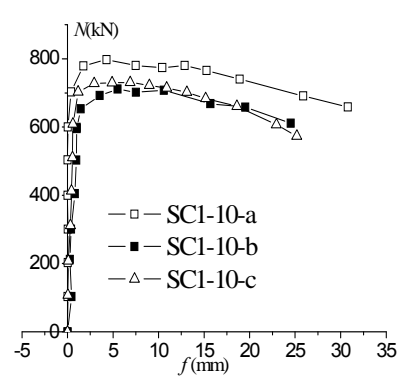

(c)

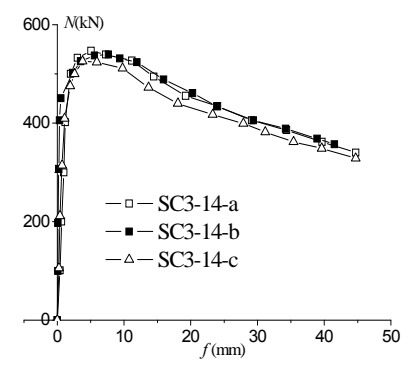

(f)

Figure 4. Load $(N)$ - Midpoint Displacement $(f)$ Curves

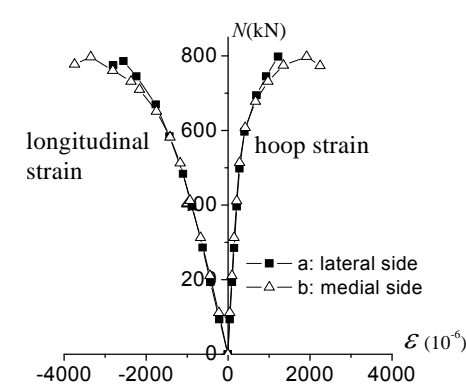

(a) SC2-7-a

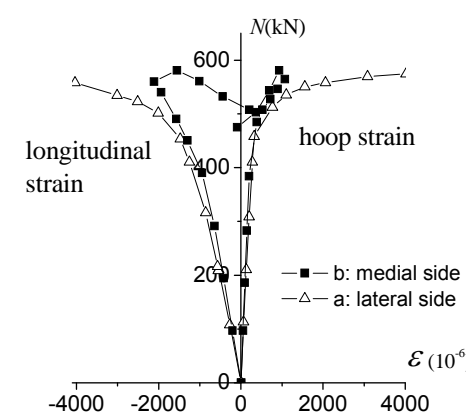

(d) SC3-10-c

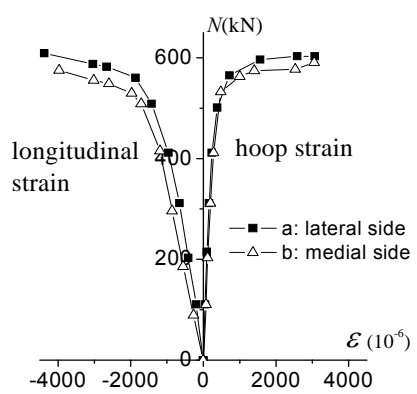

(b) SC3-7-c

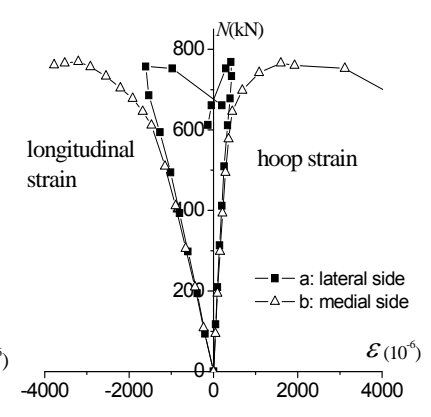

(e) SC-2-14-b

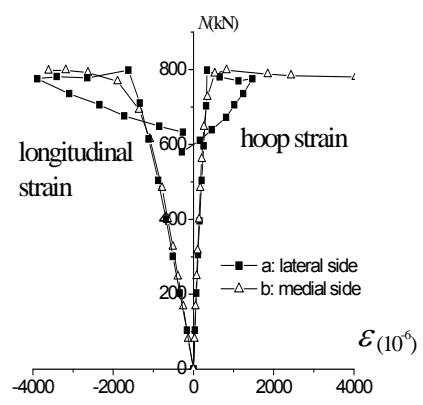

(c) SC1-10-c

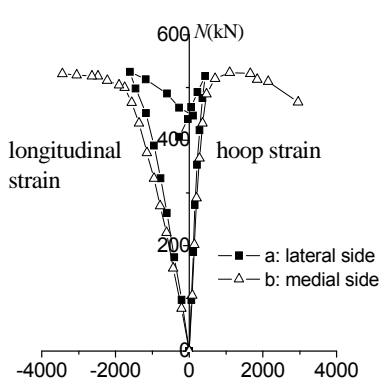

(f) SC3-14-c

Figure 5. Load $(N)$ - Middle Point Strain $\left(\varepsilon_{s}\right)$ Curves 


\subsection{Failure Characteristics}

The slenderness ratio is one of the important parameters of such test. Figure 6 shows the axial load $N$ - longitudinal strain $\varepsilon_{c}$ curves of the three groups specimens. The expression of $\varepsilon_{c}$ is following one.

$\varepsilon_{c}=\frac{\Delta}{L}$

In the expression, $\Delta$ is the longitudinal compression displacement measured by displacement meters, $L$ is the length of the specimen. From the $N-\varepsilon_{c}$ curves in Figure 6, it can be found that the failure of specimens were all elastic-plastic damage with instability.

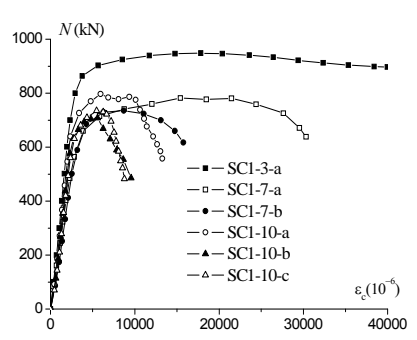

(a) SC1

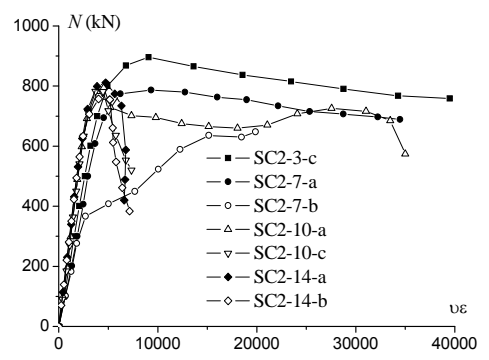

(b) SC2

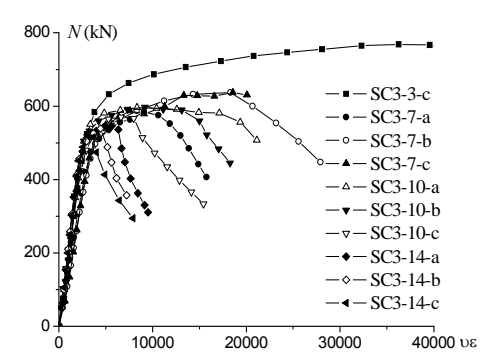

(c) SC3

Figure 6. Load $(N)$ - Longitudinal Strain $\left(\varepsilon_{c}\right)$ Curves

Study on axial compression of short LACFST columns shows that it has good mechanical performance. So the $N-\varepsilon_{c}$ curves of short column are drawn in Figure 6 to compare with the long columns. In the elastic stage, the $N-\varepsilon_{c}$ curves of all the long column specimens are almost overlap with each other, and almost the same with curves of the short column. After reaching the elastic-plastic deformation stage, the $N-\varepsilon_{c}$ curves with different slenderness ratios appear diversity between each other. With $L_{o} / D=7$ (SC1-7, SC2-7, SC3-7) and $L_{o} / D=10$ (SC1-10, SC2-10, SC3-10), the curves deviate from the original direction of elastic stage after the elastic limit. But the load grows slowly until to the ultimate load. After the ultimate load, the load decreases slowly, while the deformation increases quickly and the plastic deformation are obvious. With $L_{o} / D=$ 14(SC1-14, SC2-14, SC3-14), the curves have a shorter upward tendency and then fall down quickly after the elastic limit. The specimens almost lose bearing capacity suddenly. The $N-\varepsilon_{c}$ curves of the long column specimens are lower than that of short column specimens in the figures. Compare to the short columns, the long ones have lower bearing capacity and the elastic-plastic stage occurs earlier. The long column specimens are instability damage because of large lateral deformation. They are elastic-plastic instability failure.

\subsection{Failure Mechanism}

The lateral deformation coefficient $\mu$ is defined similar as Poisson's ratio. It can be calculated by following equation.

$\mu=\varepsilon_{s h} / \varepsilon_{s l}$ 
$\varepsilon_{s h}$ is the hoop strain and $\varepsilon_{s l}$ is the longitudinal strain of the steel at middle point. They were measured by the strain gauges on the steel tube. It can reflect whether the material has yielded or not. Figure 7 is the lateral deformation coefficient variation curve of a group of specimens with different slenderness ratio. Poisson's ratio of steel is $0.25 \sim 0.3$ usually. If the lateral deformation coefficient is less than 0.3 , the steel tube is in elastic stage. At the beginning of loading, the lateral deformation coefficient is same to the Poisson's ratio of steel. The lateral deformation of concrete provides less extrusion effect to steel tube. While the lateral deformation coefficient is larger than 0.3 , it produces interaction force between concrete and steel.

In Figure 7, after reaching the ultimate bearing capacity, the $\mu$ - $N$ curves trend on medial side(b line) was similar with different slenderness ratios, while it was different on lateral sides(a line). Because the flexure of specimens with $L_{o} / D=14$ (SC1-14, SC2-14, SC3-14), was obvious, the longitudinal stress on the lateral side changed from compression to tension (Figure 5). When the specimen with $L / D=14$ damaged, the lateral side was in elastic stage, while the medial side was in plastic stage. But for the specimens with smaller slenderness ratios, both sides were in plastic stage when damaged.

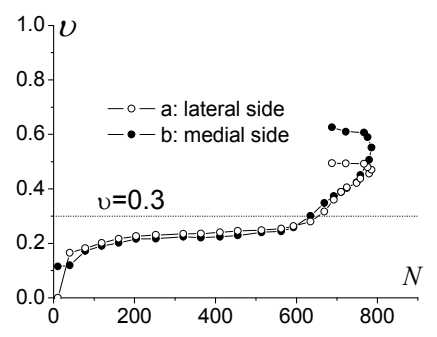

(a) SC2-7-a

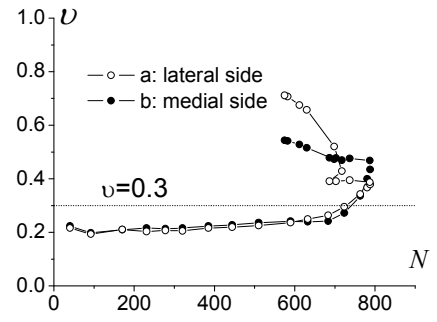

(b) SC2-10-a

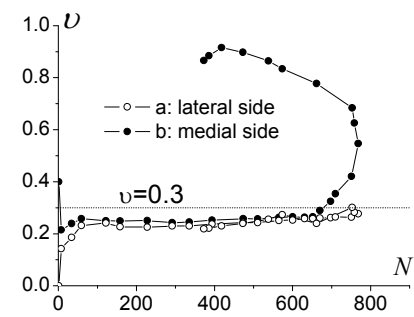

(c) SC2-14-b

Figure 7. Lateral Deformation Coefficient ( $\mu$ ) - Load $(N)$ Curves

\subsection{Influence of Slenderness Ratio to Bearing Capacity}

From the discussions above, it can be seen that the slenderness ratio influences the behavior of LACFST columns greatly. Generally, when columns have a larger slenderness ratio, the bearing capacity mainly depends on the slenderness ratio. Under the same axial force, the lateral deformation of specimens with large slenderness is greater. And it causes greater additional moment. This makes the columns have a lower bearing capacity. In this test, slenderness ratio is a controlling parameter. Through the $N-\varepsilon_{c}$ curves( Figure 6), it can be found that when the slenderness ratio is greater, the ultimate strength is lower and the plastic deformation is worse. It's same conclusion with other material columns.

\section{SABILITY BEHAVIOR ANALYSIS}

\subsection{Parameters Influence to Stability Coefficient}

Figure 8 lists the relationship between slenderness ratio and stability coefficient $\varphi$ of all the specimens in this test. With the growth of the slenderness ratio, the stability coefficient $\varphi$ gradually decreased. There is eccentric moment because of the initial imperfection. When the slenderness ratio is larger, the lateral displacement of the column middle part is greater, which produces the larger moment. It makes components damaged more easily. It is same with the other materials. 
The specimens of group SC-2 and SC-3 have the same section parameters except the concrete strength. Compared with the results of two groups in Figure 8, the stability coefficient $\varphi$ of SC-2 with higher core concrete strength is larger than that of SC-3. But for the normal CFST, Cai (2003) believes that the concrete strength has no obvious impact on the stability coefficient [13], while Han (2004) believes it has impact [14]. The reasons will be discussed later.

The confinement coefficient $\xi$ influences the behavior of short CFST columns. But for SC-1, SC-2 and SC-3, the confinement coefficient is more and more low. Especially for group SC1 and SC3, the specimens have the same concrete strength, but with different confinement coefficient $\xi$. And there is no obvious variation of $\varphi$ as $\xi$ increasing with the parameter range in this test (Figure 8).

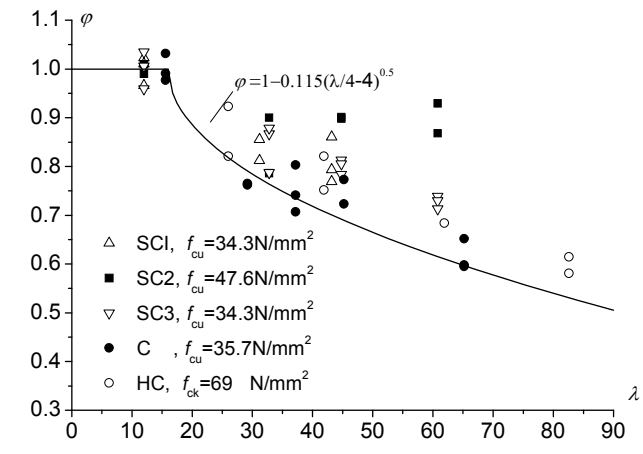

Figure 8. $\varphi-\lambda$ Relation

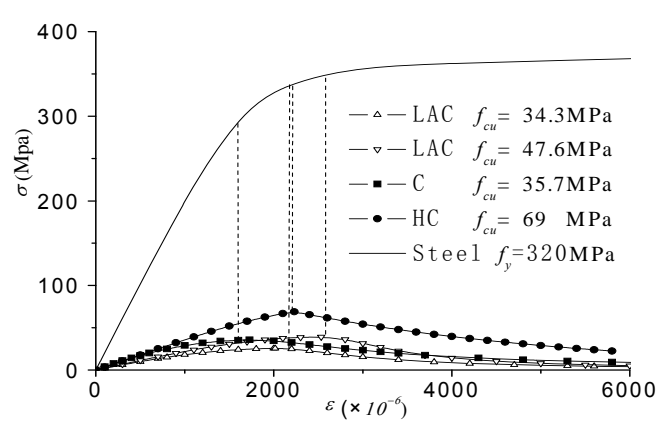

Figure 9. $\sigma-\varepsilon$ Relation of Different Concrete

\subsection{Influence Mechanism Analysis}

Core concrete not only delays the occurrence of steel local buckling, but also bears pressure. When the local strain of concrete filled steel tube specimens is larger than ultimate strain of the concrete, the concrete in near position goes into the plastic state and the load bearing by steel tube increases rapidly. Then the steel is yielded and specimen is damaged. The performances of concrete influence the mechanical behavior of specimens.

In Figure 8, the stability coefficient $\varphi$ of LACFST in this test and normal CFST tested by other researchers are listed. The empirical formula curve of normal CFST [13] is drawn in the figure too. Group C represents normal concrete, and group HC represents high strength concrete [13]. The stability coefficient results of LACFST are all above on the curve of empirical formula. Comparison from the figure, the following order can be got.

$\varphi_{L A C 47.6}>\varphi_{L A C 34.3} \approx \varphi_{H C 69}>\varphi_{C 35.7}$

Relation formula above shows that higher concrete strength does not mean higher stability coefficient. As an important indicator of concrete strength, $f_{c u}$ has no influence to the stability coefficient of CFST.

The properties of confined concrete influence by the unconfined concrete properties and constraint force mainly. And $\xi$ is the main reflection to the constraint force. Because there is no obvious variation of $\varphi$ as $\xi$ increasing in this test which is get from above analysis. So the influence to stability coefficient of the confined concrete can mainly been reflected by unconfined concrete properties. Figure 9 shows the stress-strain curves of steel and four kinds concrete. The curve of steel is obtained from the test. The curves of concrete are calculated by the unconfined concrete methods suggested in literature $[15,16]$. Comparison from the figure, the following order of peak strain can be got. It has same variation regularity with the stability coefficient $\varphi$. 
$\varepsilon_{L A C 47.6}>\varepsilon_{L A C 34.3} \approx \varepsilon_{H C 69}>\varepsilon_{C 35.7}$

Compare to the curves of steel and concrete in Figure 9, the peak strain of the normal concrete appears before the steel's. When the normal concrete goes into elastic-plastic state, the steel is also in the elastic state. Although the bearing capacity of normal concrete decreases, it will be compensated by the steel. So the specimen bearing capacity also increases slowly. The specimen damages after the steel going into the elastic-plastic state. In this case, stability bearing capacity of specimen is determined by the behavior of steel. But it is influenced by the peak strain of concrete actually.

But the peak strain of the lightweight aggregate concrete appearances after the steel's. The steel goes into elastic-plastic state before LAC. When the bearing capacity of LAC decreased, the steel can't compensate it. The specimen damages after reaching to the peak strain of LAC. In this case, stability bearing capacity of specimen is determined by the peak strain of LAC.

The peak strain of high strength concrete $\left(f_{c u}=69 \mathrm{MPa}\right)$ is almost equal to that of LAC $\left(f_{c u}=34.3 \mathrm{MPa}\right)$. And stability coefficient of high strength concrete $\left(f_{c u}=69 \mathrm{MPa}\right)$ is also almost equal to that of LAC $\left(f_{c u}=34.3 \mathrm{MPa}\right)$. Compare to the order of stability coefficient and concrete peak strain, they are same. So the larger peak strain of LAC is, the larger stability bearing capacity and coefficient of specimens are. It can be concluded that the stability coefficient of specimens are determined by the peak strain of concrete with the studied scope of parameters in this paper.

\section{BEARING CAPACITY CALCULATION}

There are no existing methods to calculate the bearing capacity of lightweight aggregate concrete filled steel tube. But for the normal concrete filled steel tube, different formulas are suggested in some country or region national codes. In this paper, three methods suggested for normal concrete filled steel tube are used to calculate the bearing capacity of specimens in this test, concluding AISC-LRFD(United States), EC4(Europe) and CECS28:90(China). The calculation results are listed in Table 4. It is compared with the test results. In Table 4, $N_{u}$ is test ultimate bearing capacity, $N_{u c}$ is calculation ultimate bearing capacity. And Figure 10 is used to show the comparison results more clearly.

Table 4. Bearing Capacity Calculation

\begin{tabular}{lcccccccc}
\hline \multirow{2}{*}{$\begin{array}{c}\text { Specimen } \\
\text { number }\end{array}$} & \multirow{2}{*}{$\lambda$} & \multirow{2}{*}{ Test } & \multicolumn{2}{c}{ AISC-LRFD(99) } & \multicolumn{2}{c}{ EC4(1996) } & \multicolumn{2}{c}{ CECS28:90(1992) } \\
\cline { 4 - 8 } & & $N_{u}(\mathrm{kN})$ & $N_{u c}(\mathrm{kN})$ & $N_{u c} / N_{u}$ & $N_{u c}(\mathrm{kN})$ & $N_{u c} / N_{u}$ & $N_{u c}(\mathrm{kN})$ & $N_{u c} / N_{u}$ \\
\hline SC1-7-a & 31.2 & 793.33 & 615.05 & 0.775 & 838.21 & 1.057 & 811.21 & 1.023 \\
SC1-7-b & 31.2 & 753.33 & 615.05 & 0.816 & 838.21 & 1.113 & 811.21 & 1.077 \\
SC1-10-a & 43.2 & 798.10 & 605.23 & 0.758 & 798.84 & 1.001 & 732.05 & 0.917 \\
SC1-10-b & 43.2 & 713.33 & 605.23 & 0.848 & 798.84 & 1.120 & 732.05 & 1.026 \\
SC1-10-c & 43.2 & 736.19 & 605.23 & 0.822 & 798.84 & 1.085 & 732.05 & 0.994 \\
SC2-7-a & 32.8 & 799.05 & 559.66 & 0.700 & 757.31 & 0.948 & 830.80 & 1.040 \\
SC2-7-b & 32.8 & 698.10 & 559.66 & 0.802 & 757.31 & 1.085 & 830.80 & 1.190 \\
SC2-10-a & 44.8 & 797.14 & 548.27 & 0.688 & 716.18 & 0.898 & 751.56 & 0.943 \\
SC2-10-c & 44.8 & 800.00 & 548.27 & 0.685 & 716.18 & 0.895 & 751.56 & 0.939 \\
SC2-14-a & 60.8 & 824.76 & 527.45 & 0.640 & 645.50 & 0.783 & 668.64 & 0.811 \\
SC2-14-b & 60.8 & 770.48 & 527.45 & 0.685 & 645.50 & 0.838 & 668.64 & 0.868 \\
\hline
\end{tabular}




\begin{tabular}{|c|c|c|c|c|c|c|c|c|}
\hline SC3-7-a & 32.8 & 584.76 & 451.30 & 0.772 & 623.17 & 1.066 & 594.60 & 1.017 \\
\hline sC3-7-b & 32.8 & 643.81 & 451.30 & 0.701 & 623.17 & 0.968 & 594.60 & 0.924 \\
\hline SC3-7-c & 32.8 & 652.38 & 451.30 & 0.692 & 623.17 & 0.955 & 594.60 & 0.911 \\
\hline SC3-10-a & 44.8 & 603.81 & 441.37 & 0.731 & 595.00 & 0.985 & 537.89 & 0.891 \\
\hline SC3-10-b & 44.8 & 598.10 & 441.37 & 0.738 & 595.00 & 0.995 & 537.89 & 0.899 \\
\hline SC3-10-c & 44.8 & 581.90 & 441.37 & 0.758 & 595.00 & 1.023 & 537.89 & 0.924 \\
\hline SC3-14-a & 60.8 & 548.57 & 423.26 & 0.772 & 547.94 & 0.999 & 478.54 & 0.872 \\
\hline SC3-14-b & 60.8 & 541.90 & 423.26 & 0.781 & 547.94 & 1.011 & 478.54 & 0.883 \\
\hline SC3-14-c & 60.8 & 529.52 & 423.26 & 0.799 & 547.94 & 1.035 & 478.54 & 0.904 \\
\hline \multicolumn{3}{|c|}{ AVERAGE $(\mu)$} & & 0.748 & & 0.992 & & 0.953 \\
\hline \multicolumn{3}{|c|}{$\mathrm{SD}(\delta)$} & & 0.055 & & 0.087 & & 0.086 \\
\hline
\end{tabular}

From Table 4 and Figure 10, the results of AISC-LRFD (1999) are the safest one, and the results of EC4 (1996) and CECS28:90(1992) approach to the test ones. But the deviation of CECS28:90(1992) is greater than that of EC4 (1996) when the specimen has a large slenderness. For the results of EC4 (1996), the average is 0.992, and the standard deviation is 0.087. It is closest to the test results and has a low discreteness. It can be used to calculate the bearing capacity of LACFST long columns. Based on the calculation using EC4 (1996) to the LACFST short columns bearing capacity, the average value is 1.077 , and the standard deviation is 0.053 . The formula in EC4 (1996) also has a preferable goodness of fit to calculate the bearing capacity of short columns. So it can be concluded that the calculation method in EC4 (1996) can be suggested to calculate the bearing capacity of LACFST under axial compression.

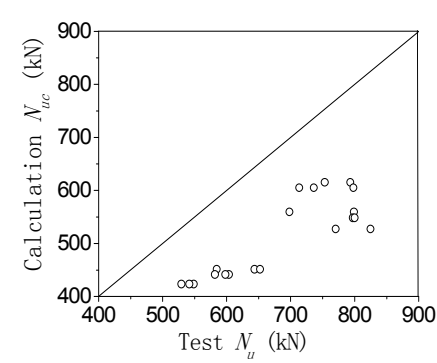

(a)AISC-LRFD(1999)

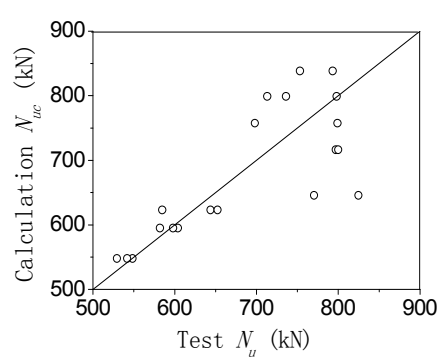

(b)EC4(1996)

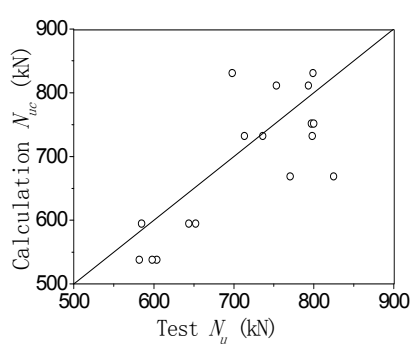

(c)CECS28:90(1992)

Figure 10. Test and Calculation Bearing Capacity Results Comparison

\section{CONCLUSIONS}

(1) Slenderness ratio is very important influence parameters to the behavior of lightweight aggregate concrete filled steel tube slender columns under axial compressive load. With the same other section parameters, the greater the slenderness ratio is, the lower the ultimate bearing capacity of the specimen is and the worse the plastic deformation capacity is. The stability coefficient decreases as the increasing of slenderness ratio. 
(2) The performances of core concrete influence the stability behavior of lightweight aggregate concrete filled steel tube and normal concrete filled steel tube columns. The stability coefficient of specimens is determined by the peak strain of concrete and the peak strength of concrete has no influence to stability coefficient. The stability coefficient increases when the peak strain of concrete increases. Because of the larger peak strain of concrete, the stability coefficient of specimens with higher strength is higher than that of core concrete with lower strength in this test.

(3) Based on the comparison of bearing capacity calculation using different methods, calculation formula in Europe code EC4 (1996) can be suggested to calculate the bearing capacity of lightweight aggregate concrete filled steel tube columns axial compression. The calculation results have a preferable goodness of fit to the test ones in this paper.

\section{ACKNOWLEDGMENTS}

The authors appreciate the support of Natural Science Foundation of Jiangsu Province, The Fundamental Research Funds for the Central Universities, and Jiangsu Civil Engineering Graduate Center for Innovation and Academic Communication foundation.

\section{REFERENCES}

[1] Ge, H.B., Susantha, K.A.S., Satake, Y., et al., "Seismic Demand Predictions of Cconcrete-filled Steel Box Columns”, Engineering Structures, 2003, Vol. 25, No. 3, pp. 337-345.

[2] Han, L.H., Lu, H., Yao, G.H., et al, "Further Study on the Flexural Behaviour of Concrete-filled Steel Tubes”, Journal of Constructional Steel Research, 2006, Vol. 62, No. 6, pp. 554-565.

[3] Kuranovas, A., Goode, D., Kvedaras, A.K., et al, "Load-bearing Capacity of Concrete-filled Steel Columns”, Journal of Civil Engineering and Management, 2009, Vol. 15, No. 1, pp. 21-33.

[4] Gao, S.B. and Ge, H.B., "Numerical Simulation of Hollow and Concrete-filled Steel Columns”, Int. J. of Advanced Steel Construction, Vol. 3, No. 3, pp. 668-678.

[5] Goode, C.D., "Composite Columns - 1819 Tests on Concrete-filled Steel Tube Columns Compared with Euro Code 4”, Structural Engineer, 2008, Vol. 86, No. 16, pp. 33-38.

[6] Chen, B.C. and Wang, T.L., "Overview of Concrete Filled Steel Tube Arch Bridges in China”, Practice Periodical on Structural Design and Construction, 2009, Vol. 14, No. 2, pp. 70-80.

[7] Susantha, K.A.S., Ge, H.B. and Usami, T., "Cyclic Analysis and Capacity Prediction of Concrete-filled Steel Box Columns”, Earthquake Engineering \& Structural Dynamics, 2002, Vol. 31, No. 2, pp. 195-216.

[8] Ge, H.B. and Usami, T. "Cyclic Tests of Concrete-filled Steel Box Columns”, Journal of Structural Engineering, ASCE, 1996, Vol. 122, No. 10, pp. 1169-1177.

[9] Liu, H.Y. and Song, Y.P., "Experimental Study of Lightweight Aggregate Concrete under Multiaxial Stresses”, Journal of Zhejiang University-Science A, 2010, Vol. 11, No. 8, pp. 545-554.

[10] Haque, M.N., Al-Khaiat, H. and Kayali, O., "Strength and Durability of Lightweight Concrete”, Cement and Concrete Composites, 2004, Vol. 26, No. 4, pp. 307-314. 
[11] Nakamura, S., Momiyama, Y., Hosaka, T., et al., "New Technologies of Steel/Concrete Composite Bridges”, Journal of Constructional Steel Research, 2002, Vol. 58, No. 1, pp. 99-130.

[12] Mouli, M. and Khelafi, H., "Strength of Short Composite Rectangular Hollow Section Columns Filled with Lightweight Aggregate Concrete”, Engineering Structures, 2007, Vol. 29, No. 8, pp. 1791-1797.

[13] Cai, S.H., "Modern Concrete Filled Steel Tube Structure", China Communications Press, 2003, pp. 63 (in Chinese).

[14] Han, L.H. and Yang, Y.F., "Modern Concrete Filled Steel Tube Structure Technology", China Architecture \& Building Press, 2004, pp. 80 (in Chinese).

[15] Wang, Z.Y., Ding, J.T. and Guo, Y.S., "Stress-Strain Curves of Structural Lightweight Aggregate Concretes”, Concrete, 2005, No. 3, pp. 39-41 (in Chinese).

[16] Chinese Code, “Code for Design of Concrete Structures (GB 50010-2002)”, 2002 (in Chinese). 


\title{
GENETIC PROGRAMMING BASED MODELING OF SHEAR CAPACITY OF COMPOSITE BEAMS WITH PROFILED STEEL SHEETING
}

\author{
M. A. Köroğlu ${ }^{1, *}$, A. Köken ${ }^{1}$, M. H. Arslan ${ }^{1}$ and A. Çevik ${ }^{2}$ \\ ${ }^{1}$ Department of Civil Engineering, Selcuk University, 42075 Konya/TURKEY \\ ${ }^{2}$ Department of Civil Engineering, University Of Gaziantep, 27310/TURKEY \\ *(Corresponding author: E-mail: makoroglu@selcuk.edu.tr)
}

Received: 27 July 2010; Revised: 16 September 2010; Accepted: 20 September 2010

\begin{abstract}
This study investigates the availability of Genetic Programming (GP) for modeling the ultimate shear capacity of composite beams with profiled steel sheeting for the first time in literature. Experimental data involving push-out test specimens of 46 composite beams from an existing database in the literature were used to develop GP model. The input parameters affecting the shear capacity were selected as stud position (strong and weak), sheeting type (width of rib of the profiled steel sheeting, depth of the rib), stud dimensions (height and diameter), slab dimensions (width, depth and height), reinforcement in the slab and concrete compression strength. Moreover, a short review of well-known building codes regarding ultimate shear capacity of composite beams is presented. The accuracy of the codes in predicting the ultimate shear capacity of composite beams was also compared with the proposed GP model with comparable way by using same test data. The study concludes that the proposed GP model predicts the ultimate shear capacity of composite beams by far more accurate than building codes.
\end{abstract}

Keywords: Shear connection, composite beams, push-out tests, genetic programming

\section{INTRODUCTION}

The composite behavior of two or more structural members joined together by using different materials is called "a composite structure". Each material of a composite structure usually has a superior property effectively used for providing the composite behavior of the materials. Although several materials are used as the shear connector of a composite structure, "headed stud" shear connectors are generally used in constructions due to their practicality.

In the composite beams with profiled steel sheeting many factors such as; dimensions and direction of profiled steel sheeting, compressive strength of concrete, reinforcement area and position and also strength, dimension and location of shear connectors affect the behavior of shear connectors. Push out tests is commonly used to determine the capacity of the shear connectors and load-slip behavior of shear connectors. According to Eurocode 4 [1], the push-out specimens consist of a steel beam section held in the vertical position by two identical concrete slabs. The concrete slabs are attached to the beam by shear connectors. The connection is subjected to a vertical load, which produces a shear load along the interface between the concrete slab and the beam flange on both sides. At a specified load or displacement the slip between the slabs and the beam flange is evaluated. The failure load divided by the numbers of the connectors is assumed as the shear connection capacity [2].

Composite construction using steel and concrete has been used since the early 1920s. It gained widespread use in bridges in the 1950s and in buildings in the 1960s [3]. Both push-out tests, which were first used in Switzerland in the 1930s [4], and full-scale beam tests have been used to develop shear stud strength prediction expressions. Push-out tests are usually used to evaluate a wide array of parameters because of the large size and expense of beam tests. 
Early shear stud strength prediction equations were for solid slab construction, the equations developed in the 1960s and 1970s were based on the results of push-out tests. The equations were modified for the use of steel deck in the late 1970s and were based on full-scale beam tests [5]. The stud strength equations given by Grant et al [6] were developed from tests mostly using deck without stiffeners where the studs were welded in the center of the deck rib. Beside the commonly used headed studs, to obtain optimum solutions for composite action, some investigations have done with different type of welded shear connectors like, perfobond, $\mathrm{T}$ connector, horseshoe, bar connector etc... in the previous studies.

There are many variables affecting the shear capacity of composite beams such as stud position (strong and weak), sheeting type (width of rib of the profiled steel sheeting, depth of the rib), stud dimensions (height and diameter), slab dimensions (width, depth and height), reinforcement in the slab and concrete compression strength. The effect of these variables on the shear capacity of composite beams has been extensively studied and some empirical approach has been developed related to variables. For instance, Zellner [7], Veldanda \& Hosain [4], Klaiber \&Wipe [8] and Valente \& Cruz [9] in the area of composite beams with perfobond ribs. Galjaard and Walraven [10] performed tests using shear studs, Perfobond connectors, T-connectors and oscillating Perfobond connectors, both with normal weight and lightweight concrete. Johnson and Oehlers [11] analyzed 125 push-out test results from 11 sources, performed 101 new push-out tests and four composite T-beam tests, and performed a parametric study. And also Köroğlu [12] conducted 4 push-out tests to study the behavior of Turkish extra seismic reinforcement steel bars as shear connector in composite beams with profiled steel sheeting perpendicular to beam. In addition, Köroğlu also performed 4 push-out tests with the headed shear connectors as shear connector to compare the Turkish extra seismic reinforcement steel bars versus headed shear connectors as shear connector $[13,14]$. In Figure 1. test specimen of a composite beam with profiled steel sheeting perpendicular to beam prepared by Köroğlu [12] is given. And also, in Figure 2 the application of the shear connectors from the existing buildings is shown [15].

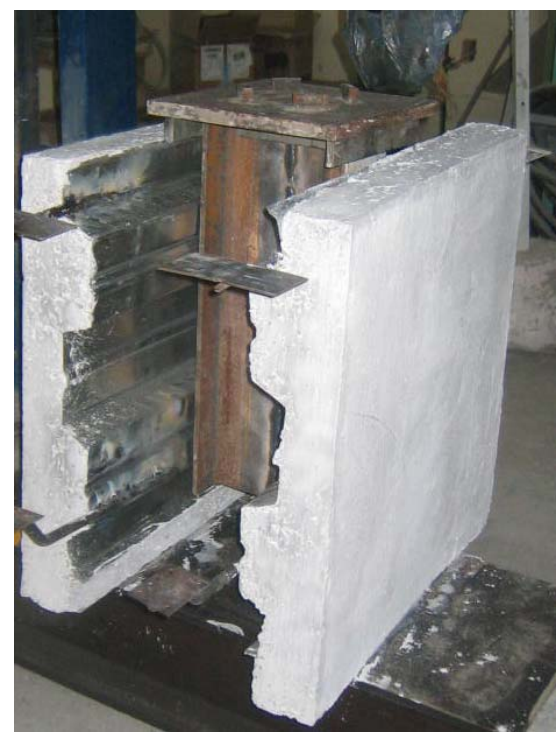

Figure 1. A Photo of a Specimen Prepared for the Push-out Tests [12] 

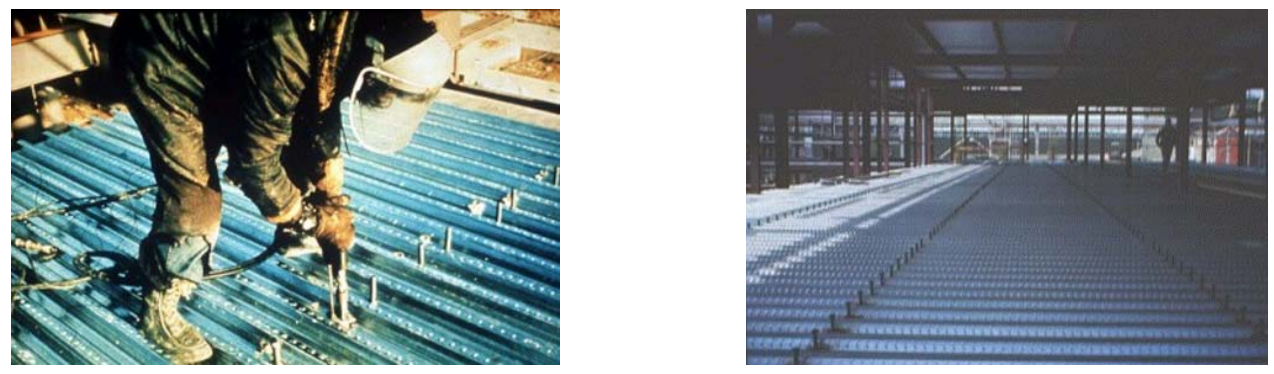

Figure 2. Photos from Application of the Shear Connectors from the Existing Buildings [15]

Because of an enormous variety of shear connectors, strength and ductility of shear connectors are suggested to be determined experimentally. So, because of fast automatic welding procedure headed stud shear connectors are commonly used to ensure composite action. Since it is certainly the most investigated and understood form of shear connection, it is probably the most common form of welded shear connection.

The scope and objectives of the present work are a) to investigate the applicability of Genetic Programming (GP) in predicting the ultimate shear capacity of composite beams by using experimental results collected from the literature, b) to discuss the effect of the selected parameters on to the shear strength. In this sense, experimental data of 46 composite beams with headed stud shear connectors subjected to push out tests were used from existing databases of Roddenbery [5], Lloyd \& Wright [16], Kim et al [17] and Köroğlu [12]. The experimental database is given in Table Appendix. Furthermore, some code' approaches as AISC [18], Eurocode-4 [1], BSI-BS 5950 [19] and CSA [20] are also examined by comparing their predictions with mentioned experimental studies results. The results obtained by the proposed ANN model and the codes are compared with each other.

\section{CALCULATING SHEAR CAPACITY OF COMPOSITE BEAMS WITH PROFILED STEEL SHEETING}

The design strength and stiffness of composite beams with profiled steel sheeting depends on the shear connection behavior. According to the experimental studies, the main depending factors defining the strength of shear connectors are:

a) Shape and dimensions of the shear connectors,

b) Quality of its material,

c) Concrete strength,

d) Type of load (static and dynamic),

e) Way of connecting the steel beams,

f) Distance between the shear connectors,

g) Dimensions of the concrete slab (see Figure 3.),

h) Percentage and way of reinforcing

i) Sheeting type and dimension of steel sheeting (see Figure 3.),

In the literature, several formulations have been proposed by various researchers. The review of these theories is given in Table 1. 


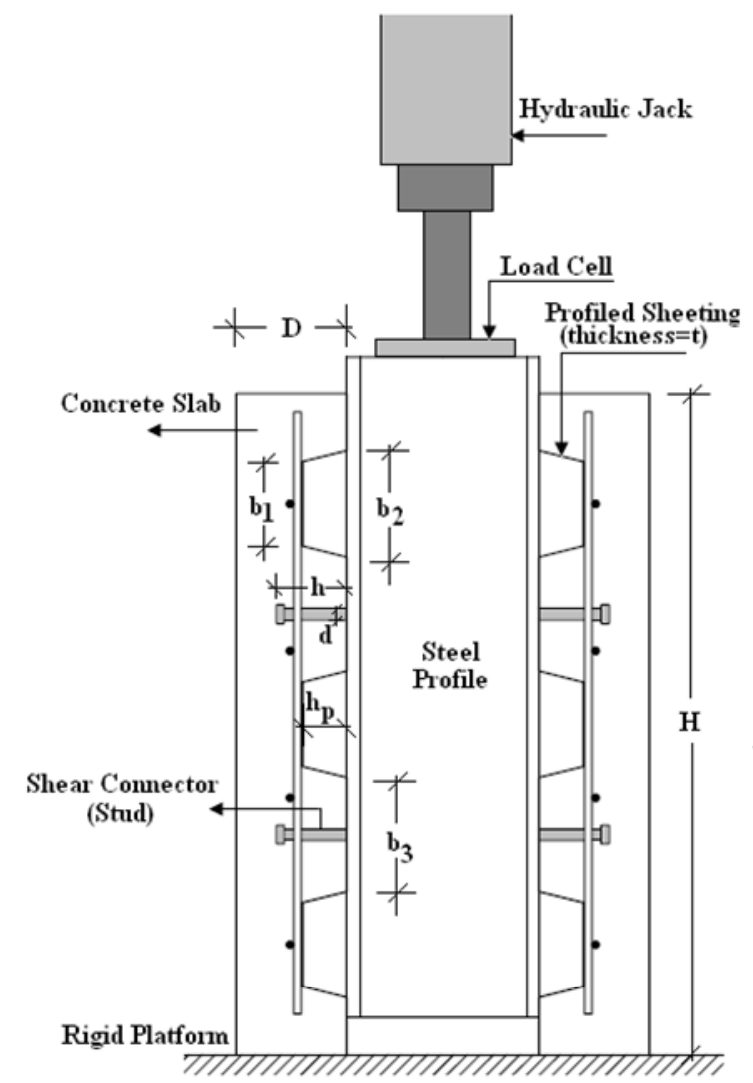

Figure 3. Test Setup, Dimension of Concrete Slab and Steel Sheeting

Early tests by Fisher [21] were performed and several conclusions were drawn regarding the design of composite beams with formed metal decks. An equation for stud connector strength is given as Equation 1. Grant et al [6] was made a modification to the equation developed by Fisher [21] including the height effect of the stud shear connectors. They provided an empirical equation to calculate the shear capacity of headed shear studs in composite beams with profiled steel sheeting. Grants expression for stud connector strength is given as Equation 2. Hawkins and Mitchell [22] performed a linear regression analysis and developed two separate equations of shear connectors shear strength due to concrete pull-out failure for $76 \mathrm{~mm}$ deck and $38 \mathrm{~mm}$ deck. In the Equation 3 , for $76 \mathrm{~mm}$ deck and $38 \mathrm{~mm}$ deck $\xi$ is 0.35 and 0.61 , respectively. $\lambda$ (factor dependent upon type of concrete) is ranging from 0.75 and 1.0 that depends on the density of concrete. Rambo-Roddenberry [5] carried out 92 push-out tests to study the behavior of headed stud shear connectors in composite beams with profiled steel sheeting perpendicular to the beam. He provided also a new strength prediction model, based on the strength prediction equations to calculate the shear capacity of headed shear studs. In his approaches, the strength prediction divided four parts which differ from each other to the $\mathrm{d} / \mathrm{t}$ ratio and stud height.

The design strength and stiffness of composite beams with profiled steel sheeting depends on the shear connection behavior. Because of the steel deck geometry of the composite beams with profiled steel sheeting the strength of the shear connectors may be reduced. An empirical expression for this reduction was developed by evaluating results of composite beam tests in many standards. 
The AISC [18], equation for the calculation of the design strength of headed stud shear connector in composite beams with profiled steel sheeting perpendicular to the steel beam is given Equation 4 . The $r_{1}$ (reduction factor), which should not be taken greater than 1.0, is a function of the deck geometry and the number of studs in a rib. Elastic modulus of concrete is $E_{c}=4700 \sqrt{f_{c}}$ according to the ACI [23] building code. In the BSI (BS 5950 Part 3) design strength of headed stud shear connector in composite beams with profiled steel sheeting perpendicular to the steel beam is determined by multiplying the values by reduction factor given as Equation 5. In the expression, if $\frac{h}{d} \geq 3$, $\alpha$ must be less than 1.0 for $\alpha=0.2\left(\frac{h}{d}+1\right)$, where $r_{2}$ is reduction factor $\left(r_{2} \leq 1.0\right)$. The design strength for EC4 [1] of the headed stud in composite beams with profiled steel sheeting perpendicular to the steel beam is similar to the AISC equations, except the constant 0.5 is changed to 0.29 in the equation, and the upper limit on this strength is $80 \%$ of the tensile strength of the stud. In the expression, if $3 \leq \frac{h}{d} \leq 4, \alpha$ is $\left(\frac{h}{d}-1\right)$ and $\alpha=1$ for $\frac{h}{d}>4$. The strength reduction factor $\left(r_{3}\right)$ is ranging from 1.0 to 0.6. Canadian Standards Association (CSA) [20], specification is the same equation as the one in the AISC [18] specification. According to the CSA, strength of headed stud shear connector depends on the depth of the rib given as Equation 7-1 and 7-2.

Table 1. A Review of the Regulations of Shear Capacity of Composite Beams

Model

Fisher [21]

Grant et al. [6]

Hawkins and

Mitchell [22]

AISC [18]

BSI BS 5950 [19]

EC 4 [1]

CSA [20]
Expression

$$
P_{\text {FISHER }}=0.36 \frac{b_{0}}{h_{p}} * 0.5 A_{s} \sqrt{f E_{c}}
$$

$$
P_{\text {GRANT }}=\frac{0.85}{\sqrt{N}}\left(\frac{b_{0}}{h_{p}}\right)\left[\left(\frac{h-h_{p}}{h_{p}}\right) 0.5 A_{s} \sqrt{f E_{c}}\right] \leq 0.5 A_{s} \sqrt{f E_{c}}
$$

$$
P_{B S 5950}=\left(0.25 r_{2} \alpha d^{2} \sqrt{0.8 f_{c} E_{c}}, \quad 0.6 r_{2} f_{u} \frac{\pi d^{2}}{4}\right) \mathrm{min}
$$

$$
P_{\text {AISC }}=\underbrace{\left(\frac{0.85}{\sqrt{N}}\left(\frac{b_{0}}{h_{p}}\right)\left[\left(\frac{h}{h_{p}}\right)-1.0\right]\right.}_{r_{1}} 0.5 A_{s} \sqrt{f E_{c}} \leq A_{s} f_{u}
$$

$$
P_{E C 4}=\left(0.29 r_{3} \alpha d^{2} \sqrt{f_{c} E_{c m}}, 0.8 r_{3} f_{u} \frac{\pi d^{2}}{4}\right) \min
$$

$P_{C S A}=\left(4.2 A_{c} \sqrt{f_{c}}, 0.5 A_{s} \sqrt{f_{c} E_{c}} \leq A_{s} f_{u}\right) \mathrm{min}$; for $76 \mathrm{~mm} \mathrm{deck}$

$P_{C S A}=\left(7.3 A_{c} \sqrt{f_{c}}, 0.5 A_{s} \sqrt{f_{c} E_{c}} \leq A_{s} f_{u}\right) \mathrm{min}$; for $38 \mathrm{~mm} \mathrm{deck}$ 


\section{GENETIC PROGRAMMING}

Genetic programming (GP) is an extension to Genetic Algorithms proposed by Koza [24]. Koza defines GP as a domain-independent problem-solving approach in which computer programs are evolved to solve, or approximately solve, problems based on the Darwinian principle of reproduction and survival of the fittest and analogs of naturally occurring genetic operations such as crossover (sexual recombination) and mutation. GP reproduces computer programs to solve problems by executing the following steps (Figure 4.) :

1) Generate an initial population of random compositions of the functions and terminals of the problem (computer programs).

2) Execute each program in the population and assign it a fitness value according to how well it solves the problem.

3) Create a new population of computer programs.

i) Copy the best existing programs (Reproduction)

ii) Create new computer programs by mutation.

iii) Create new computer programs by crossover (sexual reproduction).

iv) Select an architecture-altering operation from the programs stored so far.

4) The best computer program that appeared in any generation, the best-so-far solution, is designated as the result of genetic programming [24].

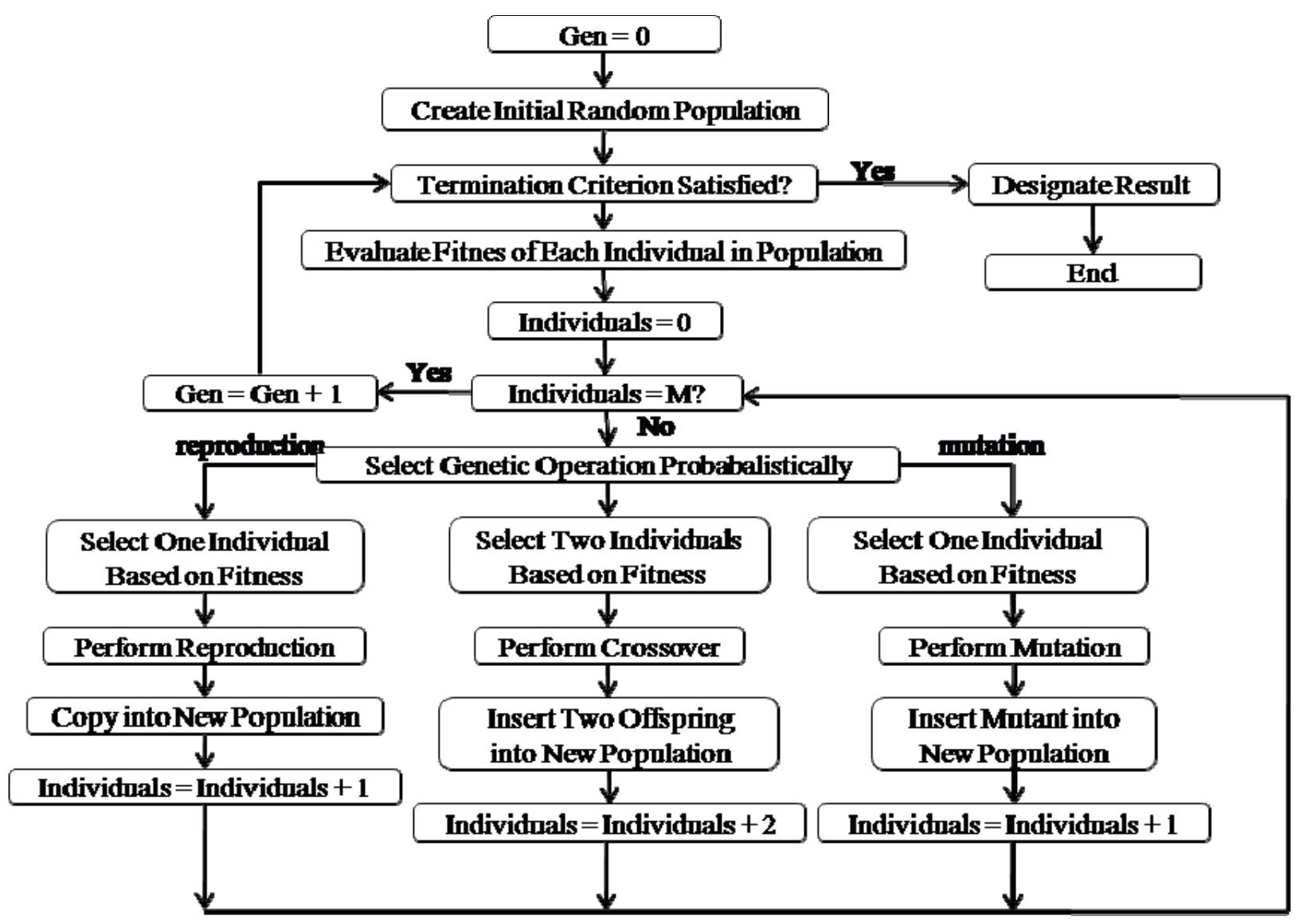

Figure 4. Genetic Programming Flowchart [24] 
Gene expression programming (GEP) software which is used in this study is an extension to GP that evolves computer programs of different sizes and shapes encoded in linear chromosomes of fixed length. The chromosomes are composed of multiple genes, each gene encoding a smaller sub-program. Furthermore, the structural and functional organization of the linear chromosomes allows the unconstrained operation of important genetic operators such as mutation, transposition, and recombination. One strength of the GEP approach is that the creation of genetic diversity is extremely simplified as genetic operators work at the chromosome level. Strength of GEP consists of its unique, multigenic nature which allows the evolution of more complex programs composed of several sub-programs. As a result GEP surpasses the old GP system in 100-10.000 times. [25-27].

The phenotype of GEP individuals consists of the same kind of diagram representations used by GP. However, these complex entities are encoded in simpler, linear structures of fixed length - the chromosomes. Thus, the main players in GEP are two entities: the chromosomes and the ramified structures or expression trees (ETs), being the latter the expression of the genetic information encoded in the former. The process of information decoding (from the chromosomes to the ETs) is called translation. And this translation implies obviously a kind of code and a set of rules. The genetic code is very simple: a one-to-one relationship between the symbols of the chromosome and the functions or terminals they represent. The rules are also very simple: they determine the spatial organization of the functions and terminals in the ETs and the type of interaction between sub-ETs in multigenic systems [26, 27].

In GEP there are therefore two languages: the language of the genes and the language of ETs and, in this simple replicator/phenotype system, knowing the sequence or structure of one, know the other. In nature, although the inference of the sequence of proteins given the sequence of genes and vice versa is possible, practically nothing is known about the rules that determine the three-dimensional structure of proteins. But in GEP thanks to the simple rules that determine the structure of ETs and their interactions, it is possible to infer exactly the phenotype given the sequence of a gene, and vice versa. This bilingual and unequivocal system is called Karva language [27].

\subsection{Solving a Simple Problem with GEP}

For each problem, the type of linking function, as well as the number of genes and the length of each gene, are a priori chosen for each problem. While attempting to solve a problem, one can always start by using a single-gene chromosome and then proceed by increasing the length of the head. If it becomes very large, one can increase the number of genes and obviously choose a function to link the sub-ETs. One can start with addition for algebraic expressions or for Boolean expressions, but in some cases another linking function might be more appropriate (like multiplication or IF, for instance). The idea, of course, is to find a good solution, and GEP provides the means of finding one very efficiently [25-27].

As an illustrative example consider the following case where the objective is to show how GEP can be used to model complex realities with high accuracy. So, suppose one is given a sampling of the numerical values from the curve (remember, however, that in real-world problems the function is obviously unknown):

$y=3 a^{2}+2 a+1$ 
over 10 randomly chosen points in the real interval $[-10,+10]$ and the aim is to find a function fitting those values within a certain error. In this case, a sample of data in the form of 10 pairs $\left(a_{i}, y_{i}\right)$ is given where $a_{i}$ is the value of the independent variable in the given interval and $y_{i}$ is the respective value of the dependent variable $\left(a_{i}\right.$ values: $-4.2605,-2.0437,-9.8317,-8.6491,0.7328$, $-3.6101,2.7429,-1.8999,-4.8852,7.3998$; the corresponding $y_{i}$ values can be easily evaluated). These 10 pairs are the fitness cases (the input) that will be used as the adaptation environment. The fitness of a particular program will depend on how well it performs in this environment [25-27].

There are five major steps in preparing to use gene expression programming. The first is to choose the fitness function. For this problem one could measure the fitness $f_{i}$ of an individual program $i$ by the following expression:

$$
f_{i}=\sum_{j=1}^{C_{t}}\left(M-\left|C_{(i, j)}-T_{j}\right|\right)
$$

where $M$ is the range of selection, $C_{(i, j)}$ the value returned by the individual chromosome $i$ for fitness case $j$ (out of $C_{t}$ fitness cases) and $T_{j}$ is the target value for fitness case $j$. If, for all $j, \mid C_{(i, j)}$ $T_{j} \mid$ (the precision) less than or equal to 0.01 , then the precision is equal to zero, and $f_{i}=f_{\max }=C_{t}{ }^{*} M$. For this problem, use an $M=100$ and, therefore, $f_{\max }=1000$. The advantage of this kind of fitness function is that the system can find the optimal solution for itself. However there are other fitness functions available which can be appropriate for different problem types [25-28].

The second step is choosing the set of terminals $T$ and the set of functions $F$ to create the chromosomes. In this problem, the terminal set consists obviously of the independent variable, i.e., $T=\{a\}$. The choice of the appropriate function set is not so obvious, but a good guess can always be done in order to include all the necessary functions. In this case, to make things simple, use the four basic arithmetic operators.

Thus, $F=\{+,-, *, /\}$. It should be noted that there many other functions that can be used.

The third step is to choose the chromosomal architecture, i.e., the length of the head and the number of genes.

The fourth major step in preparing to use gene expression programming is to choose the linking function. In this case we will link the sub-ETs by addition. Other linking functions are also available such as subtraction, multiplication and division.

And finally, the fifth step is to choose the set of genetic operators that cause variation and their rates. In this case one can use a combination of all genetic operators (mutation at $p_{m}=0.051$; IS and RIS transposition at rates of 0.1 and three transposons of length 1,2 , and 3; one-point and two-point recombination at rates of 0.3 ; gene transposition and gene recombination both at rates of $0.1)$.

To solve this problem, lets choose an evolutionary time of 50 generations and a small population of 20 individuals in order to simplify the analysis of the evolutionary process and not fill this text with pages of encoded individuals. However, one of the advantages of GEP is that it is capable of solving relatively complex problems using small population sizes and, thanks to the compact Karva notation; it is possible to fully analyze the evolutionary history of a run. A perfect solution can be found in generation 3 which has the maximum value 1000 of fitness. The sub-ETs codified by each gene are given in Figure 3. Note that it corresponds exactly to the same test fuction given above in Equation 8 [25-27]. 
Thus expressions for each corresponding Sub-ET can be given as follows:

$y=\left(a^{2}+a\right)+(a+1)+\left(2 a^{2}\right)=3 a^{2}+2 a+1$

\section{NUMERICAL APPLICATION}

In this study, GeneXproTools 4.0 [29] software package is used for GP modeling of shear capacity of composite beams with profiled steel sheeting. Among the experimental database, 10 tests were used as testing set and the remaining 36 test as training set for GP training. The proposed GP formula is an empirical equation based on the experimental database given in section 2 . In the proposed GP model, input parameters were selected based on previously published studies which are sheeting type (width of rib of the profiled steel sheeting, depth of the rib), stud dimensions (height and diameter), slab dimensions (width, depth and height), reinforcement in the slab and concrete compression strength. The ranges of variables in the experimental database where the proposed GP model will be valid are given in Table A.1. Related parameters of the GP training are presented in Table 2. Statistical parameters of the proposed GP model are given in Table 3. The performance of GP model vs. test results is shown in Figure 5. The entire database with corresponding experimental and GP results are given in Table A.1. The expression tree of the GP model is presented in Figure 6 where $\mathrm{d}_{0}, \mathrm{~d}_{1}, \mathrm{~d}_{2}, \mathrm{~d}_{3}, \mathrm{~d}_{4}$ and $\mathrm{d}_{5}$ correspond to $\mathrm{b}_{1}, \mathrm{~b}_{2}, \mathrm{~b}_{3}, \mathrm{~h}_{\mathrm{p}}, \mathrm{t}$ and $\mathrm{d}$ respectively. Constants shown in Figure 6 are $-8715,7765$ and -6405 respectively. After putting the constants, the final formulation for ultimate shear capacity of composite beams is obtained as follows:

$$
P=\left[\left(\sqrt[3]{\frac{h_{p}-b_{2}}{N}}+F_{u}-65.93+h+N-b_{3}\right) \times\left(\frac{d}{t}+d-8.72+\sqrt{\frac{A}{t}}\right) \times\left(\frac{b_{3}}{b_{3}-b_{1}+F_{u}-f_{c u}+d-b_{1}}\right)\right]
$$

Table 2. Parameters of GP Model

\begin{tabular}{lll}
\hline P1 & Function Set & $+,-,, /, \sqrt{ }, \ln$ \\
\hline P2 & Chromosomes & $30-200$ \\
\hline P3 & Head Size: & $2-6$ \\
\hline P4 & Number of Genes: & $1-4$ \\
\hline P5 & Linking Function: & Addition, Multiplication \\
\hline P6 & Fitness Function Error Type: & MAE, RMSE, Custom Function \\
\hline P7 & Mutation Rate: & 0,044 \\
\hline P8 & Inversion Rate: & 0,1 \\
\hline P9 & One-Point Recombination Rate: & 0,3 \\
\hline P10 & Two-Point Recombination Rate: & 0,3 \\
\hline P11 & Gene Recombination Rate: & 0,1 \\
\hline P12 & Gene Transposition Rate: & 0,1 \\
\hline
\end{tabular}


Table 3. Statistical Parameters of the Proposed GP Model

\begin{tabular}{llll}
\hline & Mean & COV & $\mathrm{R}^{2}$ \\
\hline GP Testing Set & 1.06 & 0.125 & 0.86 \\
\hline GP Training Set & 1.01 & 0.125 & 0.92 \\
\hline GP Total Set & 1.02 & 0.125 & 0.91 \\
\hline
\end{tabular}

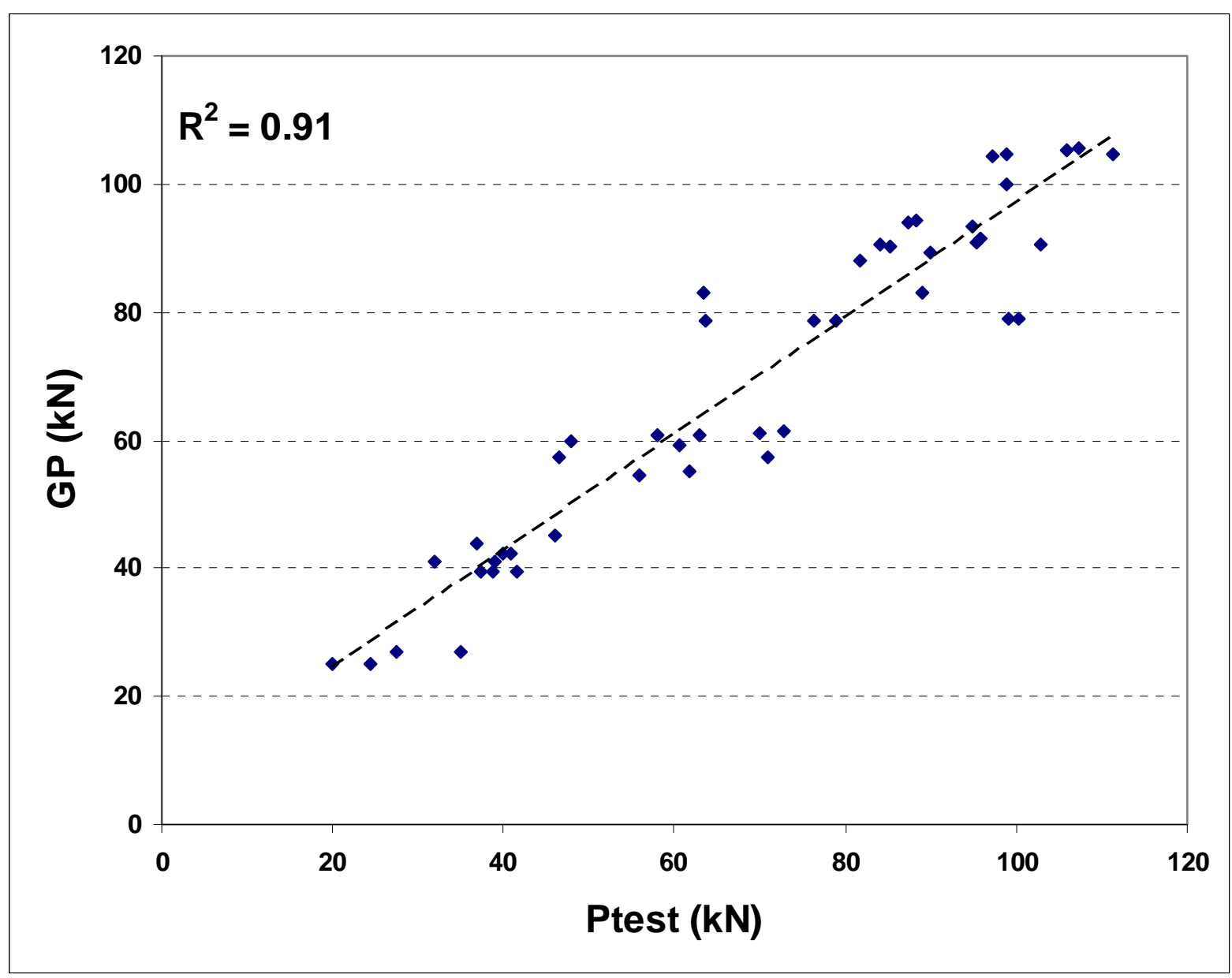

Figure 5. Performance of Test and GP Results 


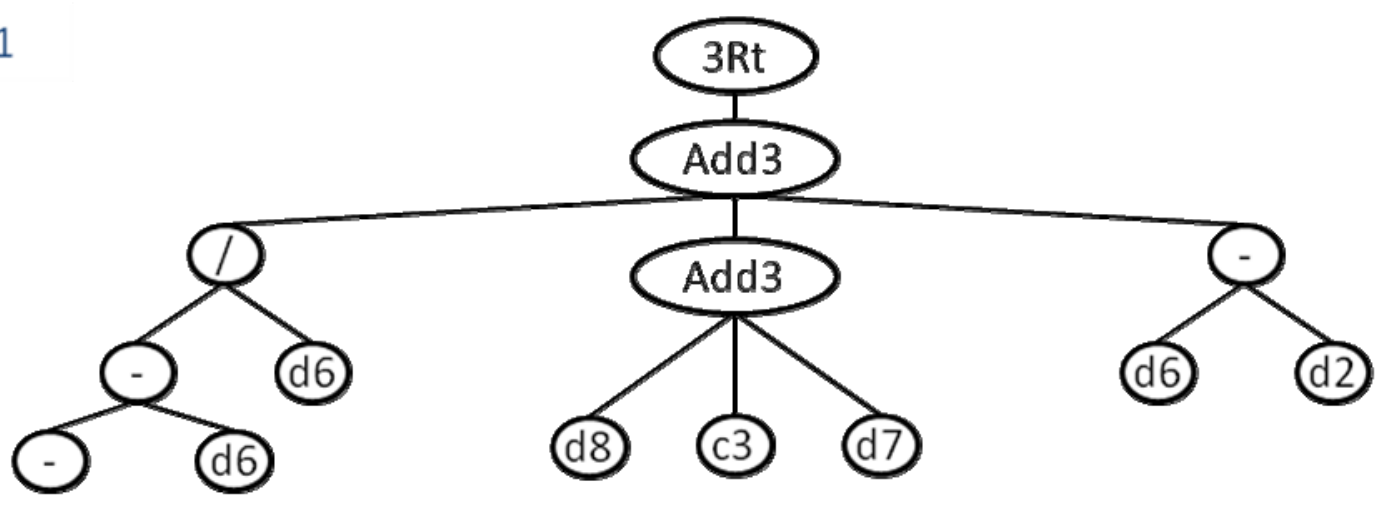

\section{Sub-ET 2}

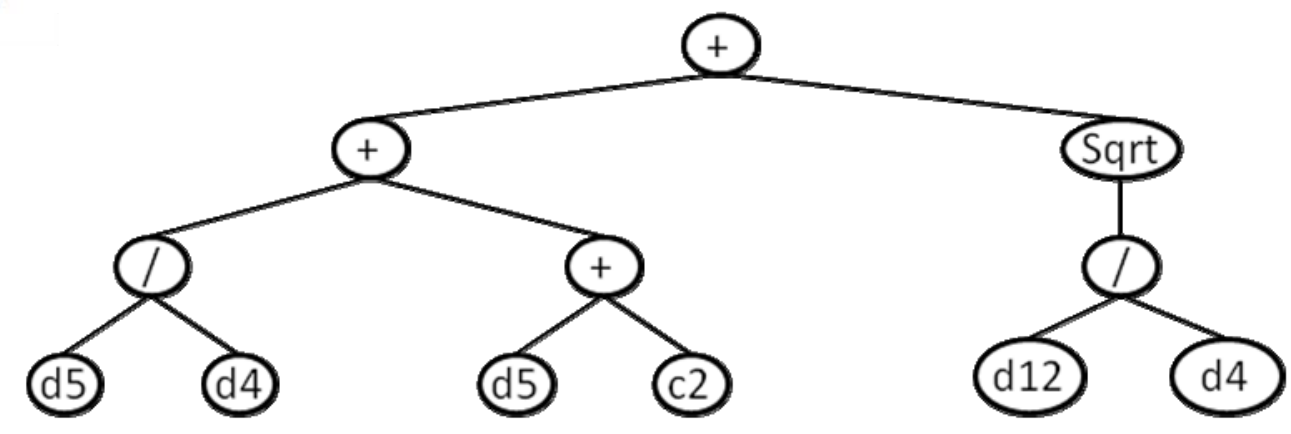

Sub-ET 3

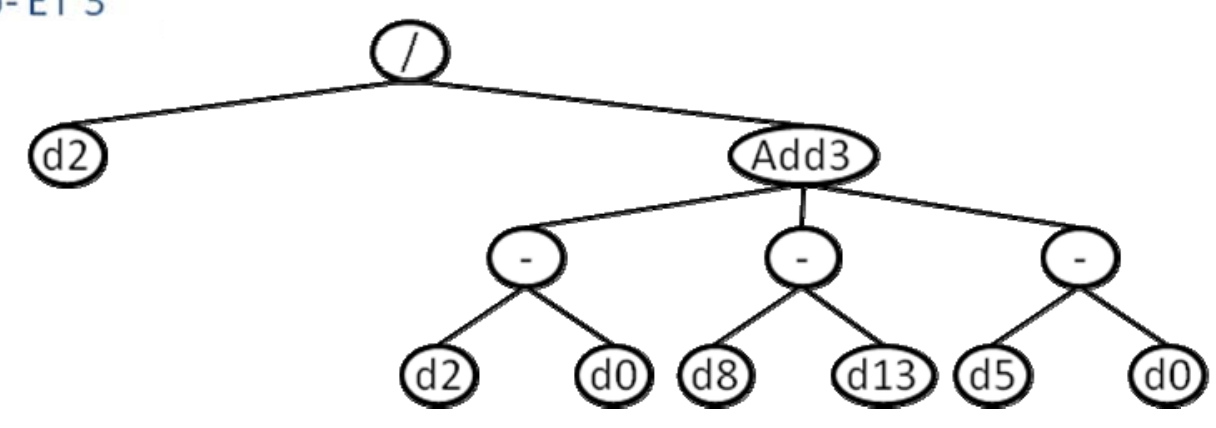

Figure 6. Expression Tree for Ultimate Shear Capacity of Composite Beams

The predicted ultimate shear strength values of the GP model are observed to be in very good agreement with the experimental data. The GP prediction accuracy is also compared with accuracies of code equations in Table 4. As seen the proposed GP model is by far more accurate than available design codes.

Table 4. Comparison of Accuracy of GP Model Versus Various Design Codes

\begin{tabular}{llllll}
\hline & GP & Paisc & Pec4 & Pbs & Pcsa \\
\hline Mean & 1.02 & 0.72 & 0.91 & 1.20 & 0.72 \\
\hline COV & 0.125 & 0.17 & 0.19 & 0.18 & 0.17 \\
\hline $\mathrm{R}^{2}$ & 0.91 & 0.79 & 0.78 & 0.79 & 0.79 \\
\hline
\end{tabular}


The prediction accuracy of various standards of building codes related to torsional strength of the beams for mentioned tested 46 specimens are presented in Table 4. As seen from Table 4., AISC 1999[18], Eurocode-4[1], BSI. BS 5950 [19] and CSA [20] shear capacity of composite beams expressions have the most powerful estimating capacity.

Although the estimation rate of design codes is nearly 79\%, GP model can estimate the shear capacity of shear studs in the composite beams with profiled steel sheeting such a high rate (91\%) GP and the other soft computing methods such as ANN, ANFIS...etc have more advantages than design codes formulas since they can train themselves in a comfortable way according to available data easily. Nevertheless, in design codes formulas all parameters that can change the result are not considered for some reason. Moreover, the maximum strength of materials and regulations are taken into consideration in the code's approaches. For instance, when calculating the shear capacity, the steel is assumed as to be yielded or the concrete reached the maximum compressive strength. While all materials could not run at full capacity during the experiments.

According to the results obtained from this study, GP can estimate the shearing capacity of shear studs in the composite beams with profiled steel sheeting in a very satisfactory way. But it is important to be known that the results can be changed by the selected data sets and using parameters in GP methods.

\section{CONCLUSION}

This study is a pioneer work that addresses the feasibility of GP as an alternative approach for the empirical formulation of shear capacity of shear studs in the composite beams with profiled steel sheeting for the first time. The proposed GP model is based on a wide range experimental database collected from the literature. The results of the proposed GP model are seen to be by far more accurate than current design codes and existing equations available in literature. Most of the design codes and equations available in literature are based on the regression analysis of predefined functions. However in the case of GP approach presented in this study, there is no predefined function to be considered. The GP approach generates various formulations and optimizes the best one that fits the experimental database best. The outcomes of this study are quite satisfactory which may serve GP approaches to widely used in further applications in the field of composite structures.

\section{NOTATION}

$A$

$A_{c}$

$A_{s}$

$B$

$b_{0}$

$b_{1}$

$b_{2}$

$b_{3}$

$D$

$d$

$E_{c}$

$E_{c m}$

$e$

$f_{c}$

Area of stud shank

Concrete pull-out failure surface area

The cross-sectional area of the headed stud shear connector

Width of composite concrete slab

Average width of concrete rib of the profiled steel sheeting

Smaller width of rib of the profiled steel sheeting

Larger width of rib of the profiled steel sheeting

Upper section of smaller width of rib of the profiled steel sheeting

Depth of composite concrete slab

Diameter of headed stud shear connector

Initial Young's modulus of concrete

Mean value of the secant modulus tabulated in the EC4

Distance from the center of the stud's longitudinal

Compressive cylinder strength of concrete 


$\begin{array}{ll}f_{c u} & \text { Compressive cube strength of concrete } \\ f_{u} & \text { Minimum specified tensile stress of the stud shear connector } \\ f_{y s} & \text { Yield stress of headed stud shear connector } \\ H & \text { Height of composite concrete slab } \\ h & \text { Height of the headed stud } \\ h_{p} & \text { Depth of the rib } \\ N & \text { Number of studs in one rib of the profiles steel sheeting } \\ n & \text { Number of studs subjected to similar displacements } \\ P_{A I S C} & \text { Design strength calculated using the American Specification } \\ P_{B S 5950} & \text { Design strength calculated using British Standard } \\ P_{C S A} & \text { Design strength calculated using Canadian Standards Association } \\ P_{E C 4} & \text { Design strength calculated using European Code } \\ P_{F I S H E R} & \text { Design strength calculated using Fisher formula } \\ P_{G R A N T} & \text { Design strength calculated using Grant formula in solid slab } \\ P_{O O L G A A R D} & \text { Design strength calculated using Oolgaard formula } \\ P_{P O S} & \text { Concrete pull-out strength of a stud in a composite slab } \\ P_{R R} & \text { Design strength calculated using Rambo-Roddenbery formula } \\ P_{S O L} & \text { Design strength calculated using Fisher formula in solid slab } \\ r & \text { Reduction factor } \\ r_{1} & \text { Reduction factor } \\ r_{2} & \text { Reduction factor } \\ r_{3} & \text { Reduction factor } \\ V_{c} & \text { Shear strength due to concrete pull-out failure (N) } \\ \lambda & \text { Factor dependent upon type of concrete } \\ t & \text { Profiled steel sheeting thickness }\end{array}$

\section{ACKNOWLEDGEMENT}

This research was supported by Gaziantep University Research project Unit and Selcuk University BAP Office (SU-BAP 2007/06201071). Some data were taken from the Master of Science Thesis of M.A. Köroğlu named "Usage of Earthquake Steel Bar as Shear Connection in Composite Slabs"

\section{REFERENCES}

[1] Eurocode 4, EN 1994-1-1:2004, "Design of Composite Steel and Concrete Structures", European Committee for Standardisation (CEN), 2004.

[2] Ellobody, E. and Young, B., "Performance of Shear Connection in Composite Beams with Profiled Steel Sheeting”, Journal of Constructional Steel Research, 2006, Vol. 62, No. 7, pp. 682-694.

[3] Ollgaard, J.G., Slutter, R.G., and Fisher, J.W., "Shear Strength of Stud Connectors in Lightweight and Normal-Weight Concrete", Engineering Journal, AISC, 1971, Vol. 8, No. 2, pp. 55-64.

[4] Veldanda, M.R. and Hosain, M.U., "Behavior of Perfobond Rib Shear connectors: Push-Out Tests", Canadian Journal of Civil Engineering, 1992, Vol. 19, No.1, pp. 1-10.

[5] Rambo-Roddenberry, M.D., "Behavior and Strength of Welded Stud Shear Connectors", $\mathrm{PhD}$ Dissertation, Department of Civil Engineering, Virgiana Politechnic Institute and State University, USA, 2002.

[6] Grant, J.A., Fisher, J.W. and Slutter, R.G., "Composite Beams with Formed Steel Deck", Engineering Journal, AISC, 1977, Vol. 14, No. 1, pp. 24-43. 
[7] Zellner, W., "Recent Designs of Composite Bridges and a New Type of Shear Connectors", Proceedings of the IABSE/ASCE Engineering Foundation Conference on Composite Construction, Henniker, N.H., pp. 240-252.

[8] Klaiber, F.W. and Wipe, T.J., "An Alternate Shear Connector for Composite Action”, Proc. Mid-continent Transportation Symposium 2000, Iowa State University, 2000.

[9] Valente, I. and Cruz, P.J.S., "Experimental Analysis of Perfobond Shear Connection between Steel and Lightweight Concrete", Journal of Constructional Steel Research, 2004, Vol. 60, No. 3-5, pp. 465-479.

[10] Galjaard, J.C. and Walraven, J.C., "Behavior of Shear Connector Devices for Lightweight Steel-Concrete Composite Structures-Results", Observations and Comparisons of Static Tests, 2000, pp. 221-230.

[11] Johnson, R.P. and Oehlers, D.J., "Analysis and Design for Longitudinal Shear in Composite T-Beams.” Proc. Instn Civ. Engrs, 1981, Part 2, Vol. 71, No. 4, pp. 989-1021.

[12] Köroğlu, M.A., "Usage of Earthquake Steel Bar as Shear Connection in Composite Slabs", MSc Thesis, Selçuk University, Konya Turkey, 2007 (In Turkish).

[13] Köroğlu, M.A. and Köken, A., "Load Bearing Capacity of Headed Studs in Composite Beams” 3th National Steel Structures Symposium, 8-10 October, 2009 - Gaziantep, Turkey (In Turkish).

[14] Köken, A. and Köroğlu, M.A., "An Experimental Study on the Usability of Earthquake Resistant Steel Bar as a Shear Connector in Composite Slabs", $10^{\text {th }}$ European Conference on Non-Destructive Testing 2010, 7-11 June, Moscow, Russia.

[15] http://www.corusconstruction.com/en/

[16] Lloyd, R.M. and Wright, H.D., "Shear Connection between Composite Slabs and Steel Beams", Journal of Constructional Steel Research, 1990, Vol. 15, No. 4, pp. 255-285.

[17] Kim, B., Wright, H.D. and Cairns, R., "The Behavior of Through-deck Welded Shear Connectors: An Experimental and Numerical Study", Journal of Constructional Steel Research, 2001, Vol. 57, No. 12, pp. 1359-1380.

[18] AISC, "Load and Resistance Factor Design Specification for Structural Steel Building", 1999, American Institute of Steel Construction, Chicago.

[19] BSI, BS 5950, Part 3: Section 3.1. "Code of Practice for Design of Simple and Continuous Composite Beams", 1990, British Standards Institution, London.

[20] CSA, "Steel Structures for Buildings - Limit State Design", 1984, Canadian Standards Association.

[21] Fisher, J.W., "Design of Composite Beams with Formed Metal Deck", Engineering Journal, AISC, 1970, Vol. 7, No.3, pp. 88-96.

[22] Hawkins, N.M. and Mitchell, D., "Seismic Response of Composite Shear Connections", Journal of Structural Engineering, ASCE, 1984, Vol. 110, No. 9, pp. 2120-2136.

[23] ACI, "Building Code Requirements for Structural Concrete and Commentary", 1999, American Concrete Institute, Detroit.

[24] Koza, J.R., "Genetic Programming: On the Programming of Computers by Means of Natural Selection”, Cambridge, MA: MIT Press, 1992.

[25] Ferreira, C., "Gene Expression Programming in Problem Solving", 6th Online World Conference on Soft Computing in Industrial Applications, September 10-24, 2001.

[26] Ferreira, C., "Gene Expression Programming: A New Adaptive Algorithm for Solving Problems", Complex Systems, 2001, Vol. 13, No. 2, pp. 87-129.

[27] Ireland, J.C., Baeten, M., Foster, J., Lutton, E. and Ryan, C., "Genetic Programming”, $5^{\text {th }}$ European Conference, 2002, EuroGP.

[28] Cevik, A., Arslan, M.H. and Köroglu, M.A., "Genetic-programming-based Modeling of RC Beam Torsional Strength" KSCE Journal of Civil Engineering, 2010, Vol. 14, No. 3, pp. 371-384.

[29] www.gepsoft.com 


\section{APPENDIX}

Table A.1. Database with corresponding experimental and GP results

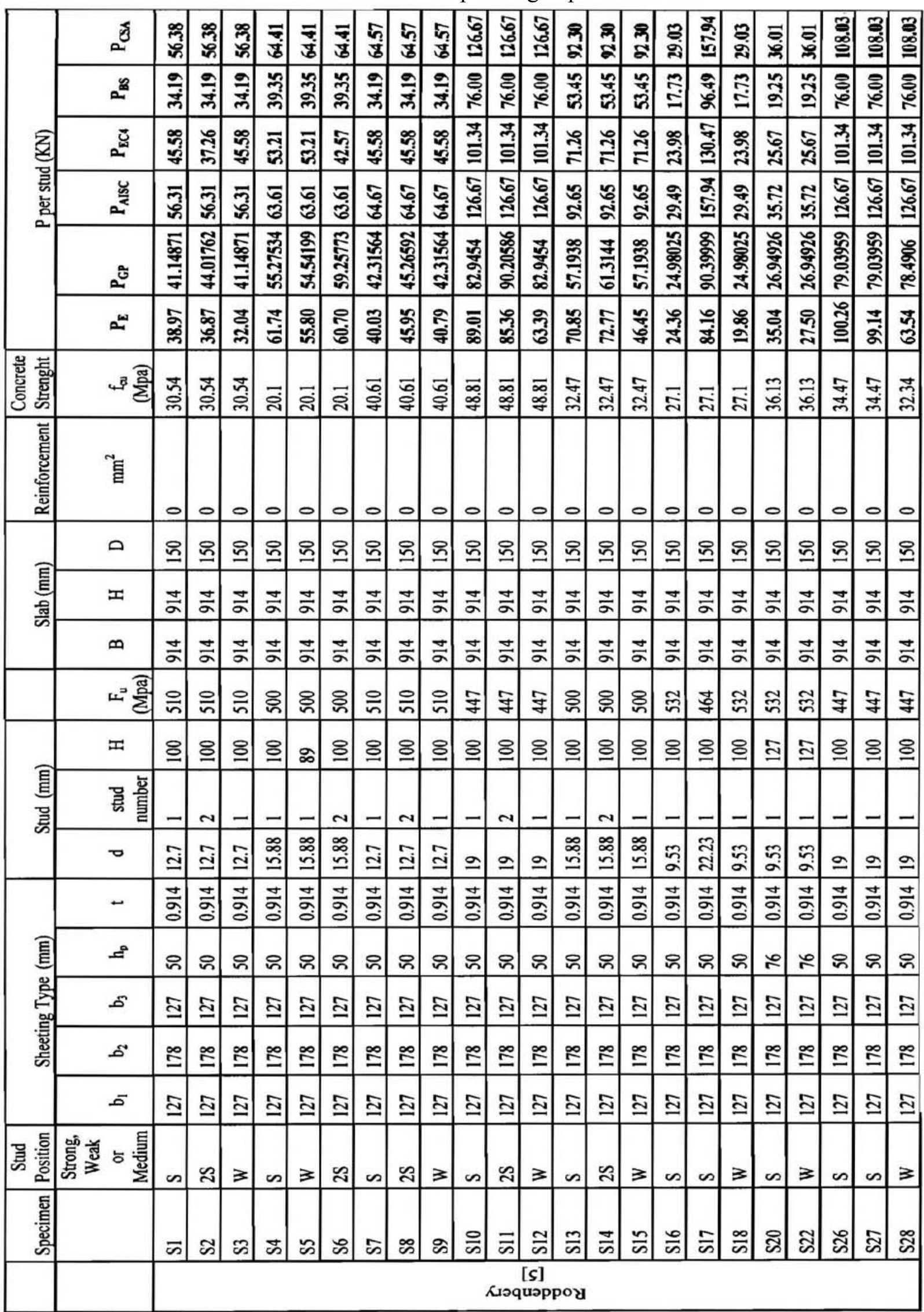




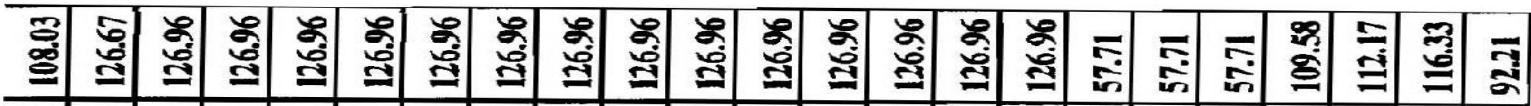

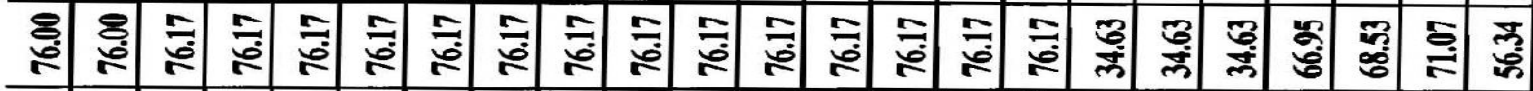

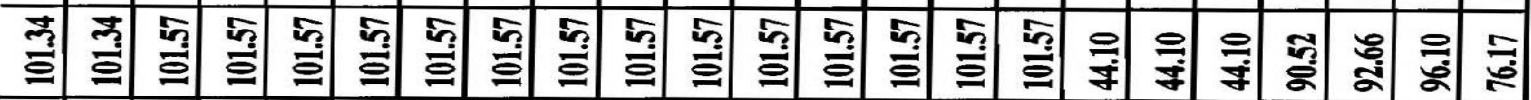

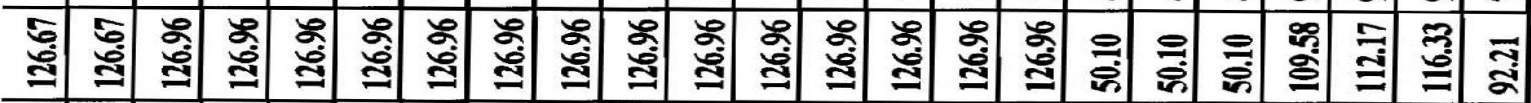 \\ 站 总

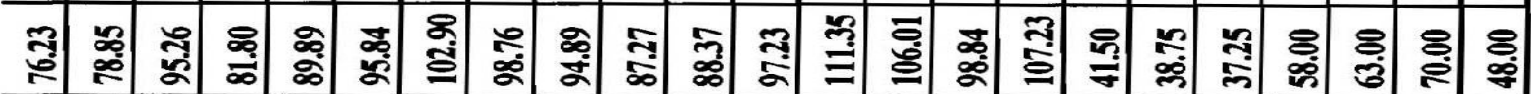

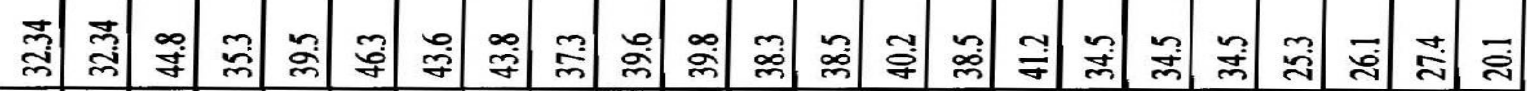

이

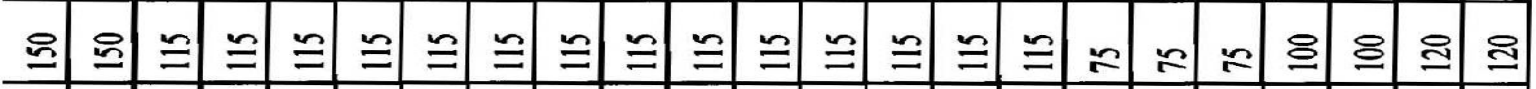

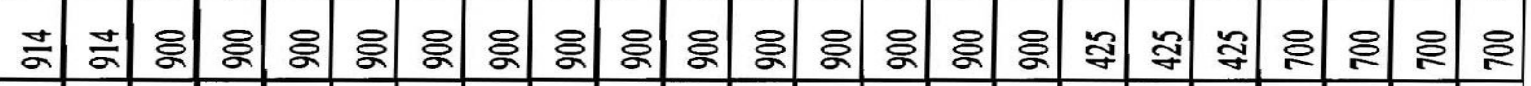

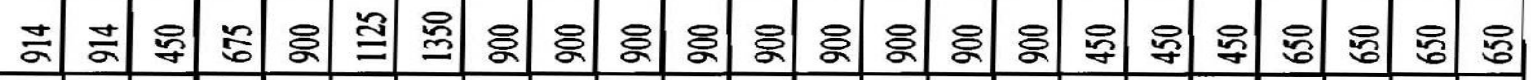

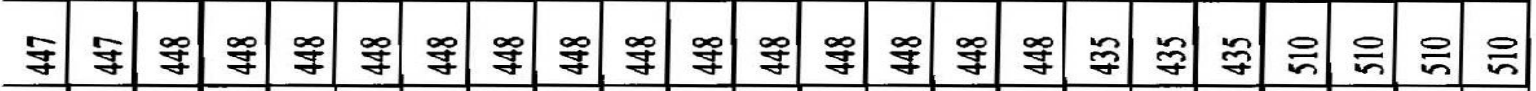

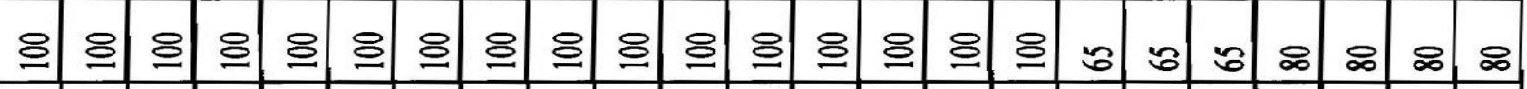

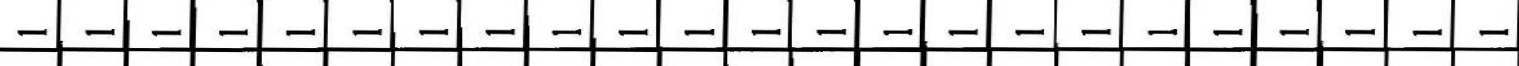

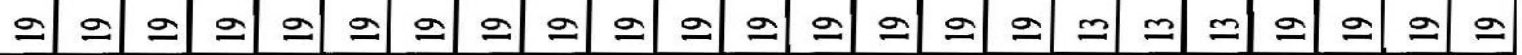

妾

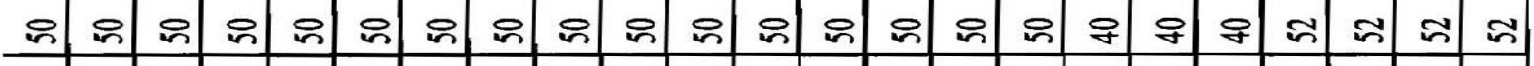

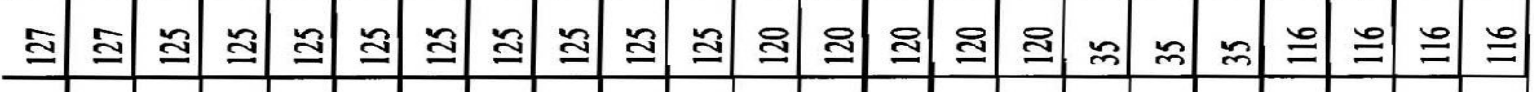

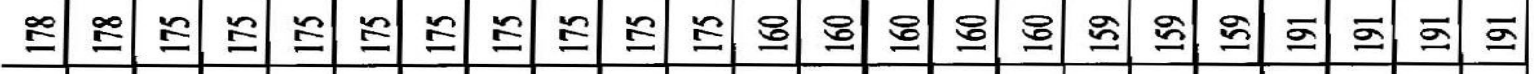

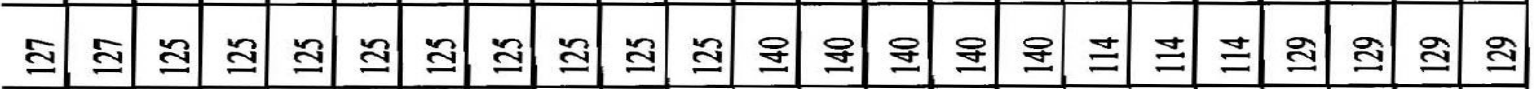

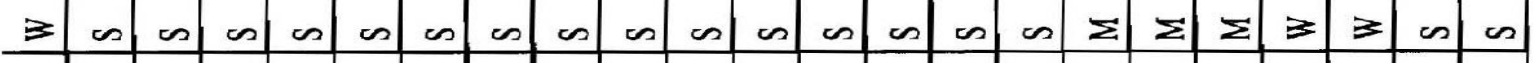
灾灾 


\title{
HYSTERETIC PERFORMANCE OF STEEL BEAM TO GANGUE CFST COLUMN CONNECTIONS WITH RING STIFFENERS UNDER LOW REVERSED CYCLIC LOADING
}

\author{
Guochang $\mathrm{Li}^{1^{*}}$, Wei Sun ${ }^{2}$ and Roberto T. Leon ${ }^{3}$ \\ ${ }^{1}$ School of Civil Engineering,Shenyang Jianzhu University, Shenyang 110168, China \\ ${ }^{2}$ Tianjin Chenli Technology CO., LTD, Tianjin 300400, China \\ ${ }^{3}$ School of Civil and Environmental Engineering, Georgia Institute of Technology \\ Atlanta: 30332-0355, U.S.A \\ *(Corresponding author: E-mail: cegcli@sjzu.edu.cn)
}

Received: 7 September 2010; Revised: 29 September 2010; Accepted: 12 October 2010

\begin{abstract}
In order to study the hysteretic performance of connections to gangue, tests of steel beams to gangue concrete-filled steel tube column (CFST) with ring stiffeners under low reversed cyclic loading were carried out including interior and exterior connections. The gangue is industrial waste dug out from under ground with coal. The curves of load and beam end displacement, strength degeneration, rigidity degeneration were drawn. On the basis of the above, the hysteretic behavior, energy dissipation, rigidity degeneration, strength degeneration and ductility of the joints were studied. It's shown that the joints of gangue CFST are featured with excellent quake-resistance and excellent hysteretic performance, energy dissipation and ductility. It will be referred to structure design and project application. This lays a good foundation in the application of gangue concrete-filled steel tubular structure.
\end{abstract}

Keywords: Gangue CFST, column to beam connection, reversed low cyclic loads, hysteretic performance, ductility

\section{INTRODUCTION}

Concrete-filled steel tubes (CFST) have been widely used in building construction [1]. The CFST column has many advantages compared with the ordinary steel or the reinforced concrete system due to its high-strength, stiffness, durability, ductility and better seismic resistance [2-5]. The composite members can make good use of mechanical property of steel and concrete. The main advantage of CFST columns in structural properties is due to the composite action between the constituent elements. The steel tube provides confining pressure to the concrete, which puts the concrete under a triaxial state of stress, and the strength of concrete is increased by the confining effect of the steel tube and prevents brittle fracture of infilled concrete. On the other hand, the steel tube is stiffened by the concrete core. This can prevent the inner local buckling of the steel tube, and increase the stability and strength of the column.

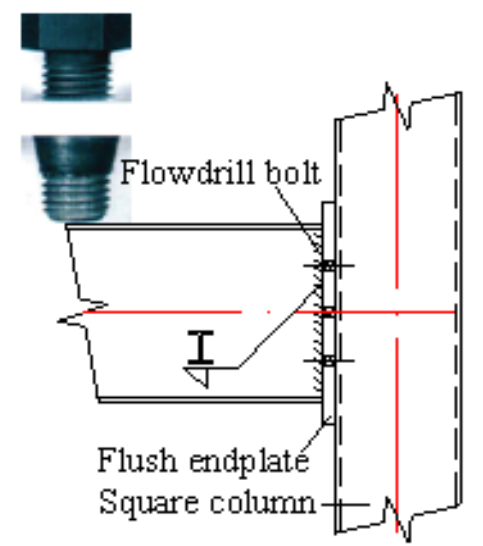

Figure 1. Connection of Hollobolt [7]

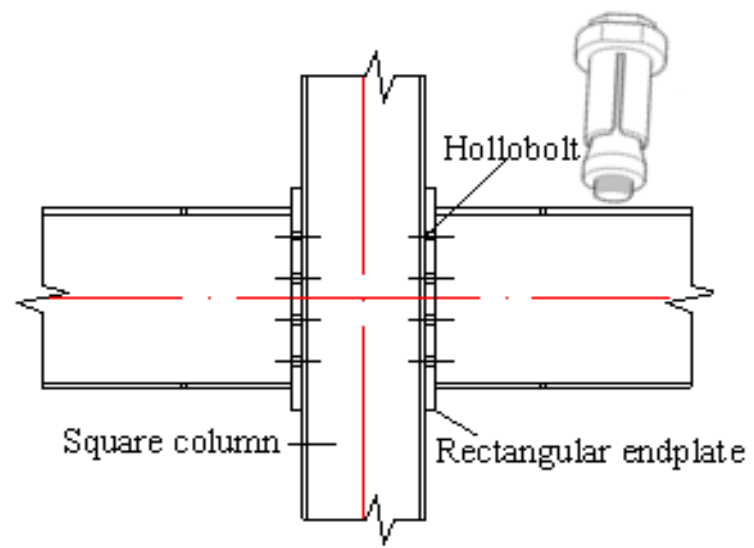

Figure 2. Connection of Flowdrill Bolt [10] 
It is well known that the performance of joints is the key parameter to assess behavior of multi-story frame structures. A large amount of researches have been carried out to study the behavior of beam-to-column connections both under the monotonic and cyclic loading [6-10]. Alostaz [6] presented a non-linear 3-D finite element study on a variety of details for connections to CFST. France [7] conducted a series of joint tests under monotonic loading to investigate the moment capacity and rotational stiffness of end plate connections to CFST columns with flowdrill connectors, as shown in Figure 1. Elremaily [8] conducted seven two-thirds scale connection specimen tests to study the behavior of through beam connection and develop the accompanying design provisions. Varma [9] reported the test results of eight monotonic beam-column specimens and eight cyclic beam-column specimens, which were square CFST beam-columns made from high-strength materials. Wang [10] studied the hysteretic behaviour of a type of connection for CFST columns, which was constructed using an approach of a flush end plate to circular or square concrete-filled hollow columns with blind bolts as shown in Figure 2. Gangue is a kind of industrial waste dug out from underground with coal. Compared to the ordinary concrete, gangue concrete features lighter weight, excellent heat-insulating capacity, and ductility. For this same compressive strength as ordinary concrete, the density of the corresponding gangue concrete is decreased by 20 percent. While gangue concrete is used primarily for floor systems, its use in columns can also reduce the weight of the building [11]. In this paper, half-scale connections between steel beams and gangue concrete-filled steel tube column with ring stiffeners were tested under reversed low cyclic loads. The seismic performances of the joints were analyzed. The results can be used as the references in practical projects.

\section{EXPERIMENTAL INVESTIGATION}

\section{$2.1 \quad$ Specimen Design}

Compared with other forms of welded connections to concrete filled columns, those incorporating ring stiffeners need to be carefully researched, as their performance is significantly influenced by their specific detailing [12-14]. In this research, interior and exterior connections, as shown in Table 1 and Figure 3, were used to study the performance of gangue concrete filled columns with ring stiffeners. The specimens were designed to represent connections in the lower stories of a typical multi-story building.

The column was a welded tube with a wall thickness of $6 \mathrm{~mm}$ and a slenderness of about 55; no local buckling problems were expected until substantial yielding had been reached. The beam was a welded I-shape with stiffeners welded $200 \mathrm{~mm}$ from the ends of the beam to facilitate the force transfer from the actuators. The ring stiffeners had the same thickness $(10 \mathrm{~mm})$ as the beam flanges. All welds were fillets, $6 \mathrm{~mm}$ thick. To confirm the mechanical properties of the steel used in the specimens, a tensile test of the steel was performed. Actual yield $\left(f_{y}\right)$ and ultimate stresses $\left(f_{u}\right)$, modulus of elasticity $\left(E_{\mathrm{s}}\right)$ are shown in Table 2 for the different thicknesses of the plates used (6 $\mathrm{mm}, 8 \mathrm{~mm}$ and $10 \mathrm{~mm}$, respectively).

Table 1. Dimensions

\begin{tabular}{|c|c|c|c|c|c|c|c|}
\hline \multicolumn{4}{|c|}{ Beam } & \multicolumn{3}{c|}{ Column } & \multicolumn{3}{c|}{ Stiffener Plate/ Weld } \\
\hline$b_{f}(\mathrm{~mm})$ & $t_{f}(\mathrm{~mm})$ & $t_{w}(\mathrm{~mm})$ & $H(\mathrm{~mm})$ & $(D \times t)(\mathrm{mm})$ & $b_{s}(\mathrm{~mm})$ & $t_{1}(\mathrm{~mm})$ & $h_{f}(\mathrm{~mm})$ \\
\hline 150 & 10 & 8 & 350 & $\Phi 325 \times 6$ & 80 & 10 & 6 \\
\hline
\end{tabular}

Note: $b_{f}$ is width of steel beam flange. $t_{f}$ is thickness of steel beam flange. $t_{w}$ is width of steel beam web. $h$ is thickness of steel beam. $b_{s}$ is width of ring stiffener. $t_{l}$ is thickness of ring stiffener. $D$ is diameter of steel tube. $t$ is thickness of steel tube shell. $h_{f}$ is welding size. 
Table 2. Average Material Performance of Q235B Steel

\begin{tabular}{|c|c|c|c|}
\hline Steel type & $f_{y} / M P a$ & $f_{u} / M P a$ & $E_{s} / G P a$ \\
\hline$t_{s}=6 \mathrm{~mm}$ & 324.8 & 459.9 & 197 \\
\hline$t_{s}=8 \mathrm{~mm}$ & 306.4 & 417.5 & 202 \\
\hline$t_{s}=10 \mathrm{~mm}$ & 347.1 & 578.2 & 204 \\
\hline
\end{tabular}

The concrete is C30 gangue concrete. When pouring the concrete, the concrete in the tubes was vibrated with poker vibration. After two weeks' curing, the $20 \mathrm{~mm}$ thickness steel plates with the size of $400 \mathrm{~mm} \times 400 \mathrm{~mm}$, were welded on the top of steel tubes.

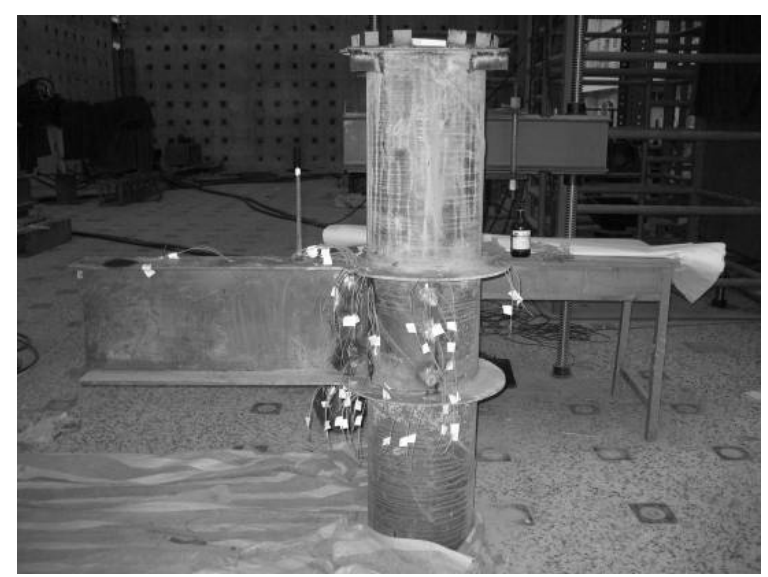

(a) Exterior Joint

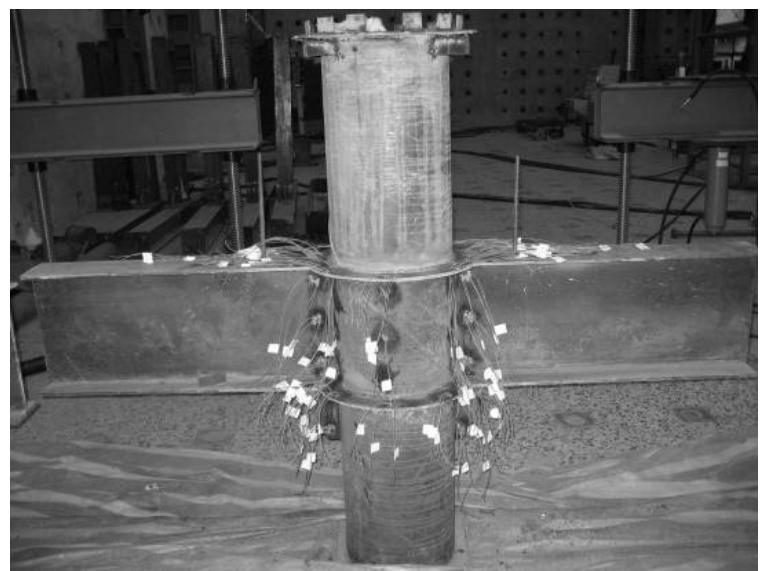

(b) Interior Joint

Figure 3. Specimen

\section{$2.2 \quad$ Experimental Setup and Loading Protocol}

The tests were carried out on $5000 \mathrm{kN}$ reaction frame in the Construction Engineering Laboratory of Shenyang Jianzhu University (Figure 4). A hinge was placed under the bottom of the gangue CFST column. The axial load was introduced by a $5000 \mathrm{kN}$ jack at the top of the gangue CFST column. The end of the steel beams were connected with $500 \mathrm{kN}$ hydraulic loading actuators with a $\pm 200 \mathrm{~mm}$ displacement range. Vertical reversed low cyclic loads were applied on the steel beam ends by the hydraulic actuators. The loading scheme was such so as to put opposite vertical deformations at the end of each beam.

To start the tests, a $1800 \mathrm{kN}$ axial compressive force was applied to the top of the concrete-filled steel tube using a $5000 \mathrm{kN}$ jack. This axial load corresponded to about 0.6 of the nominal axial strength of the column and was maintained through the whole experiment. Vertical reversed low cyclic loads were then imposed on the steel beams by electro-hydraulic actuators. 


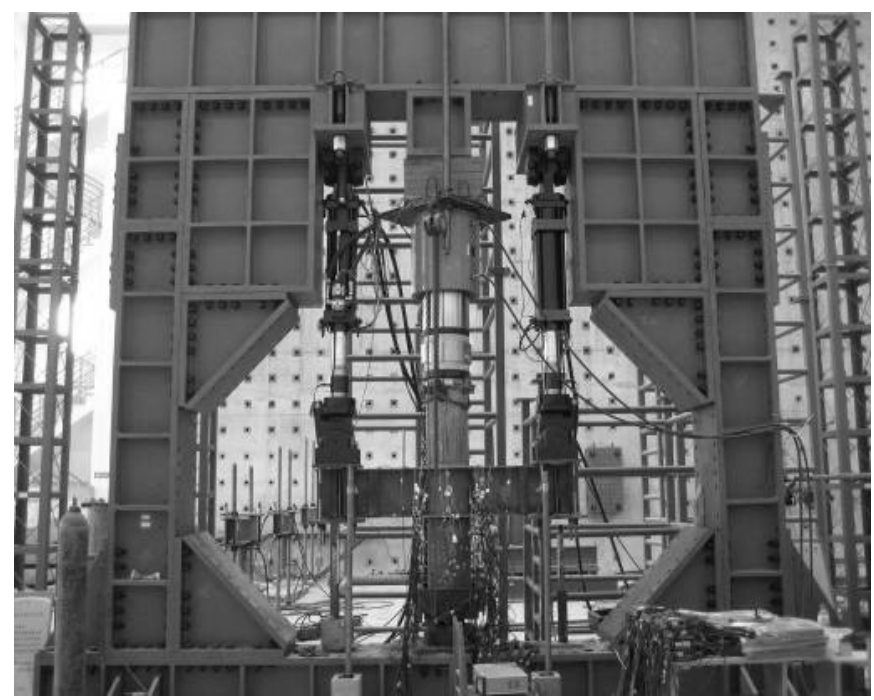

Figure 4. Experimental Device

For the exterior joint, the initial load was $10 \mathrm{kN}$ with $5 \mathrm{kN}$ added at each new load level. The specimen was cycled 3 times at each of these load levels until the load reached $160 \mathrm{kN}$. Afterwards, the test was controlled by beam end displacements, in increments of $2 \mathrm{~mm}$, until the load reached $280 \mathrm{kN}$ when the joint failed. For the interior joint, displacement control was used for the whole experiment. The initial displacement was $3 \mathrm{~mm}$, and $2 \mathrm{~mm}$ were added at every displacement increment, which consisted of 3 cycles. After yield was reached, the displacement change was increased to $3 \mathrm{~mm}$ and only 2 cycles were applied until the load reached $250 \mathrm{kN}$ when the joints failed.

\section{ANALYSIS OF SEISMIC PERFORMANCE}

\subsection{Hysteretic Behavior}

The hysteretic curves of the interior joint are shown in Figure 5 and Figure 6, while those for the exterior joint are shown in Figure 7.

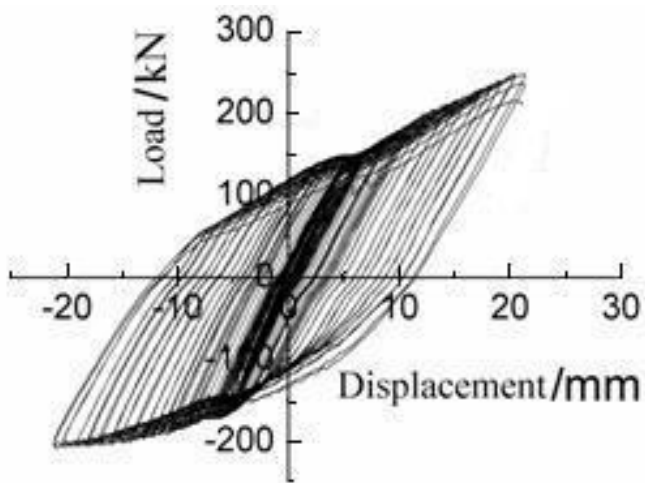

Figure 5. Right Beam of Interior Joint

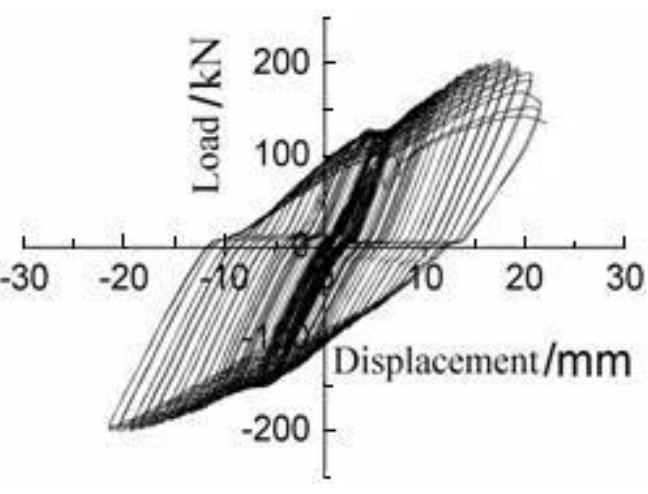

Figure 6. Left Beam of Interior Joint

It can be seen from Figure 5 through Figure 7 that the curves are almost perfectly elasto-plastic full, which shows the joints have excellent energy dissipation and hysteretic behavior. After the joints yield, the successive cycles at the same displacement coincide with a gradual strength decline. As the deformations increased beyond yield, every $0.3 \mathrm{~mm}$ increment resulted in a load increase of about $6.5 \mathrm{kN}$ until failure occurred. 
It can be seen from Figure 7, the shape of exterior joint's curve is approximate to that of the interior joint and shows the same hysteretic behavior as the interior joint.

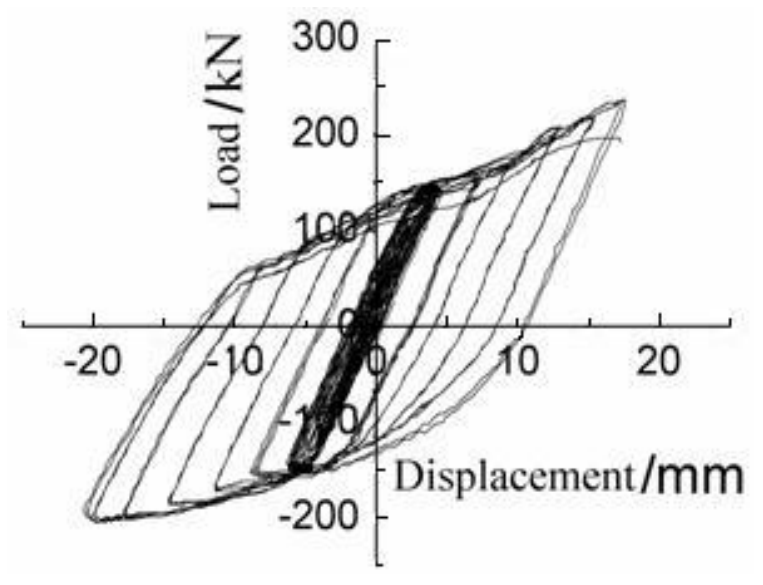

Figure 7. Beam End Load- Displacement Curve of Exterior Joint

\subsection{Ductility and Energy Dissipation}

An earthquake imparts energy to the structure and the structure reacts by absorbing and dissipating that energy. After the structure enters the non-linear range, the seismic performance depends primarily on the structural members' and joints' ability to dissipate energy without any sudden fracture. The area inside the load-displacement line (Figure 8) indicates the energy absorption capacity (the deformation energy sent out by the structure). The shadowed area between that curve and the horizontal axis is the energy dissipated. In Figure $8, \mathrm{~S}_{1}$ is the energy absorbed and $\mathrm{S}_{2}$ is the energy dissipated. $\mathrm{S}_{1}+\mathrm{S}_{2}$ is the total energy created by the horizontal force. $\Psi$ is energy dissipation ratio. $\Psi=\mathrm{S}_{1} /\left(\mathrm{S}_{1}+\mathrm{S}_{2}\right)$. The bigger the value of $\Psi$ is, the more energy is dissipated through frictional resistance or local damage (such as cracking or rotations of the plastic hinges) [15].

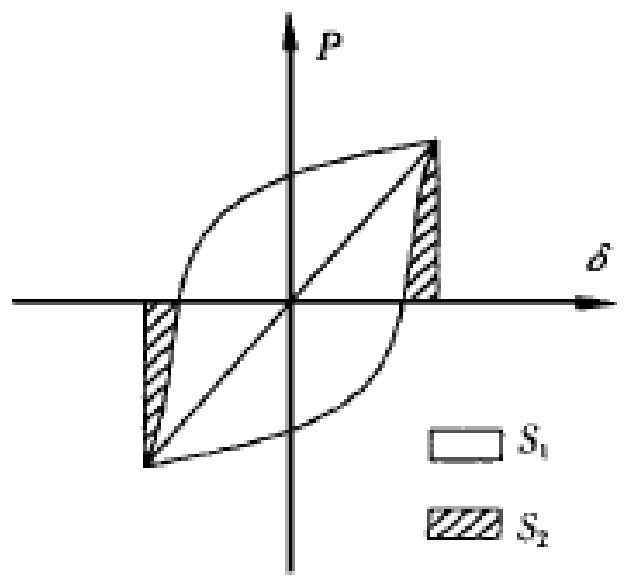

Figure 8. Hysteretic Circle

Another measure of the cyclic response is the displacement ductility factor $\delta$. The joint ductility factor is generally givens as $\delta=\delta u / \delta y$, where $\delta y$ is yield displacement and $\delta u$ is the ultimate displacement. Table 3 shows $\Psi$ and $\delta$ for the two specimens. The value of $\delta$ is greater than 4 in all cases, indicating moderately good ductility. 
Table 3. $\Psi$ and $\delta$ of the Models

\begin{tabular}{|c|c|c|c|}
\hline models & Right beam interior & Left beam interior & Exterior \\
\hline$\Psi$ & 0.816 & 0.818 & 0.807 \\
\hline$\delta$ & 4.602 & 4.476 & 4.119 \\
\hline
\end{tabular}

\subsection{Strength Degradation}

Strength degradation defined as the progressive loss of strength with cycling at a given deformation level [16]. Strength degradation can be represented by bearing capacity degradation factor $\lambda_{i}$ given by:

$\lambda_{i}=\frac{Q_{j, \max }^{i}}{Q_{j, \max }^{1}}$

In this equation, $Q_{j \text {,max }}^{i}$ is the load value of the peak point of $i$ load cyclic when $\delta$ value is $j . Q_{j, \max }^{1}$ is the load value of the peak point of the first load cyclic when $\delta$ value is $j$.

According Figure 9 shows the capacity degradation factor-displacement curve. It can be seen from Figure 9 that capacities degrade slowly when the displacements are less than $8 \mathrm{~mm}$. When the displacements are larger than $8 \mathrm{~mm}$, degradation factor begins to decline as the strength of the models begin to degenerate. Strength degradation for the exterior joint is slightly faster than for the interior joint. The reason is that exterior joint loading was controlled by the force before the joint yields. So, the displacement is larger. The main reason of strength degradation is that the bearing capacities of steel beams degrade.

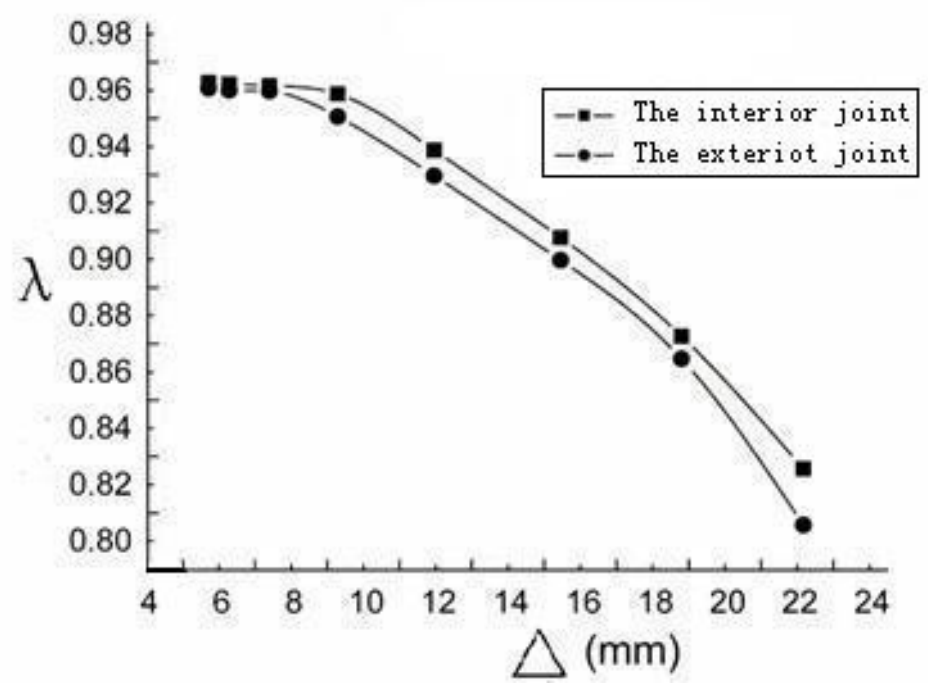

Figure 9. Strength Degradation Curve 


\subsection{Rigidity Degradation}

Joint stiffness influences not only the accuracy of the structure calculations but also inter-story displacements. Large joint distortion can increase inter-story drifts appreciably, and lead to non-structural failures. With cycling at a constant amplitude, the joint stiffness degrades. The less reduced rate is, the better energy dissipation is. In experiment, rigidity degradation can be researched through unvaried amplitude loading usually. In order to qualify the member rigidity degradation under low reversed cyclic loading, rigidity degradation should be represented by cyclic linear rigidity in the same load step. Cyclic linear rigidity can be calculated through the equation below [17]:

$$
K_{i}=\frac{\sum_{i=1}^{n} P_{j}^{i}}{\sum_{i=1}^{n} \Delta_{j}^{i}}
$$

In this equation, $K_{i}$ is cyclic linear rigidity, $P_{j}^{i}$ is the load value of the peak point of the $i$ load cyclic when $\delta$ value is $\mathrm{j}$, and $\Delta_{j}^{i}$ is the displacement value of the peak point of the $\mathrm{i}$ load cyclic when $\delta$ value is $\mathrm{j}$.

The $\mathrm{P}-\triangle$ curve, which is obtained through restoring force experiment, put forwards that rigidity is related with displacement and the number of cyclic. Rigidity changes all the time. Rigidity degradation is that peak point displacement increase as the number of cyclic increase when maintaining the same peak point load value. In order to analyze earthquake reaction, tangent rigidity should be replaced by secant rigidity [15]. This method is used in this paper to define rigidity degradation. According to the loading process, rigidity degradation is the secant slope of the hysteretic curve cyclic when structure on the same load, Figure 10 shows this.

According to rigidity degradation definition, rigidities of the 2 models in the experiment were calculated and rigidity degradation curves were also drawn, Figure 11 shows them.

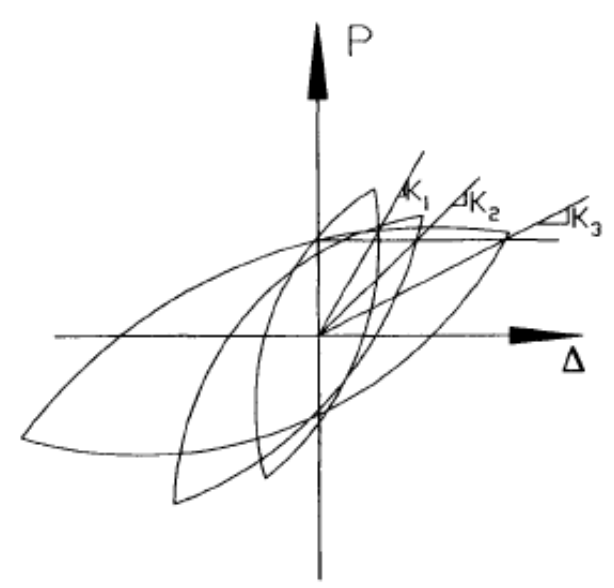

Figure 10. Rigidity Degradation Sketch

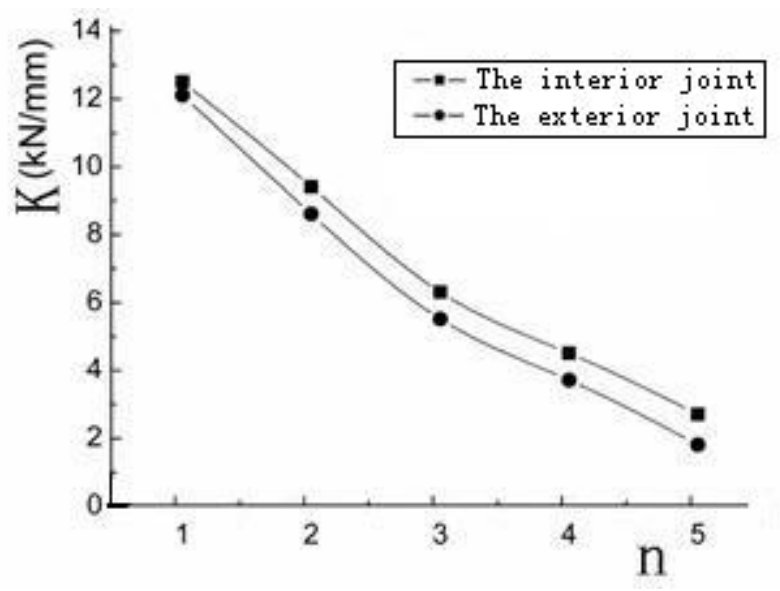

Figure 11. Rigidity Degradation Curves 
In above curves, $\mathrm{n}$ is the number of cyclic. The rigidities of the 2 models degrade gradually. Rigidity degradation of the exterior joint is faster than the interior joint. The reason is that stability of the exterior joint is worse than the interior joint. In each load step cyclic after the model yield, the interior joint's displacement at the beam end is larger. Otherwise, interior joint loading was controlled by the displacement in the whole process. So, its rigidity degrades gradually.

\section{CONCLUSIONS}

(1) Joints of steel beams to gangue concrete-filled steel tube column with ring stiffeners are excellent in seismic performance under low reversed cyclic loading. Joints have good strength, ductility and stiffiness.

(2) The steel tube column and the frame joint are content with designing concepts of the strong column and weak beam. The joints are safe and the designing method is feasible.

(3) On the other hand, the gangue used as aggregate can reduce the weight of building, make non-renewable resources, gravel, sustainable to be developed. So, gangue concrete filled steel tubular composite structure can be called green structure.

\section{ACKNOWLEDGEMENTS}

This project was supported by supported by Technology Program of Ministry of Housing and Urban-Rural Development (2010-k3-35) \& Research Program of Liaoning Province Office of Education (LS2010134).

\section{REFERENCES}

[1] Morino, S. and Tsuda, K., "Design and Construction of Concrete-filled Steel Tube Column System in Japan”, Earthquake Engineering and Engineering Seismology, 2003, Vol. 4, No. 1, pp. 51-73.

[2] Usami, T., Ge, H.B. and Saizuka, K., "Behavior of Partially Concrete-filled Steel Bridge Piers Under Cyclic and Dynamic Loading”, Journal of Constructional Steel Research, 1997, Vol. 41, No. 2, pp. 121-136.

[3] Ding, F.X. and Yu, Z.W., "Behavior of Concrete and Concrete-filled Circular Steel Tubular Stub Columns at Constant High Temperatures", Journal of Central South University of Technology (English Vesion), 2006, Vol. 37, No. 6, pp. 726-732.

[4] He, A.L. and He, Y.B., "Stress-strain Relation of Core Concrete of Axially-loaded Steel Tubular Columns Filled with Steel-reinforced Concrete", Journal of Central South University of Technology, 2010, Vol. 41, No. 1, pp. 341-346.

[5] Liang, Q.Q. and Fragomeni, S., "Nonlinear Analysis of Circular Concrete-filled Steel Tubular Short Columns Under Cccentric Loading", Journal of Constructional Steel Research, 2010, Vol. 66, pp. 159-169.

[6] Alostaz, Y.M. and Schneider, S.P., "Analytical Behavior of Connections to Concrete-filled Steel Tubes”, Journal of Constructional Steel Research, 1996, Vol. 40, No. 2, pp. 95-127.

[7] France, J.E., Davison, J.B. and Kirby, P.A., "Strength and Rotational Response of Rigid Connections to Tubular Columns Using Flowdrill Connectors", Journal of Constructional Steel Research, 1999, Vol. 50, No. 1, pp. 1-14. 
[8] Elremaily, A. and Azizinamini, A., "Experimental Behavior of Steel Beam to CFT Column Connections", Journal of Constructional Steel Research, 2001, Vol. 57, pp. 1099-1119.

[9] Varma, A.H., Ricles, J.M., Sause, R. and Lu, L.W., "Seismic Behavior and Modeling of High-strength Composite Concrete-filled Steel Tube (CFT) Beam-columns", Journal of Constructional Steel Research, 2002, Vol. 58, pp. 725-758.

[10] Wang, J.F., Han, L.H. and Uy, B., "Hysteretic Behaviour of Flush End Plate Joints to Concrete-filled Steel Tubular Columns", Journal of Constructional Steel Research, 2009, Vol. 65, pp. 1644-1663.

[11] Li, G.C. and Ren, Q.S., "Dynamic Performance of Pure Bending of Gangue Concrete-filled Steel Circular Tubualr", Sixth International Conference on Advances in Steel Structures, Hong Kong, China, Dec. 2009.

[12] Federico, M.M., "Moment Resistant Connections of Steel Frames in Seismic areas - Design and Reliability", London : E \& FN Spoon, 2000.

[13] Beutel, J., Thambirtnam, D. and Perera, N., "Cyclic Behavior of Concrete filled Steel Tubular Column to Steel Beam Connection”, Engineering Structures, 2002, Vol. 24, No. 11, pp. 29-38.

[14] Ge, H.B., Susantha, K.A.S. and Satake, Y. et al., "Seismic Demand Predictions of Concrete-filled Steel Box Columns", Engineering Structures, 2003, Vol. 25, pp. 337-345.

[15] Tao, Zhong. and Yu, Q., "New Type of Composite Structure Column: Test, Theory and Methods", Beijing: Science Press, 2006.

[16] Zhong, S.T. and Bai, G.L., "Beam to Column Frame Connection of Tall Building Composite Structure Analysis and Design”, Beijing: Renmin Communication Press, 2006.

[17] He, Y.Q., "Theoretical Analysis and Experimental Research on New Type of Joint of Concrete filled Steel Tubular Column with RC Beam. Master degree thesis", Nanjing: School of Civil Engineering, Hehai University, 2006. 


\title{
THE APPLICATION OF A \\ HHT BASED ULTRASONIC DETECTING METHOD IN QUALITY ASSESSMENT OF CFST
}

\author{
Fu-xiang $\mathrm{Ye}^{1}$, Xiao-xiong $\mathrm{Zha}^{2, *}$ and Hong-xin $\mathrm{Wang}^{3}$ \\ ${ }^{1}$ Shenzhen Graduate School, Harbin Institute of Technology, Shenzhen 518055, China \\ ${ }^{2}$ Professor, Department of Urban and Civil Engineering, Shenzhen Graduate School, \\ Harbin Institute of Technology, China \\ ${ }^{3} \mathrm{PhD}$ Candidate, Shenzhen Graduate School, Harbin Institute of Technology, Shenzhen 518055, China \\ *(Corresponding author: E-mail: zhaxx@hit.edu.cn)
}

Received: 14 October 2010; Revised: 21 November 2010; Accepted: 26 November 2010

\begin{abstract}
Owed to the features of concrete and concrete pumping construction craft, empty holes, osteoporosis, construction joints and poor cementation often appear inside CFST. In view of this situation, ultrasonic detecting method has been developed to assess the quality of CFST. However, traditional methods are limited because of the effect of noise signal and distortion of signal. In this paper, the filtering process and HHT were applied to the ultrasonic signal received, and the Hilbert energy spectrum and the first-order intrinsic mode function were used to assess the quality of CFST. Actual testing results show that the HHT analysis method, combined with filtering process, can effectively improve the identification of the arrival time, the amplitude value, the waveform and the frequency of the first wave of the ultrasonic signal, and thus improve the damage identification quality of CFST.
\end{abstract}

Keywords: Hilbert-Huang transform; hilbert energy spectrum; ultrasonic detecting; bandpass digital filter; CFST

\section{INTRODUCTION}

The concrete-filled steel tube (CFST) is a kind of bearing component made by pumping concrete into a prefabricated steel tube. Advantages of this structure such as high bearing capacity, good ductility, good aseismic performance, easy constructing, short constructing period, thus CFST structures have been widely used in all kinds of high-rise buildings, heavy-duty workshops and highway bridge projects. However, affected by the features of concrete and the concrete pumping construction craft, empty holes, osteoporosis, construction joints and poor cementations often appear inside CFST, which may directly influence the quality of CFST. Therefore, it is necessary to assess construction quality of CFST adopt scientific and effective method [1].

Hilbert-Huang Transform (HHT) has been considered as a significant breakthrough in recent years to the linear and steady-state spectral analysis which is based on the Fourier transform, especially for it can show the time-frequency information of the signal. This method adopts the multi-scale analysis advantage of the wavelet analysis, meanwhile, overcome the difficulty of the wavelet analysis in needing to select the suitable wavelet basis. Moreover, it can analyze not only linear stationary signals, but also the linear non-stationary signals by self-adapting. In this paper, the HHT is applied to the experiment investigation by using the ultrasonic wave to detect the delamination, sundry and empty hole defects in CFST, the Hilbert energy spectrum and the first-order intrinsic mode functions of the ultrasonic wave signals is used to assess the quality of CFST. It shows that the HHT analysis method, combined with filtering process, can effectively improve the identification of the arrival time, the amplitude value, the waveform and the frequency of the first wave of the ultrasonic signal, which can improve the damage identification of CFST quality. 


\section{EXPERIMENTAL SPECIMEN}

The experimental specimen is a CFST column, the height of which is $700 \mathrm{~mm}$, outer diameter is 219 $\mathrm{mm}$ and thickness of steel tube is $6 \mathrm{~mm}$. Before the experiments, three kinds of defects of specimen are prefabricated made as follow: 1) At the bottom of the column, a thin timber packed in the plastic membrane is used to separate out a hole to create the delamination defect, and after the initial solidification of concrete the timber is uprooted in Figure 1;2) In the middle of the CFST column, a timber block is vertically embedded into the concrete to create the sundry defect. As shown in Figure 2, the dimension of the timber block is $150 \mathrm{~mm} \times 50 \mathrm{~mm} \times 25 \mathrm{~mm}$; 3) As shown in Figure 3, for creating the hole defect, a $200 \mathrm{~mm}$-long cylinder hole is made with diameter gradually increasing from $10 \mathrm{~mm}$ to $20 \mathrm{~mm}$, at the center of the section, in the upper part of the CFST column.

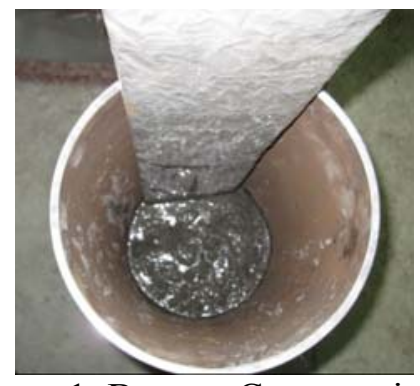

Figure 1. Bottom Construction

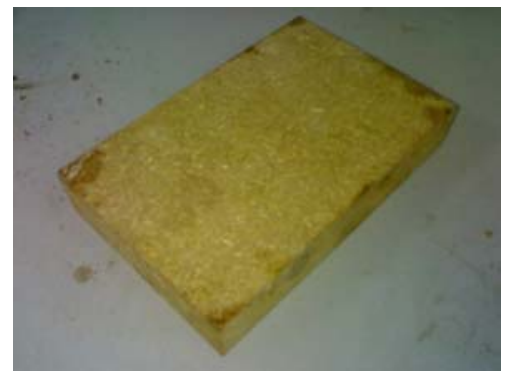

Figure 2. The Timber Block

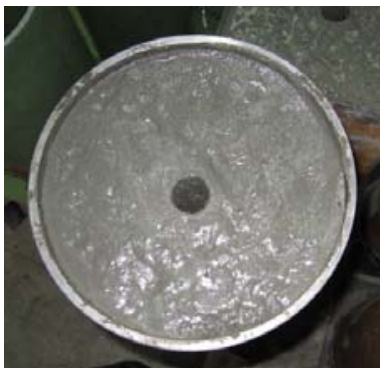

Figure 3. The Hole in the Upper Part

\section{TEST METHOD}

\subsection{Prerequisites of the Test Method}

As it is shown in Figure 4(a), in CFST with good quality, the signal expected to be received is the signal which penetrate the steel tube along the radial direction of steel tube, then propagate through the concrete in the steel tube and then penetrate the steel tube again to reach the receiver; and signal propagate along the half circumference of steel tube to reach the receiver is considered as interfering signal.

The ultrasonic time measured by the receiver is the arrival time of the first ultrasonic wave, if the ultrasonic propagation along the half circumference of steel tube arrive earlier than the ultrasonic propagation through the core concrete, the ultrasonic wave method to measure the quality of concrete-filled steel tube would be meaningless.

Denote the time the ultrasonic propagate along the radial direction of the CFST as $t_{1}$, the time the ultrasonic propagate along the half circumference of steel tube as $t_{2}$, then the following relationship between $t_{1}$ and $t_{2}$ is shown in Eq. 1 (Due to the thickness of steel tube is far less than the diameter of the core concrete, the penetration time of the ultrasonic through the steel tube is ignored.):

$\frac{t_{2}}{t_{1}}=\frac{\pi}{2} \cdot \frac{V_{1}}{V_{2}}$

Where: $V_{1}, V_{2}$ are velocities of the ultrasonic in the concrete and in the steel tube, respectively $(\mathrm{m} / \mathrm{s})$. 


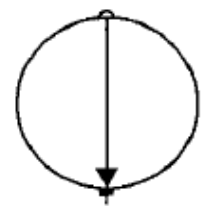

(a)

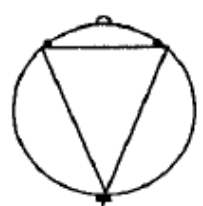

(b)

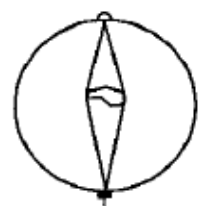

(c)

Figure 4. Paths of Ultrasonic in CFST

Ultrasonic velocity in Steel tube is about $5700 \mathrm{~m} / \mathrm{s}$, therefore, to satisfy the request of $t_{2} / t_{1}>1$, the ultrasonic velocity in concrete must greater than $3628 \mathrm{~m} / \mathrm{s}$. And the label of the concrete usually used in CFST is C30, whose ultrasonic velocity is about $4400 \mathrm{~m} / \mathrm{s}$. Obviously, when the concrete and steel tube is close-grained and of good cementation, the first wave received in penetrating detecting method is the ultrasonic wave propagate along the radial direction of CFST, and the ultrasonic wave propagate along the half circumference of steel tube arrived the receiver later. Thus, the application of ultrasonic testing method to the CFST quality is feasible and efficient.

When the concrete and steel tube is in poor cementation condition or even delaminated, the ultrasonic wave propagating path in concrete is as show in Figure 4(b), when there is a hole in the concrete the ultrasonic wave propagating path in concrete is as show in Figure 4(c). In these two conditions, time needed for the ultrasonic wave to arrive the receiver is longer than time needed in the compact concrete, expressing as the ultrasonic velocity in concrete with defects is smaller. Thus, the method of inspecting the arrival time of the first ultrasonic wave is practicable in detecting defects of CFST.

In addition, the amplitude, the distortion degree and the frequency of the first wave signal can also be used to judge the casting quality inside CFST $[2,3]$.

\subsection{Hilbert-Huang Transform}

The Hilbert-Huang transform is composed of two parts: Empirical mode decomposition (EMD) and Hilbert transform (HT). The key point of this method is the Empirical mode decomposition; it can process linearization and smoothing process on nonlinear, non-stationary signals, keeping the characteristic of the signal $[4,5]$. Any complicated data can be directly extracted energy in proper time range, which would generate a group of intrinsic mode functions who have very good Hilbert transformation properties. Then, after be applied the Hilbert transform, the intrinsic mode functions (IMF) would possess instantaneous frequency and instantaneous amplitude, the distribution of the instantaneous amplitude in the frequency-time plane is called the Hilbert spectrum, indicating the relationship among energy, frequency and time [6,7], the Hilbert energy spectrum can be obtained by integrating the square of the amplitude in the time domain.

\subsubsection{Empirical mode decomposition method (EMD)}

The basic thought of the Empirical mode decomposition method is to use the average value of the upper and lower envelopes of the signal to determine "the instantaneous average balance position", and then extract the intrinsic mode functions. The upper and the lower envelope of the signal are obtained by fitting the maximum points and the minimum points by cubic-spline interpolation method, respectively. 
The basic process of EMD process can be summarized as follows:

(1) Find out all local maximas and local minimums of signal $x(t)$. In order to retain the characteristics of the original signal better, local maxima is defined as a value in a moment of the time series, who meet the condition that is greater than both the value of just a moment before and the value of just a moment after. The local minimum value is defined similarly. Then, using cubic-spline function to fit the data, the upper envelope $x_{\max }(t)$ and the lower envelope $x_{\min }(t)$ of the signal are got;

(2) Calculate the mean value of the upper envelope and the lower envelope: $m(t)=\left[x_{\max }(t)+x_{\min }(t)\right] / 2$;

(3) Subtracting the original signal $x(t)$ by the mean value $m(t)$, the first component $h(t)=x(t)-m(t)$ can be got. Due to the differences between original sequences, component $h(t)$ may not be an IMF. If $h(t)$ does not meet the two conditions of IMF: Within the data scope, the difference of the number of extreme value points and the times of the data sequence across the zero is less than two; At any point, the mean value of the envelope formed by all the maximum points and the envelope formed by all the minimum points is equal to zero. Then treat $h(t)$ as the original signal, and repeat processes (1) - (3), until the two conditions are met. Then $h(t)$ can be treated as an IMF, let $I_{1}(t)=h(t)$, till now the first IMF has been successfully extracted. Due to the fact that: the rest of the signal $r_{1}(t)=x(t)-I_{1}(t)$ still contains information with longer periodic components, so it can be treated as a new signal, and repeat the extracting process. Similarly, $I_{2}(t), I_{3}(t), \ldots I_{n}(t)$ can be got. When $r_{n}(t)$ is a drab sequence or a constant sequence, extracting processes would be terminated, the task of extracting IMFs is completed, and $r_{n}(t)$ is called the over trend term of the original signal. So the signal $x(t)$ can be expressed as $x(t)=\sum_{i=1}^{n} I_{i}(t)+r_{n}(t)$, that is the original signal is composed of $n$ IMFs and an over trend term. As it is mentioned above, the whole process is just like a selecting process, to extract the IMFs from the signal according to the time characteristics.

\subsubsection{Hilbert transform}

For stochastic time sequence $X(t)$, applying Hilbert transform to it [8], Y(t) can be got as follow Eq. 2 :

$Y(t)=\frac{1}{\pi} P V\left(\int_{-\infty}^{\infty} \frac{X(\tau)}{t-\tau} d \tau\right)$

Where, $P V$ is the Cauchy principal value. This equation indicate that $Y(t)$ is the convolution of $X(t)$ and $\frac{1}{\pi \tau}$. Through this definition, $X(t)$ and $Y(t)$ formed a conjugated-complex-number couple, then an analytical signal $Z(t)$ can be defined as Eq. 3 :

$Z(t)=X(t)+i Y(t)=a(t) e^{i \theta(t)}$ 
Where, $a(t)$ and $\theta(t)$ can be defined as Eq. 4 :

$$
\left\{\begin{array}{l}
a(t)=\left[X^{2}(t)+Y^{2}(t)\right]^{1 / 2} \\
\theta(t)=\arctan \left(\frac{Y(t)}{X(t)}\right)
\end{array}\right.
$$

As the phase of the signal is got, because the instantaneous frequency is the derivative of the phase, the instantaneous frequency can be expressed as Eq. 5 :

$$
w=\frac{d \theta(t)}{d t}
$$

After applied Hilbert transform to intrinsic mode functions, the signal can be expressed Eq. 6 :

$$
X(t)=\sum_{i=1}^{n} a_{j}(t) \exp \left(i \int w_{i}(t) d t\right)+r_{n}(t)
$$

Due to the energy in signal $r_{n}(t)$ is very small, it is ignored here.

The amplitude and the frequency obtained from Hilbert transform are both function of time, either using 3D graphic to express the relationship among amplitude, frequency and time, or displaying the amplitude with gray form graphic in the frequency-time plane, the Hilbert spectrum $H(w, t)$ can both be got. Integrating the square of the amplitude of energy in the time domain, the Hilbert energy spectrum is got according to Eq. 7 :

$$
E S(w)=\int_{T} H^{2}(w, t) d t
$$

The Hilbert energy spectrum provides the energy measurement to each frequency, and expresses the energy accumulation of each frequency in the whole length of time.

\subsection{Preprocessing to Ultrasonic Signal}

The original signal emitted from the Ultrasonic detector is a narrowband signal with a center frequency $45 \mathrm{KHz}$, and the signal received by the receiver has induced the low-frequency and high-frequency noise signal. Based on the matlab software, the Kaiser-window bandpass digital filter is used to filter out the noise signal in the ultrasonic signals, setting the lower frequency as $10 \mathrm{KHz}$ and the upper frequency as $80 \mathrm{KHz}$. Considering that during the filtering process, an overall phase delay would be induced into the signal, which would also leads to a loss of the data and information at the end of the original signal. In order to eliminate this loss and delay, before the filtering process, zeros are added to the end of the signal, the length of zeros is set to be the length of the phase delay time; and after the filtering process, data with the same length are removed from the front part of the signal, and finally the graphs of the signal before and after the filtering process (Figure 5 and Figure 6) and their corresponding Hilbert energy spectrum graphs (Figure 7 and Figure 8) are got. It can be found that: after the filtering process, the signal has become noticeably smooth, with no burr, greatly convenient for the identification of the first wave time. Meanwhile, by comparing the Hilbert energy spectrums before and after the filtering process, it can be found that the bandpass digital filter does a good job in filtering out the low-frequency noise signal. 


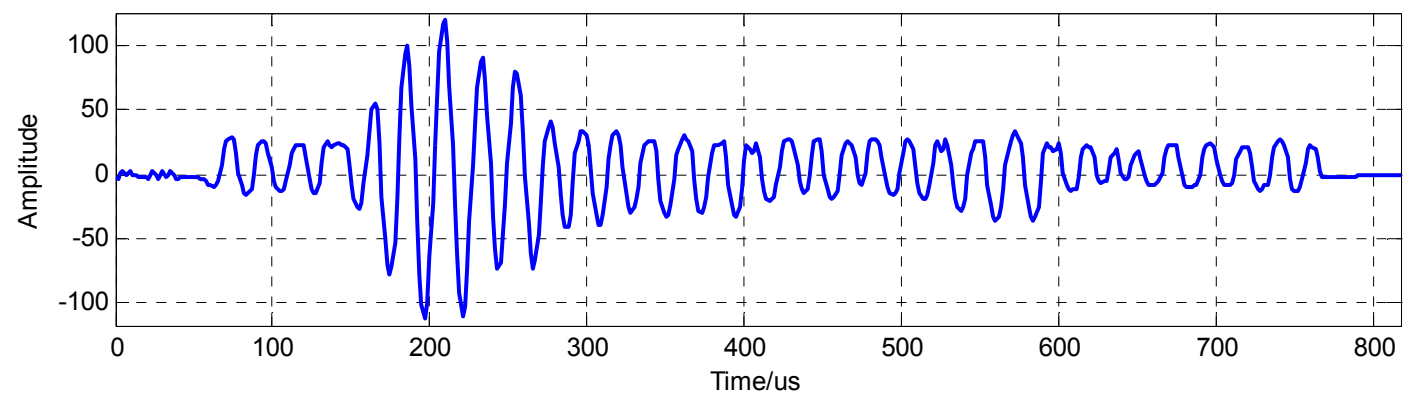

Figure 5. Signal before Filtering Process

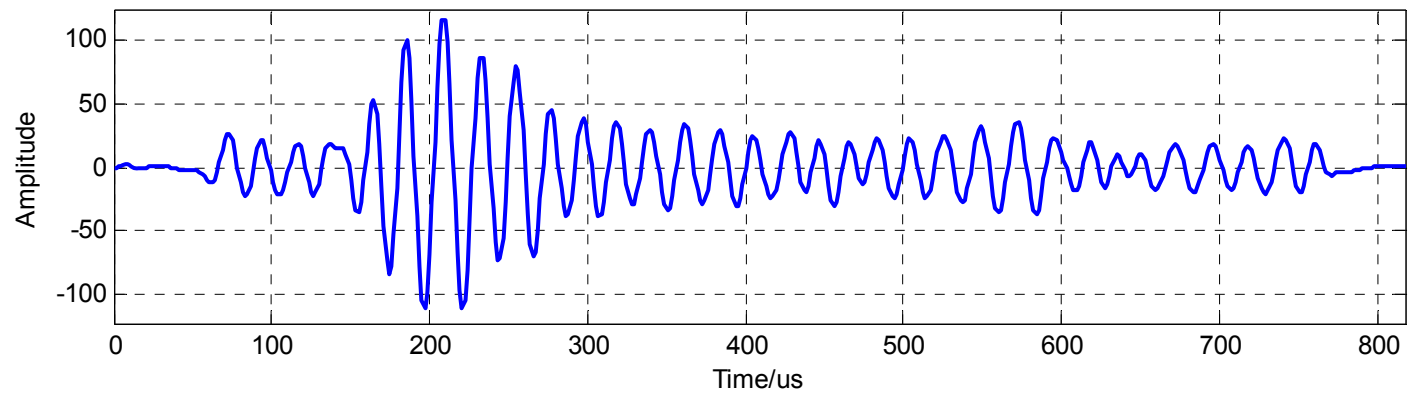

Figure 6. Signal after Filtering Process

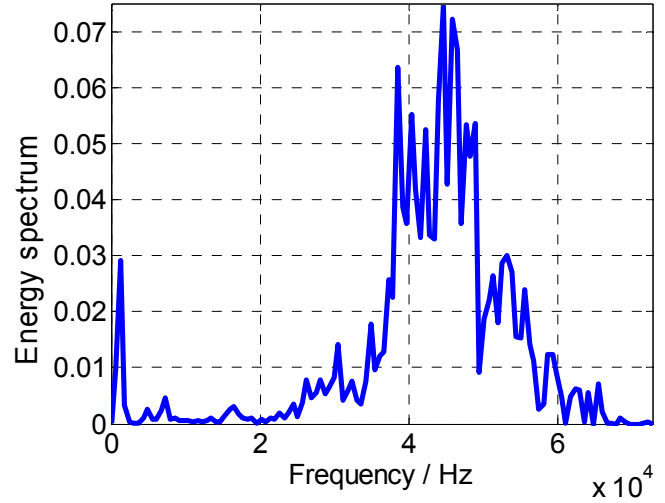

Figure 7. Hilbert Energy Spectrums before Filtering Process

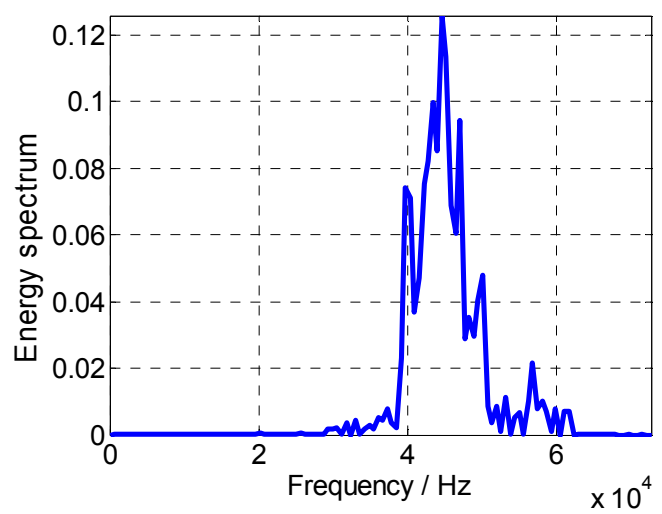

Figure 8. Hilbert Energy Spectrums after Filtering Process

\section{EXPERIMENT RESULT}

In order to verify the effectiveness of applying the HHT into the ultrasonic detection technology of the quality inspection of CFST, ultrasonic detection technology is applied to the experimental model mentioned above, and after the filtering process, the ultrasonic signal is dealt with HHT. Comparing the Hilbert energy spectrums and the first-order intrinsic mode functions, the results are obtained as follows.

As the diameter of the steel tube is $219 \mathrm{~mm}$ and the ultrasonic velocity in concrete is $4400 \mathrm{~m} / \mathrm{s}$, the ultrasonic velocity in the steel tube propagating in the form of surface wave is $2900 \mathrm{~m} / \mathrm{s}$, time for the ultrasonic to propagate through the core concrete to the receiver can be calculated by: $t_{1}=0.219 \div 4400=49.8 \mu \mathrm{s}$, and time for the ultrasonic to propagate along the half circumference of steel tube to reach the receiver can be calculated by: $t_{2}=0.219 \times \pi \div 2 \div 2900=118.6 \mu$ s . 


\subsection{Comparison of Undamaged Position and Delaminated Position}

Comparing Figure 9 and Figure 10, it can be found that: Attached with filtering process, the intrinsic mode decomposition results can effectively suppress the noise signals. Analysis results show that: For no defect position, much energy of ultrasonic propagate directly through the core concrete and reach the receiver, obvious waveform can be observed from $50 \mu \mathrm{s}$; In the position with delaminating defect, only a few energy propagate directly through the air into the core concrete, and most energy propagate in the form of surface wave along the half circumference of steel tube to reach the receiver, thus till around $120 \mu \mathrm{s}$, obvious waveform can be observed.

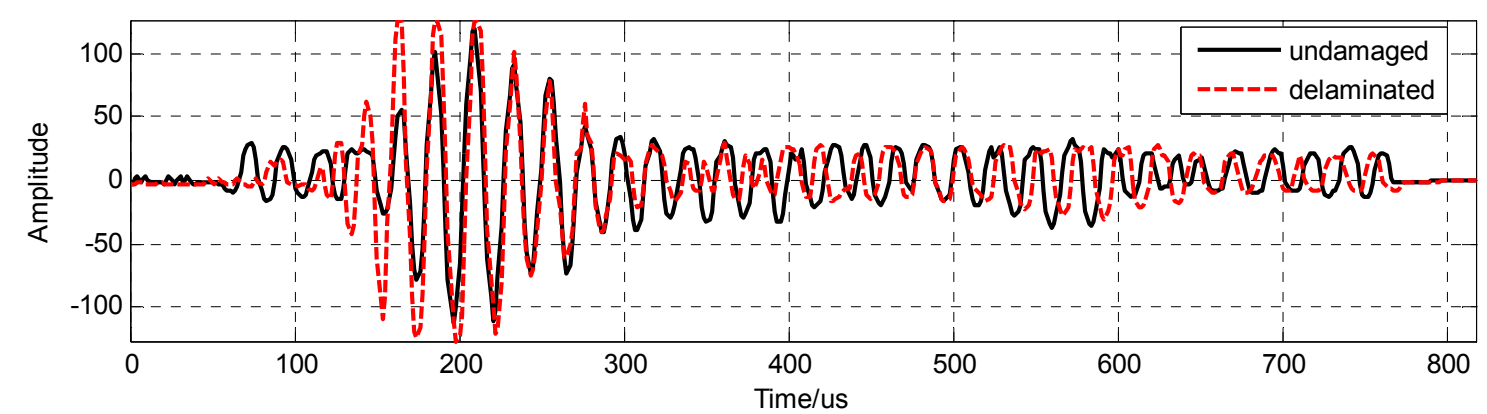

Figure 9. Waveform Comparison before Filtering

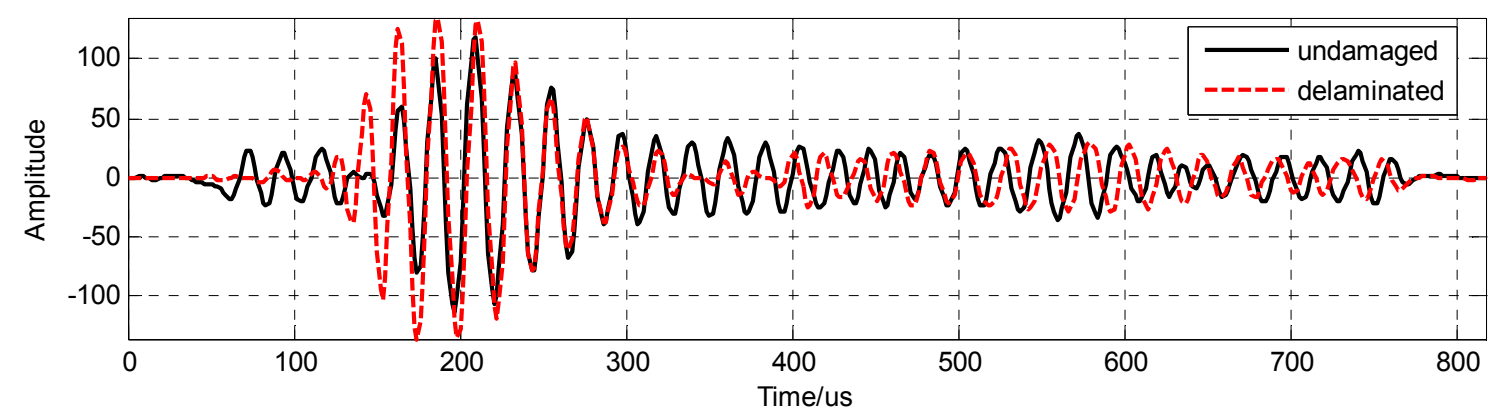

Figure 10. Comparison of the First-order Intrinsic Mode Functions of Undamaged Position and Delaminated Position

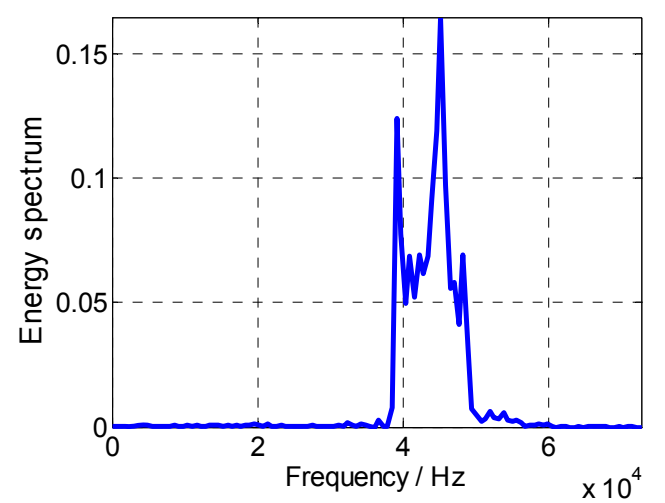

Figure 11. Energy Spectrum of Undamaged Position

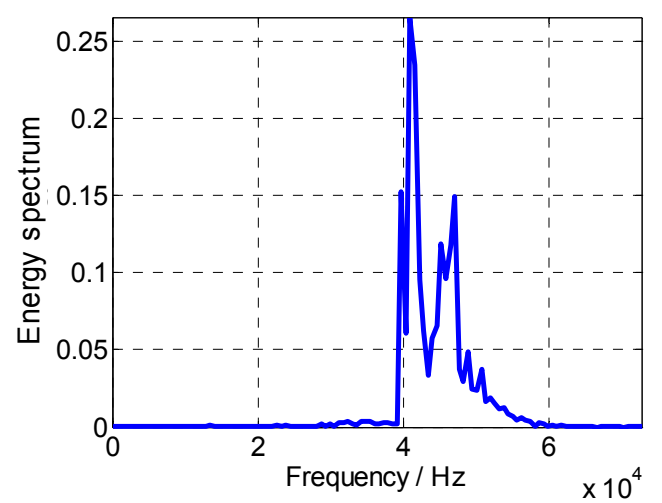

Figure 12. Energy Spectrum of Delaminated Position 
Comparing Figure 11 and Figure 12, it can be found that: Amplitude of energy spectrum in delaminated position is obviously higher than that in undamaged position, and energy in the high frequency domain in delaminated position is also greater than that in undamaged position. That is because: In delaminated position, most energy propagates in steel, resulting in less attenuation of energy.

\subsection{Comparison of Undamaged Position and Position with Sundry Inside}

Observing the two wave lines in Figure 13, conclusion can be made as follow: For undamaged position, obvious waveform can be observed from $50 \mu \mathrm{s}$; for position with sundry inside, obvious waveform cannot be observed until about $80 \mu$ s .

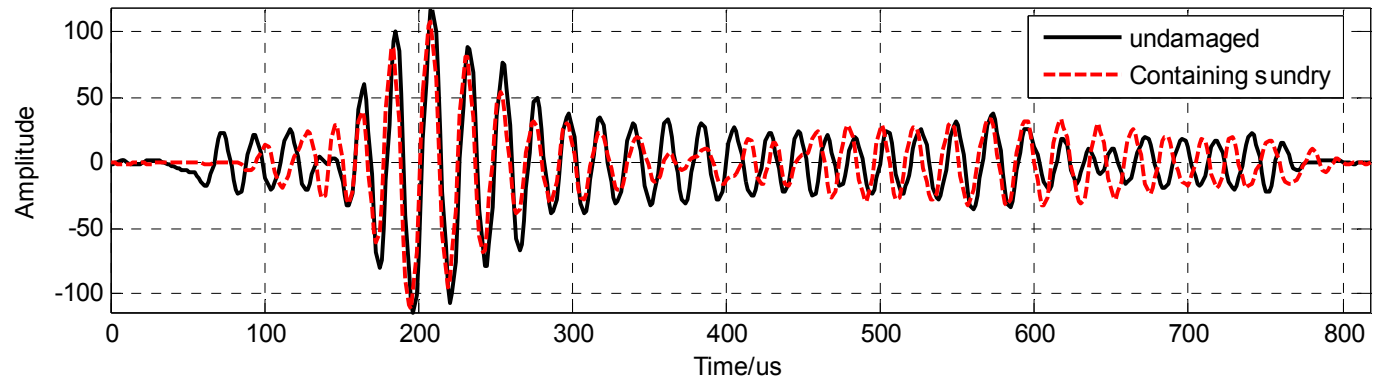

Figure 13. Comparison of the First-order Intrinsic Mode Functions of Undamaged Position and Position with Sundry Inside

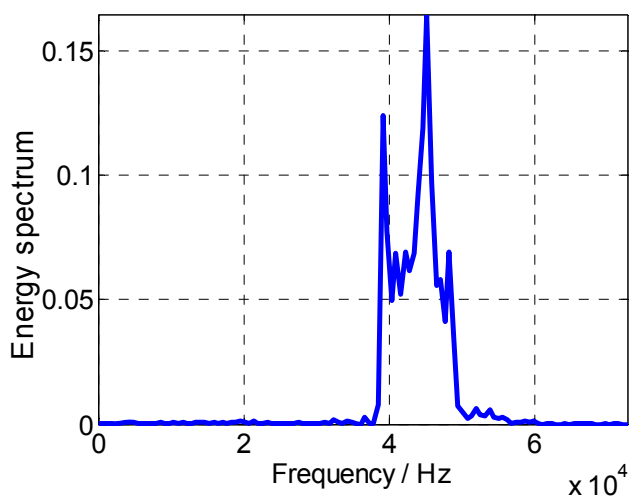

Figure 14. Energy Spectrum of Undamaged Position

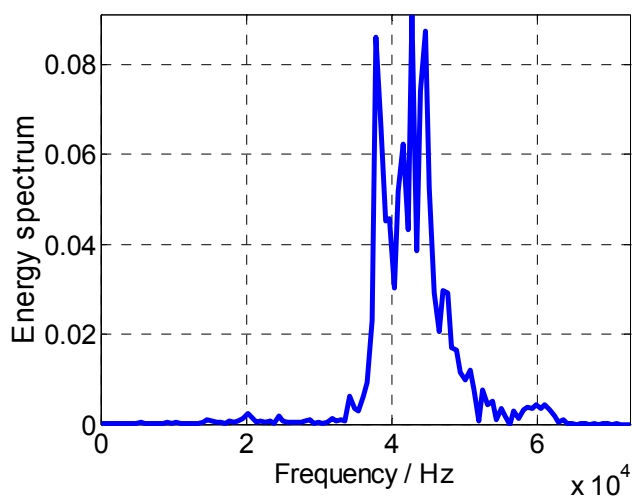

Figure 15. Energy Spectrum of Position with Sundry Inside

Inspecting Figure 14 and Figure 15, obvious difference can be found: the amplitude and the peak value of the energy spectrum in position with sundry inside is notably smaller than that in undamaged position. That is because some of the ultrasonic energy is lost due to the reflection on the boundary surface between the sundry and the concrete.

\subsection{Comparison of Undamaged Position and Position with Hole in the Section Center}

Detect position with a $1.5 \mathrm{~mm}$ diameter hole at the section center with ultrasonic signal and then compare the results of it with the results of undamaged position as follow.

As it is shown in Figure 15, the first wave arrival time of the first-order IMF of the position with hole is a little late than that of undamaged position. Moreover, the two curves in Figure 16 can be observed obvious phase difference throughout the sampling time, the curve of the position with hole always arrive the peak value before the curve of the undamaged position. 


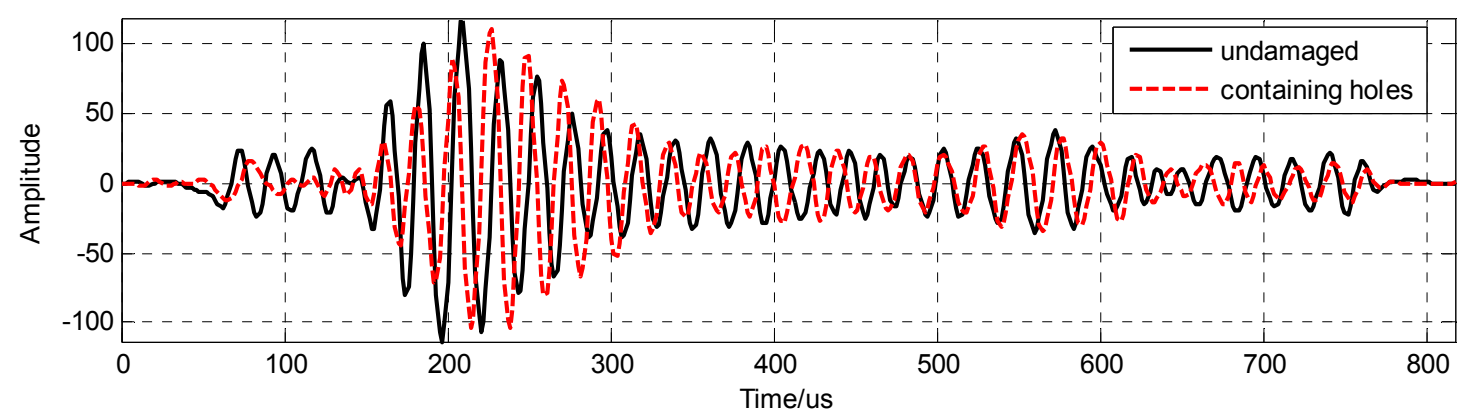

Figure 16. Comparison of the First-order Intrinsic Mode Functions of Undamaged Position and Position with Hole

Comparing Figure 17 with Figure 18, only very small difference can be observed, the amplitude of energy at about $40 \mathrm{KHz}$ in position with hole is smaller than that in undamaged position. It can be expected that when the diameter of the hole is very small, the effect of it to the energy spectrum may be hard to be identified.

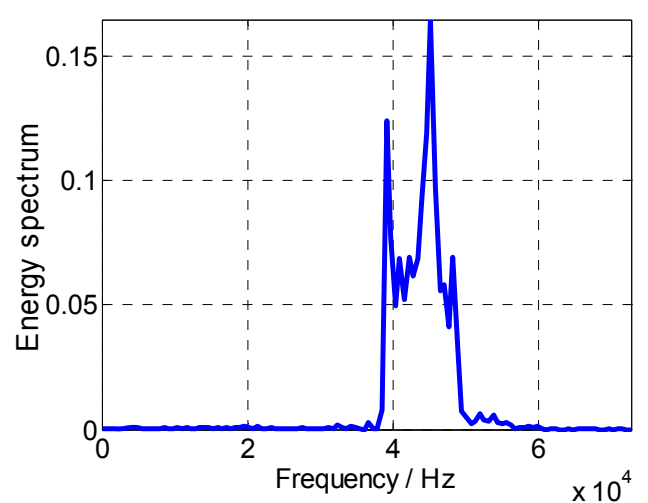

Figure 17. Energy Spectrum of Undamaged Position

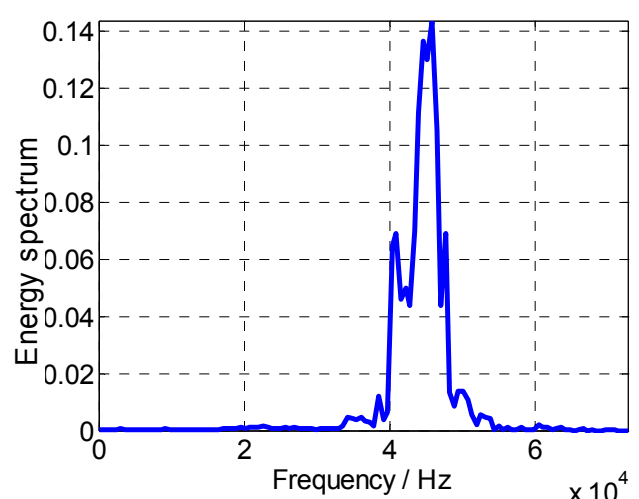

Figure 18. Energy Spectrum of Position with Hole

\section{CONCLUSION}

Experimental results show that the ultrasonic method combining with the filtering process and HHT is feasible to inspect the quality of CFST. No matter the defect is delamination between the steel and concrete, sundry inside the concrete or small hole inside the concrete, it can be effectively recognized. However, further investigation is needed to determine the size of the defect. And, for concrete filled hollow steel tube, it would be difficult to recognize the defect in it, efforts is needed to distinguish the effect of the hole in the concrete to the ultrasonic signal. 


\section{REFERENCES}

[1] Wu, X.X., “Concrete Nondestructive Testing Technology Manual”, China Communications Press, 1999 (in Chinese).

[2] Technical Specification for Ultrasonic Testing of Concrete Defects (CECS21:90), China Engineering Construction Standardization Association (in Chinese).

[3] Zhou, X.Y., Xiao, Y.F. and Cao, G.H., "Investigation into the Ultrasonic Method for the Quality of CFST, Railway Science and Engineering. 2006, Vol. 6, No. 3, pp. 50-54 (in Chinese).

[4] Xu, S.W. and Shi, H., "First Exploration of Time-Frequency Analysis Method", Modern Electronics, 1996, Vol. 54, No. 1, pp. 38-44 (in Chinese).

[5] Braun, S. and Feldman, M., "Time-frequency Characteristics of Non-linear Systems", Mechanical Systems and Signal Processing, 1997, Vol. 11, No. 4, pp. 611-620.

[6] Norden, E., Huang, Z.S., Steven, R. and Long, et al., "The Empirical Mode Decomposition and the Hilbert Spectrum for Nonlinear and Non-stationary Time Series Analysis", Proc. R. Soc. Lond. A., 1998, Vol. 454, pp. 899-955.

[7] Vesselin, V., "The Analysis of the Empirical Mode Decomposition Method", USC, November 20, 2002.

[8] Gong, M.S. and Xie, L.L., "Preliminary Study of the Application of HHT Method in Earthquake Engineering", World Earthquake Engineering, 2003, Vol. 19, No. 3 (in Chinese). 


\title{
EFFECT OF DAMPERS ON SEISMIC DEMAND OF SHORT PERIOD STRUCTURES IN DEEP COHESIONLESS SITES
}

\author{
N.S. Armouti \\ Associate Professor of Civil Engineering \\ University of Jordan, Amman 11942, Jordan \\ (Corresponding author: E-mail: armouti@ju.edu.jo)
}

Received: 18 October 2010; Revised: 26 December 2010; Accepted: 3 January 2011

\begin{abstract}
Seismic behavior of short period structures with dampers founded on deep cohesionless soil is investigated. A Single bay frame with diagonal damper that represents short period structures is evaluated in response to the excitation of a set of earthquake records. The frame system is modeled as a Generalized Single Degree of Freedom System, and is subjected to five earthquake records representative of deep cohesionless site conditions. The relationship between the force modification factor and the global ductility demand for short period structures founded on deep cohesionless soil, in the presence of dampers, tends to approach those of long period ones. Compared with seismic demand under general site conditions, short period structures founded on deep cohesionless soil show less seismic demand and lower sensitivity to earthquake excitations. Similar to seismic demand in general site conditions, and except for period of 0.1 second, short period structures in deep cohesionless sites with dampers having damping ratios higher than $20 \%$ tend to keep the structural response in the elastic range even for high values of force reductions. Seismic code provisions should be revised to account for short period effect under seismic excitation.
\end{abstract}

Keywords: Ductility demand, seismic demand, short period, dampers, deep cohesionless soil

\section{INTRODUCTION}

Earthquake-resistant structures are generally designed with strength much less than their elastic strength demand due to earthquake excitation. According to modern seismic codes, typically welldetailed structures may be designed with strength capacity as low as $12 \%$ of their elastic strength demand (IBC [1]).

This reduction in strength demand is possible due to many factors such as ductility, energy dissipation, and frequency shift. In general, such strength reduction imposes special demand on structures in terms of detailing to achieve specified levels of ductility and energy dissipation which are function of the specified levels of strength reduction. Seismic codes, in general, utilize parameters such as force modification factor, $\mathrm{R}$, and global ductility demand, $\mu_{\mathrm{d}}$, to implicitly account for strength reductions. Force modification factor is defined as the ratio of elastic strength demand to actual yield force of the structure, whereas, global ductility demand is defined as the maximum inelastic displacement under seismic excitation to the actual yield displacement of the structure.

However, the codes do not explicitly address the damping of structures which is an indication of the energy dissipation capacity of the structure. Furthermore, codes do not distinguish between short period and long period structures in their treatment of strength and ductility requirements for design of earthquake-resistant structures. 
Many research results on seismic demand indicate that even though ductility demand is feasible for long period structures (tall buildings), they impose high levels of ductility for short period structures (low rise buildings and structures) which may not be achievable (Nassar and Krawinkler [2]). Furthermore, research results also indicate that ductility demand is very sensitive to strength reduction for short period structures (Armouti [3]).

Consequently, short period structures should rely on factors other than ductility to achieve strength reduction such as energy dissipation. Therefore, this study focuses on examining the effect of explicit damping on ductility demand on one hand, and on the feasibility of dampers as an alternative to ductility requirements for short period structures on the other.

Dampers are widely used in structures to alleviate the harmful effect of earthquakes on structures. Dampers are known to be used in new buildings (Nagarajaiah and Narasimhan [4]), in bridges (Madhekar and Jangid [5]), and in retrofit of existing structures (Malhotra et al. [6]), (Potty and Nambissan [7]). Dampers have proven to be effective systems for reducing earthquake forces in structures (Chandra et al. [8]), (Raju et al. [9]), (Takewaki et al. [10]). Performance of dampers near collapse during large seismic events has proven feasible by analytical and experimental investigation (Miyamoto et al. [11]).

The behavior of short period structures with dampers under the excitation of earthquakes representative of dominant site conditions, namely, rock, deep cohesionless soil, and soft areas is investigated (Armouti [12]). The investigation has shown that dampers reduce the high ductility demand of short period structures. In order to explore the deviation of the behavior of short period structures founded on specific site conditions from those founded on the general site conditions presented by (Armouti [12]), this study considers the behavior of short period structures founded on deep cohesionless soil such as sand areas.

In order to examine the effect of dampers on the behavior of short period structures founded on deep cohesionless soil under seismic excitation, a typical one bay frame with a diagonal viscous damper is considered for this study to examine the effect of viscous dampers on the $\mathrm{R}-\mu_{\mathrm{d}}$ relationship. A frame with a damper having a coefficient of damping, $\mathrm{C}$, is subjected to a horizontal component of ground motion, $\ddot{u}_{g}$, as shown in Figure 1 . In order to get a better understanding of the effect of ductility and energy dissipation as outlined above; and to be consistent with previous studies on this subject, the frame is modeled as a generalized single degree of freedom, SDOF, system, and subjected to five earthquake records generated to be representative of earthquakes in deep cohesionless sites. Consequently, the force reduction factor, $\mathrm{R}$, and the global ductility demand, $\mu_{\mathrm{d}}$, are evaluated and compared with previous studies to examine the effect of damping on the ductility demand as an indicator of the behavior of short period structures founded on deep cohesionless soil.

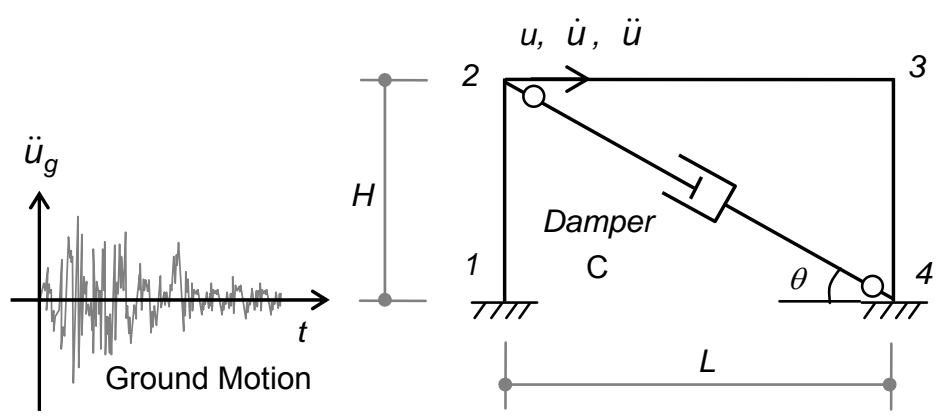

Figure 1. Frame Layout 
To achieve these objectives, a parametric study using inelastic dynamic analysis is performed by varying the period and the intensity of earthquake excitation. The parameter variation includes five periods, five levels of relative yielding of the hysteresis model, and three damping ratios for each of the five earthquake records. This parameter variation results in 375 pairs of $\mathrm{R}$ and $\mu_{\mathrm{d}}$ values as a result of 125 runs of elastic dynamic analysis and 375 runs of inelastic dynamic analysis which are grouped and evaluated.

For completeness of presentation, a description of the structure, the earthquake records used, and the inelastic dynamic analysis procedures including the hysteretic model of the frame are presented.

\section{STRUCTURAL MODEL}

As mentioned previously, the structural model is selected as a frame having four nodes 1 through 4 as shown in Figure 1. The frame consists of one bay frame fixed at both supports which is considered typical of low rise steel buildings, hungers, and storage facilities. The frame is provided with explicit diagonal viscous damper with coefficient of damping, $C$, between nodes 2 and 4 . The frame may be modeled as a Generalized Single Degree of Freedom, GSDOF, system by assuming the total mass to be lumped at one node, node 2, as shown in Figure 2. The generalized degree of freedom in this case is the mass displacement in the direction of, $\mathrm{u}$, at node 2 . The generalized resistance of the frame without the damper is obtained due to an induced displacement of the mass in direction, $\mathrm{u}$, as a generalized spring force, $\mathrm{F}_{\mathrm{S}}{ }^{*}$, whereas the component of the reactive force of the damper in the direction of displacement, $u$, is obtained due to induced velocity in the direction of, $\dot{u}$, as the generalized damping force, $\mathrm{F}_{\mathrm{D}}{ }^{*}$.

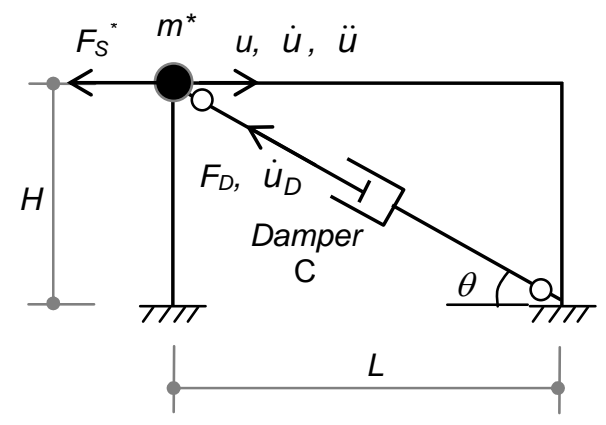

Figure 2. Lumped Mass as GSDOF

In case of elastic analysis, the generalized stiffness, $\mathrm{k}^{*}$, is simply evaluated by subjecting the frame to a unit displacement in direction of, u, which can be easily obtained by any structural analysis software. The generalized coefficient of damping, $C^{*}$, can be obtained as function of the damper coefficient of damping, $\mathrm{C}$, with reference to Figure 3 as follows:

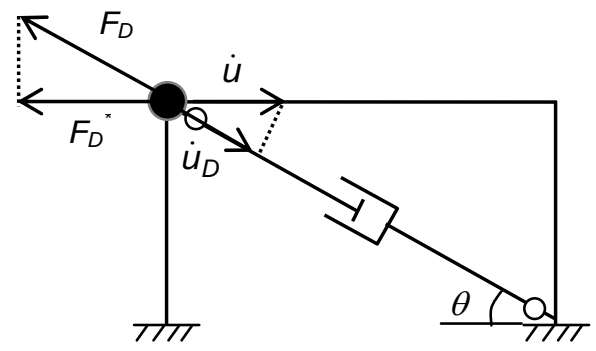

Figure 3. Generalized Damping due to Velocity, $\dot{u}$ 
Since damper velocity is

$$
\dot{u}_{D}=\dot{u} \cos \theta
$$

The force in the damper is given as $\quad F_{D}=C \cdot \dot{u}_{D}=C \cdot \cos \theta \dot{u}$

The generalized force of the damper in the direction of, $\mathrm{u}$, becomes:

$F_{D}^{*}=F_{D} \cos \theta=C \cdot \cos ^{2} \theta \dot{u}=C^{*} \dot{u}$

Therefore, the generalized damping becomes: $C^{*}=C \cdot \cos ^{2} \theta$

The frame system, therefore, can be represented by a system with a generalized single dynamic degree of freedom consists of a lumped mass subjected to a generalized forces and displacements as shown in Figure 4. The equation of motion in this case takes the form

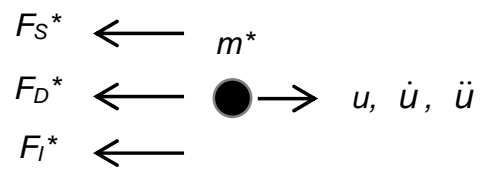

Figure 4. Generalized SDOF

$F_{I}^{*}+{F_{D}}^{*}+{F_{S}}^{*}=-m^{*} \ddot{u}_{g}$

In case of elastic analysis, the equation becomes

$$
\begin{aligned}
& m^{*} \ddot{u}+C^{*} \dot{u}+k^{*} u=-m^{*} \ddot{u}_{g} \\
& \ddot{u}+2 \zeta \omega \dot{u}+\omega^{2} \quad u=-\ddot{u}_{g}
\end{aligned}
$$

where

$u$ = generalized displacement.

$\dot{u}=$ generalized velocity.

$\ddot{u}$ = generalized acceleration.

$\ddot{u}_{g}=$ ground acceleration (earthquake).

$m^{*}=$ generalized mass.

$F_{I}{ }^{*}=$ generalized inertial force.

$C^{*}=$ generalized coefficient of damping.

$F_{D}{ }^{*}=$ generalized damping force.

$k^{*}$ = generalized stiffness.

$F_{S}{ }^{*}=$ generalized spring force.

$\omega=$ frequency of the generalized system.

$\zeta=$ damping ratio of the generalized system.

Since the parametric study uses predefined values of period and damping ratios, the exact values of these parameters, in this study, become immaterial. Therefore, the values of the mass, stiffness, damping, and level of ground motion are adjusted to produce the intended parameter values of the study.

Consequently, the force reduction factor, $\mathrm{R}$, is defined as the ratio of the elastic strength demand of the frame, $F_{e}$, to the actual yield strength, $F_{y}$, whereas global ductility demand, $\mu_{d}$, is defined as the ratio of the maximum displacement that is reached during the excitation history, $\mathrm{u}_{\max }$, to the actual yield displacement of the frame, $\mathrm{u}_{\mathrm{y}}$. These ratios are given in mathematical form as follows 
$R=\frac{F_{e}}{F_{y}}, \quad \mu_{d}=\frac{u_{\max }}{u_{y}}$

\section{RECORDS OF EARTHQUAKES}

In view of earthquake characteristics, earthquake records are selected to be representative of the deep cohesionless soil conditions found in reality. In order to be comparative, three synthetic records that are used in this analysis were adopted from previous studies (Armouti [3]), (Armouti [12]). Additional two records are generated with the same power spectral density curve for deep cohesionless sites. The records are based on the PSD distribution for soft sties given in Figure 5.

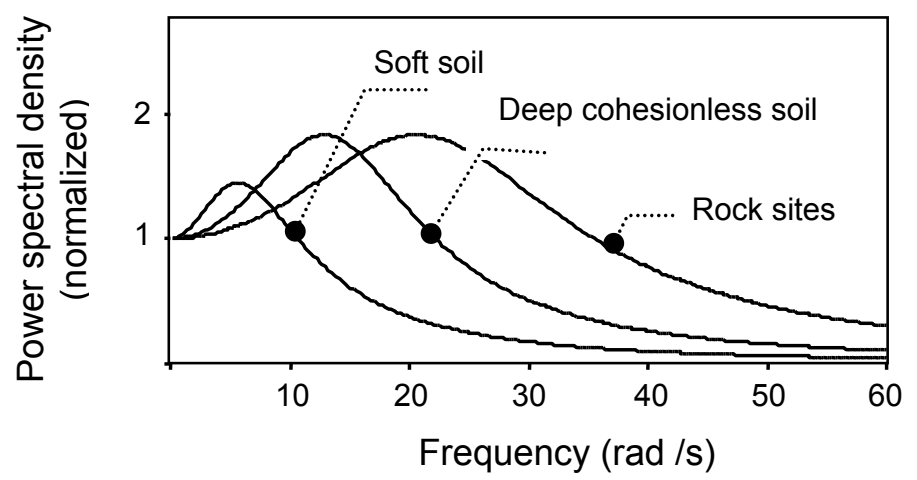

Figure 5. Distribution of Power Spectral Density of Earthquakes According to their Site Conditions

Using this PSD distribution, five synthetic records are generated. If the letter (D) indicates deep cohesionless site for future reference, these records are designated as D1.nsa, D2.nsa, D3.nsa, D4.nsa, and D5.nsa. Sample of these records, D1.nsa, with its associated Fourier Amplitude Spectrum are shown in Figure 6.

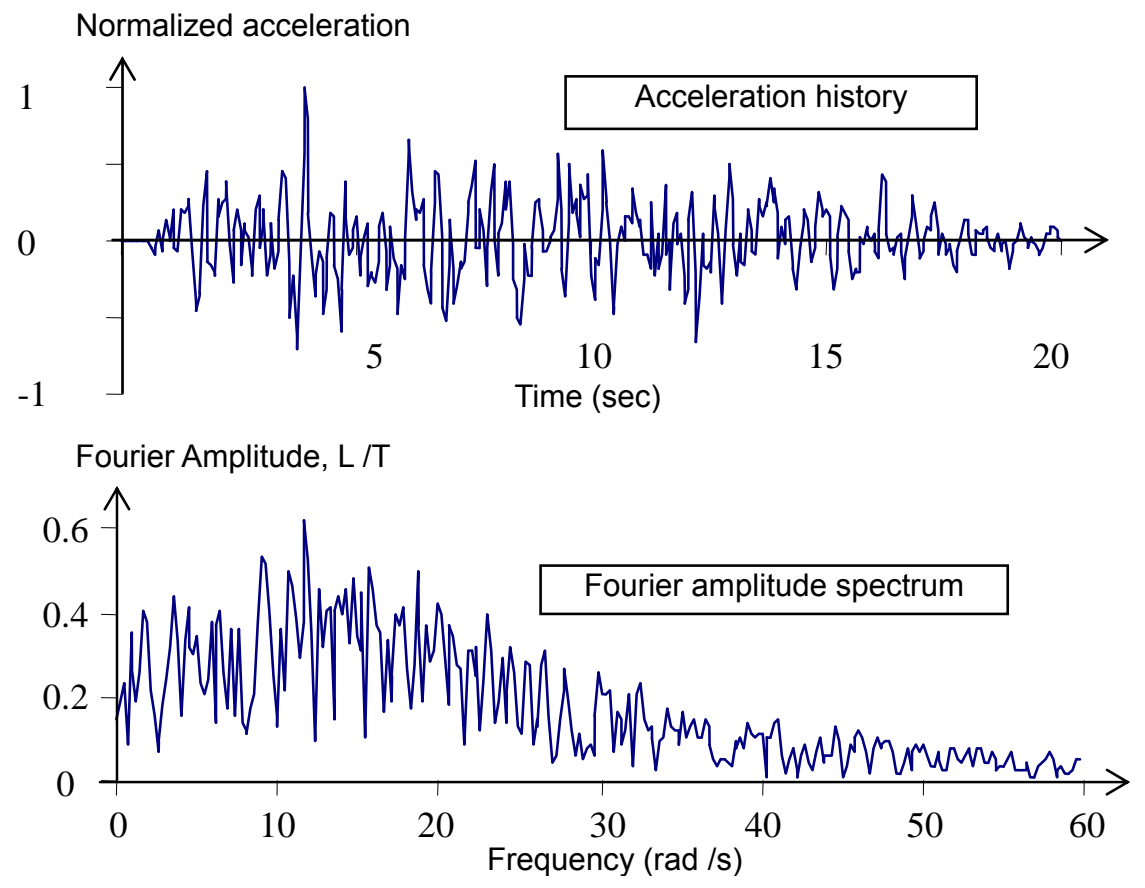

Figure 6. Properties of Synthetic Record D1.nsa 


\section{INELASTIC DYNAMIC ANALYSIS}

The purpose of this study is to examine the effect of viscous dampers on the relationship between $\mathrm{R}$ and $\mu_{\mathrm{d}}$ for short period structures founded on deep cohesionless soil. Since the relationship between $\mathrm{R}$ and $\mu_{\mathrm{d}}$ can only be evaluated in a statistical sense due to the extreme randomness and uncertainty of earthquake characteristics, inelastic dynamic analysis (Clough and Penzien [13]) is needed to generate a data base for this purpose. In addition to the selected five earthquake records, the parameter variation includes five periods, five ductility ratios, and three damping ratio resulting in $5 \times 5 \times 5 \times 3=375$ data points.

The inelastic dynamic analysis can be performed using SAP2000 software (CSI [14]) under Time History Function. The GSDOF frame may be modeled in SAP2000 as direct elasto-plastic link, whereas the damper is modeled as damper link. The parameters of the link and the damper are selected in view of the intended parameter variation values in conjunction with the equation of motion which is given before as

$m^{*} \ddot{u}+C^{*} \dot{u}+k^{*} u=-m^{*} \ddot{u}_{g}$

In case of inelastic dynamic analysis, the stiffness will not be constant, and hence the frame resistance is taken as a reactive generalized restoring force, $F_{S}{ }^{*}$, hence the equation of motion takes its final form as

$m^{*} \ddot{u}+C^{*} \dot{u}+F_{S}^{*}=-m^{*} \ddot{u}_{g}$

where

$u$ = generalized displacement of the mass in the direction of the single degree of freedom.

$\dot{u}$ = generalized mass velocity.

$\ddot{u}$ = generalized mass acceleration.

$\ddot{u}_{g}=$ horizontal ground acceleration.

$m^{*}=$ generalized total mass.

$C^{*}=$ generalized coefficient of viscous damping.

$F_{S}{ }^{*}=$ generalized restoring force (hysteresis model).

The structural response is represented by a bilinear hysteresis model with post yielding stiffness equals to $10 \%$ of its initial stiffness as shown in Figure 7 . The properties of the hysteresis model are included in SAP2000 through the elasto-plastic link nonlinear properties. A yield force of 10 $\mathrm{kN}$ and yield displacement of $0.01 \mathrm{~m}$ are used for this purpose. Since the model properties are required arbitrarily to obtain predefined periods, the elastic stiffness, $\mathrm{k}_{0}$, of the model is selected as $1000 \mathrm{kN} / \mathrm{m}$, whereas the mass is calibrated for each case to obtain the desired period since the period is given as

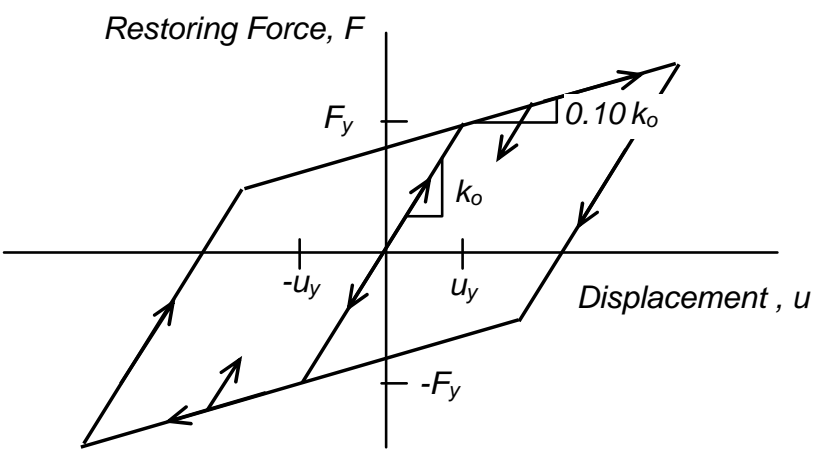

Figure 7. Bilinear Hysteresis Model 
$T=2 \pi \sqrt{\frac{m^{*}}{k^{*}}}$

The generalized damping coefficient is calculated in view of the desired damping ratio and the selected mass and stiffness as follows

The critical damping, $\mathrm{C}_{\mathrm{CR}}^{*}$, is calculated as $\quad C_{C R}^{*}=2 \sqrt{k^{*} m^{*}}$

The damping coefficient, $\mathrm{C}^{*}$, is then calculated as function of damping ratio, $\zeta$ and critical damping, $\mathrm{C}_{\mathrm{CR}}^{*}$, as

$C^{*}=\zeta C_{C R}^{*}$

The five periods of the model are chosen by adjusting the mass to produce the desired period. Since the R- $\mu_{\mathrm{d}}$ relationship is targeted in this study for short period structures, the five periods used in this study are $0.1,0.2,0.3$, and 0.4 seconds. A fifth period of 0.5 seconds is also included in the study as it marks the border line between short and long period values of structures under typical earthquake excitation.

In order to obtain various levels of $\mathrm{R}$ values, the yield level of the frame is kept constant while changing the intensity of the earthquakes, i.e. the peak ground acceleration of the earthquakes. Accordingly, the parameter variation is generated by taking a different level of peak ground acceleration for each period and each earthquake record. The elastic strength demand, i.e. the maximum elastic force, $\mathrm{F}_{\mathrm{e}}$, and the maximum elastic displacement, $\mathrm{u}_{\mathrm{e}}$, are then obtained using elastic dynamic analysis, i.e. Time History Analysis with infinite yielding. The damping ratio is taken $5 \%$ as customary used. For each value of, $F_{e}$, an R-value is calculated as follows:

$R=\frac{F_{e}}{F_{y}}$

For each value of $\mathrm{R}$ obtained above and for each level of damping of the damper, inelastic dynamic analysis, i.e. Time History Analysis with yielding force, at $10 \mathrm{kN}$, is performed to evaluate the maximum displacement demand during the time of excitation, $\mathrm{u}_{\max }$. Knowing $\mathrm{u}_{\max }, \mathrm{u}_{\mathrm{y}}$, the quantities $\mu_{\mathrm{d}}$ is calculated as follows

$\mu_{d}=\frac{u_{\max }}{u_{y}}$

A total number of 375 pairs of $\mathrm{R}$ and $\mu_{\mathrm{d}}$ from the above procedures are obtained. Samples of such results are shown in Figure 8 for 20\% damping ratio and in Figure 9 for $40 \%$ damping ratio. It can be noticed that the data points still exhibit the level of randomness associated with such analysis. 


\section{NASSAR AND KRAWINKLER MODEL}

Based on extensive study resulted in large data base of seismic demand characteristics using fifteen actual earthquake records, Nassar and Krawinkler, N\&K, (Nassar and Krawinkler [2]) have proposed the following expression for a relationship between $\mathrm{R}$ and $\mu_{\mathrm{d}}$ factors as follows

$R=\left[C \cdot\left(\mu_{d}-1\right)+1\right]^{1 / C}$

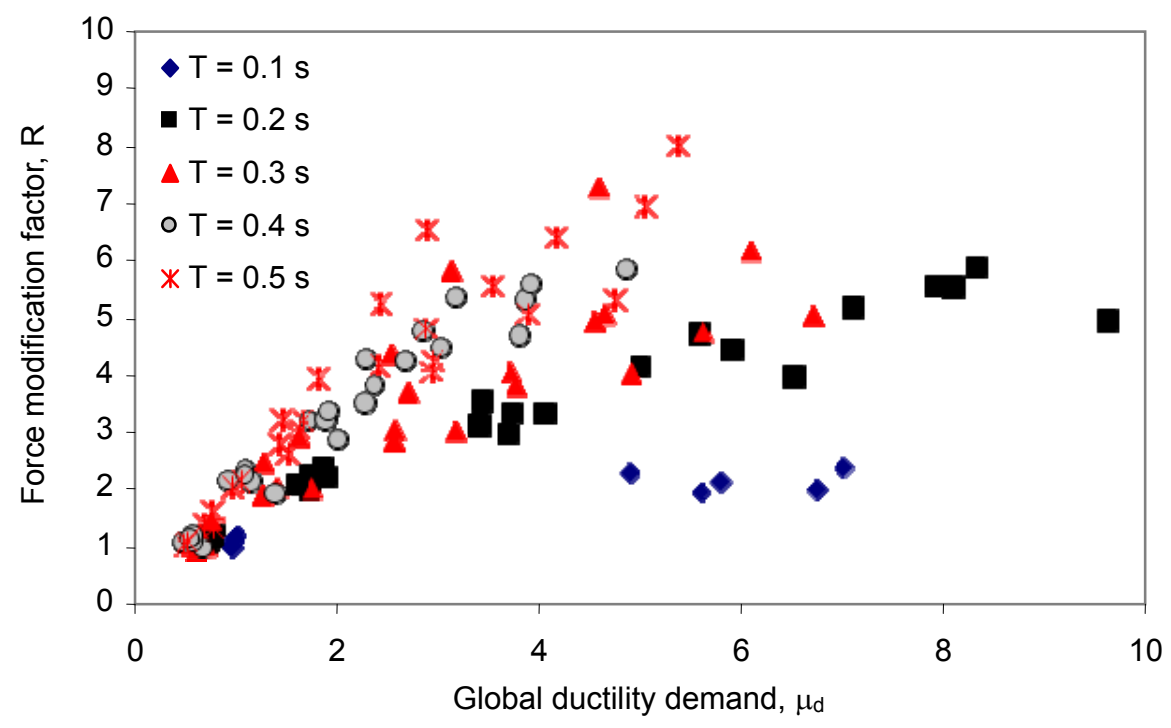

Figure 8. Relationship between Force Modification Factor and Global Ductility Demand at Damping Ratio of 20\%

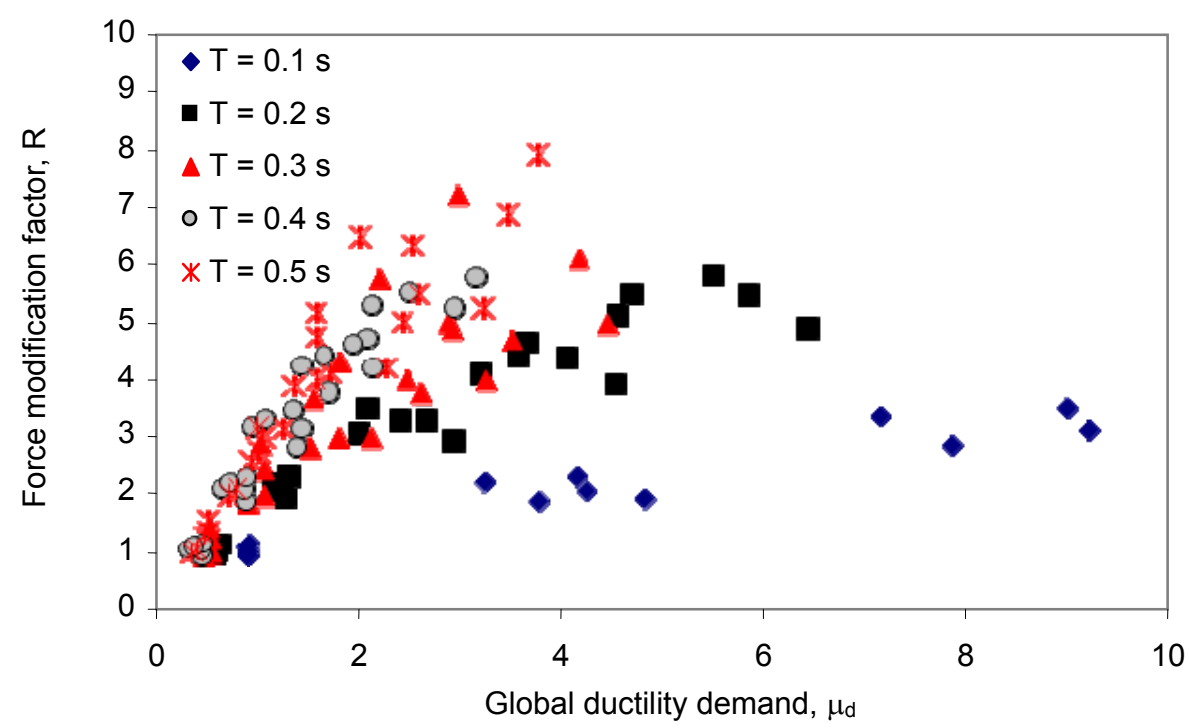

Figure 9. Relationship between Force Modification Factor and

Global Ductility Demand at Damping Ratio of $40 \%$

where $\mathrm{C}$ is given as

$C(T)=\frac{T^{a}}{1+T^{a}}+\frac{b}{T}$ 
For a bilinear model with $10 \%$ post yielding stiffness and typical damping ratio of $5 \%$, N\&K have used nonlinear regression analysis to produce values of $(a=0.8)$ and $(b=0.29)$. Using these values, a plot of the parameter $C$ versus period $T$ is shown in Figure 10. This figure will be used in this study as the reference relationship between $\mathrm{R}$ and $\mu_{\mathrm{d}}$ for a bilinear hysterisis model under the excitation of earthquake records. It is worthwhile to mention that when the value of the parameter $\mathrm{C}=1$, the $\mathrm{R}-\mu_{d}$ relationship tends to the well known equal displacement criteria $\left(R=\mu_{d}\right)$; and when the value of the parameter $\mathrm{C}=2$, the $\mathrm{R}-\mu_{d}$ relationship tends to the well known equal energy criteria $(R=\sqrt{2 \mu-1})$.

Parameter C

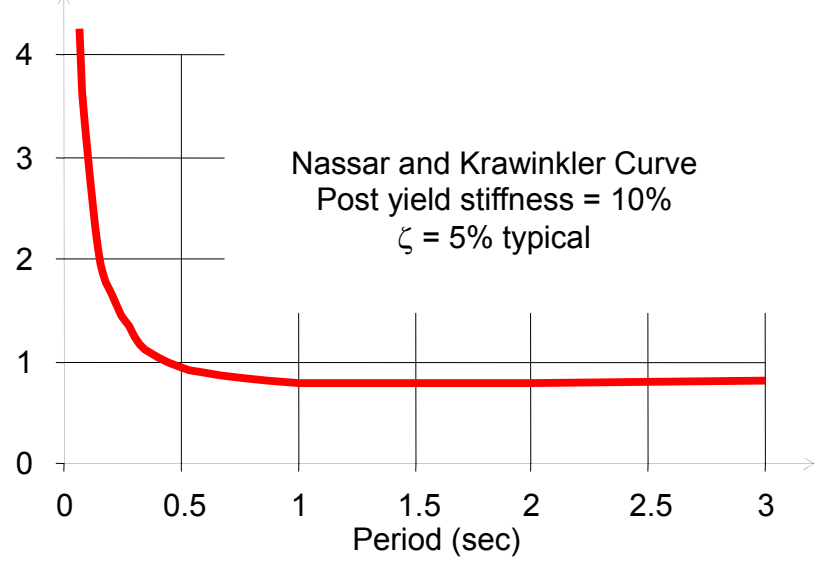

Figure 10. Relationship between Parameter C and Period

(Nassar and Krawinkler [2])

It is worthwhile also to point out that, in the statistical sense, the C-T relationship shown in Figure 10 seems to become steady in the long period region $(T>0.5 \mathrm{sec})$. For long period regions, where parameter $\mathrm{C}$ is low $(\mathrm{C}<1)$, ductility demand is usually low and steady, whereas, for short period regions where parameter $\mathrm{C}$ is high $(\mathrm{C}>>1)$, the seismic demand becomes sensitive and high. This type of behavior is known to be a characteristic behavior of structures in response to earthquake excitation. It should also be pointed out that when the value of $\mathrm{C}$ is greater than one, the ductility demand becomes more than the force reduction values, and when the value of $C$ is smaller than one, the ductility demand becomes less than the force reduction values.

\section{ARMOUTI REFERENCE RESULTS FOR GENERAL SITE CONDITIONS}

Response of short period structures with dampers under general site conditions was investigated by Armouti (Armouti [12]). His study considered nine earthquakes representative of the three dominant site conditions, namely, rock conditions, deep cohesionless conditions, and soft soil conditions where three earthquakes of each type where included in the analysis. A comparison with N\&K model was presented as shown in Figure 11 where the study showed that using dampers have smoothen seismic demand in presence of dampers for short period.

Table 1 shows values of the parameter $\mathrm{C}$ obtained by Armouti study which are also plotted in Figure 11 for reference comparison with this study which includes the effect of dampers on short period structures founded on deep cohesionless sites. 
Table 1 Nonlinear regression results for parameter $\mathrm{C}$ under general site conditions (Armouti [12])

\begin{tabular}{|c|c|c|c|c|}
\hline \multirow{2}{*}{$\begin{array}{c}\text { Period } \\
\text { (second) }\end{array}$} & \multicolumn{4}{|c|}{ Damping ratio } \\
\cline { 2 - 5 } & $20 \%$ & $40 \%$ & $60 \%$ & $80 \%$ \\
\hline 0.1 & 2.75 & 2.35 & 2.09 & 1.88 \\
\hline 0.2 & 1.42 & 0.89 & 0.56 & 0.31 \\
\hline 0.3 & 1.08 & 0.63 & 0.35 & 0.18 \\
\hline 0.4 & 0.84 & 0.31 & $* * *$ & $* * *$ \\
\hline 0.5 & 1.03 & 0.67 & 0.39 & 0.17 \\
\hline
\end{tabular}

Parameter C

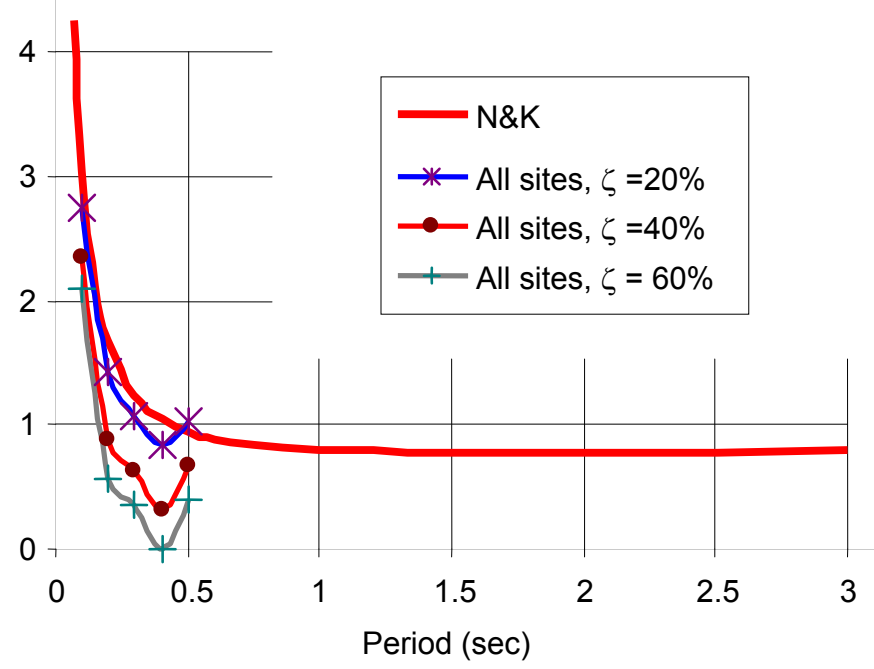

Figure 11. Values of Parameter C for Different Periods from Reference Models of N\&K [2], and Study of Armouti [12]

\section{ANALYSIS OF NUMERICAL RESULTS}

Evaluation of the numerical results obtained as outlined previously is accomplished through comparison with N\&K model and (Armouti [12]) results which is established by finding the parameter $\mathrm{C}$ at the selected periods of the system under the excitation of the selected earthquake records at each damping ratio. The resulting values of the parameter $\mathrm{C}$ will then be compared with C-T plot results from N\&K model and Armouti results.

Figure 12 shows one sample of nonlinear regression curve used to find the parameter $\mathrm{C}$ for a period of 0.1 second at damping ratio of $20 \%$, from which a value of $\mathrm{C}=2.751$ is obtained. Similar nonlinear regression analysis is conducted to produce the rest of the C-values for the selected periods as given in Table 2. 
Force modification factor,

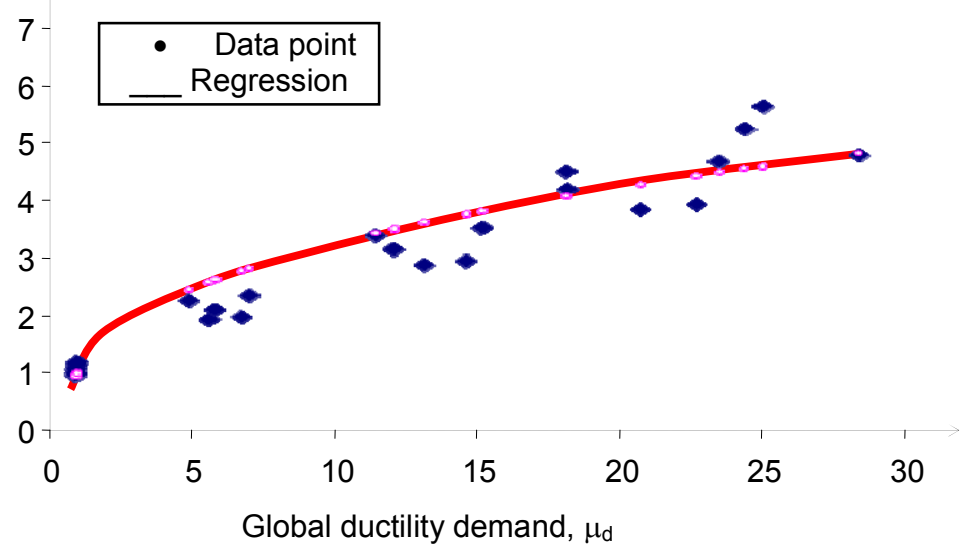

Figure 12. Sample Nonlinear Regression Curve for C Value at Period of $0.1 \mathrm{sec}$ and Damping Ratio of 20\%

Table 2 Nonlinear Regression Results for Parameter C under Deep Cohesionless Site Conditions

\begin{tabular}{|c|c|c|c|}
\hline \multirow{2}{*}{$\begin{array}{c}\text { Period } \\
\text { (second) }\end{array}$} & \multicolumn{3}{|c|}{ Damping ratio } \\
\cline { 2 - 4 } & $20 \%$ & $40 \%$ & $60 \%$ \\
\hline 0.1 & 2.75 & 2.31 & 2.04 \\
\hline 0.2 & 1.43 & 0.99 & 0.71 \\
\hline 0.3 & 1.00 & 0.54 & 0.19 \\
\hline 0.4 & 0.61 & 0.10 & $* * *$ \\
\hline 0.5 & 0.62 & 0.22 & $* * *$ \\
\hline
\end{tabular}

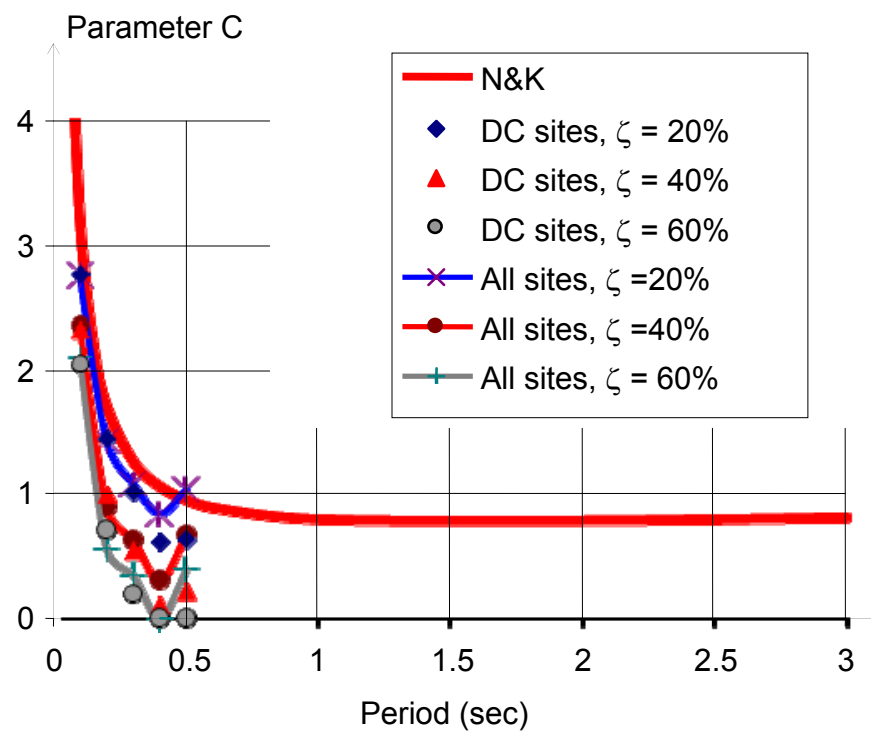

Figure 13. Values of Parameter C for Different Periods from this Study Against Reference Models of N\&K [2], and Armouti [12] 


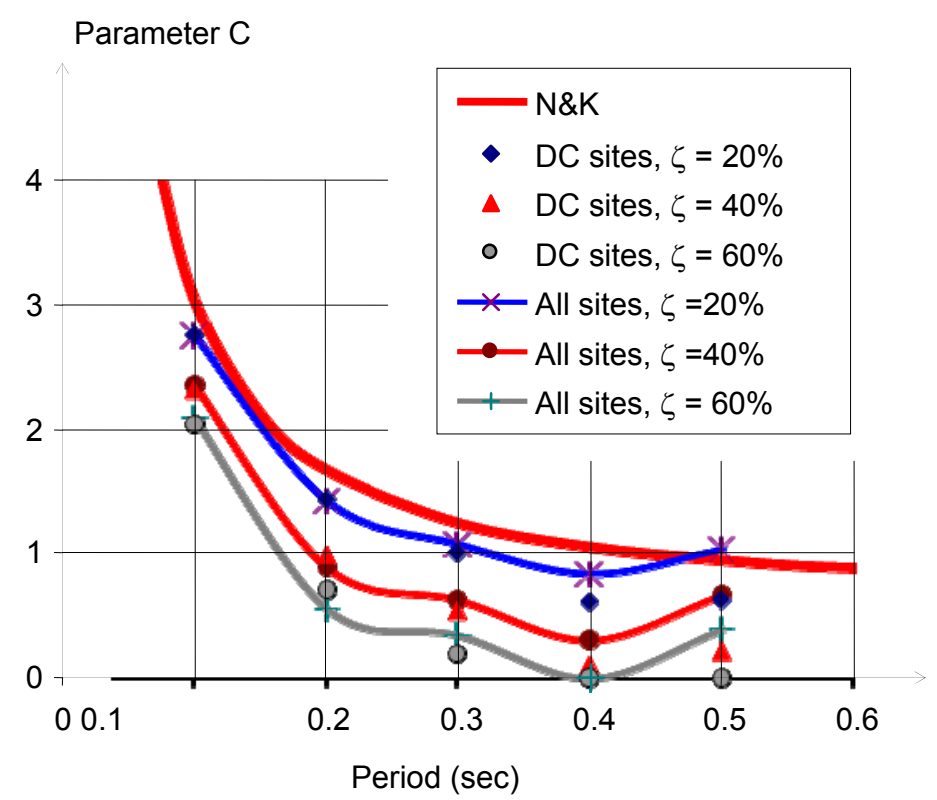

Figure 14. Values of Parameter C for Different Periods from this Study Against Reference Model of N\&K [2], and Armouti [12]

Figure 13 and Figure 14 show a comparison between the obtained C-values from this study and the references N\&K model and (Armouti [12]) results. It can be observed that the results from this study almost coincide with the results of All-site conditions for periods 0.1 and 0.2 second, whereas for periods $0.3,0.4$, and 0.5 second, these results lie below those of All-site conditions curves given in N\&K and Armouti studies. It can therefore be noted that the behavior of short period structures founded on deep cohesionless soil tends to be less demanding than those in the general site conditions.

It can also be noted that the C-values for the period of 0.1 second remain above the value of 2 which means that, for this period even with high values of damping, the ductility demand remains much higher than force reduction. However, high damping brings the level of demand closer to a value of 2 which is the equal energy criterion. Furthermore, the figure indicates that the behavior of short period structures founded on deep cohesionless area requires less seismic demand than those founded on general site conditions.

Since the C-values for period of 0.1 second remains in the high range values regardless of the damping values, it can be concluded that dampers have little effect on the behavior of structures with period of 0.1 second, therefore, structures of period of 0.1 second needs measures to elongate the period rather than increasing damping. Seismic isolation, for example, offers an ideal solution in this case since it usually shifts the period to the long period range resulting in large reduction in seismic forces.

Referring to Figure 8 and Figure 9, the scatter of data can be observed which is reflected by the extreme randomness of earthquakes and their random effect on the response of structures. Careful examination of these two figures shows that the data points of Figure 9 ( $40 \%$ damping) seem to shift to the left of the data points of Figure 8 (20\% damping) indicating less ductility demand with increased damping. Furthermore, it should be noticed that many responses of the structure remain elastic at reduced force values which are marked by the values of $(\mathrm{R}>1)$; and the values of $\left(\mu_{\mathrm{d}}<\right.$ 1). This general trend is also observed in the case of response of short period structures under general site conditions in previous research (Armouti [12]). 
Comparison between Figure 8 and Figure 9 indicates also that the points that remain elastic at reduced force are much more for the case of $40 \%$ damping than the case of $20 \%$ damping. It can be noticed also that the structure with $40 \%$ damping remains elastic at higher values of $\mathrm{R}$ ( $\mathrm{R}$ goes up to 3 ) than the structure with $20 \%$ (R goes up to 2). In other words, the reduction in elastic strength demand is simply shared between the system ductility and the damper.

\section{CONCLUSIONS}

Response of structures to earthquake records are known to impose high ductility demand on short period structures much higher than those of long period structures. Such high demand for short period structures may not even be feasible to achieve. Seismic codes, in general, overlook this issue and do not distinguish between long and short periods for this matter.

Armouti (Armouti [12]) has evaluated the effect of explicit dampers as a mean of alleviating the high ductility demand for short period structures through parametric study using one bay frame with diagonal damper under the excitation of nine earthquakes representative of dominant site conditions. His work examined this issue through the relationship between the force modification factor and the global ductility demand under seismic excitation as defined by most modern seismic codes (IBC [1]). This relationship constitutes the basic relationship for defining seismic design forces and the associated required ductility capacities.

In view of the extreme randomness of earthquake characteristics and the reflection of this randomness on the response of structures, and in order to explore the deviation of the behavior of short period structures founded on specific site conditions from those founded on the general site conditions, this study focuses on the response of structures founded on deep cohesionless sites. The obtained results in this study indicate, in statistical sense, that the response of short period structures founded on deep cohesionless soil to earthquakes after yielding is in fact close but less sensitive and less demanding than the case of response to earthquakes under general site conditions. Except of periods of 0.1 second, dampers with higher critical damping than $20 \%$ seem to bring the behavior of short period structures to levels of the behavior of long period ones. Even more, they show that higher damping improves the behavior of short period structures to levels that are feasibly achievable in practice. It has also been found that the higher the damping presence in the structure, the higher will be the presence of elastic behavior of the structure at even higher values of force reduction.

This study also indicates that dampers have little effect on the behavior of structures with period of 0.1 second, therefore, structures of period of 0.1 second need measures to elongate the period rather than increasing damping, for example, seismic isolation systems.

It can be concluded that response of short period structures founded on deep cohesionless sites is close, but less demanding than the response of short period structures founded on general site conditions, which emphasizes that structures with short periods founded on deep cohesionless soil still need attention to be carefully designed taking into consideration additional measures other than ductility to include some acceptable levels of safety. Furthermore, as this issue is overlooked in seismic codes, the codes ought to revisit the concept of force reduction and distinguish between long period structures and short period structures. Short period structures may need additional provisions to provide them with enough safety measures. 


\section{REFERENCES}

[1] IBC., "International Building Code”, International Code Council, Washington, DC. 2006

[2] Nassar, A. A. and Krawinkler H., "Seismic Demands for SDOF and MDOF systems", The John A. Blume Earthquake Engineering Center, Stanford University, California, 1991, Report No. 95.

[3] Armouti, N.S., "Response of Structures to Synthetic Earthquakes", Proceeding of the $9^{\text {th }}$ Arab Structural Engineering Conference, Abu Dhabi, UAE, 2003, Vol. 1, pp. 331-339.

[4] Nagarajaiah, S. and Narasimhan, S., "Seismic Control of Smart Base Isolated Buildings with New Semiactive Variable Damper”, Earthquake Engineering and Structural Dynamics, 2007, Vol. 36, No. 6, pp. 729-749.

[5] Madhekar, S. and Jangid, R., "Variable Dampers for Earthquake Protection of Benchmark Highway Bridges”, Smart Materials and Structures, 2009, Vol. 18, No. 11, pp. 115011, No. 18.

[6] Malhorta, A., Carson, D., Gopal, P., Braimah, A., Giovanni, G. and Pall, R., "Friction Dampers for Seismic Upgrade of St. Vincent Hospital, Ottawa”, Proceeding of the 13th World Conference on Earthquake Engineering, Vancouver, B.C., Canada, 2004, Paper No. 1952.

[7] Potty, N. and Nambissan, S., “Seismic Retrofit of Elevated Steel Water Tanks”, Proceeding of the International Conference on Construction and Building Technology, Kuala Lumpur, Malaysia, 2008, pp. 99-108.

[8] Chandra, R., Masand, M., Nandi, S., Tripathi, C., Pall, R. and Pall, A., "Friction-dampers for Seismic Control of La Gardenia Towers South City, Gurgaon, India”, Proceeding of the 12th World Conference on Earthquake Engineering, Auckland, New Zealand, 2000, Paper 2008.

[9] Raju, K., Prasad, A., Lakshmanan, N., Muthumani, K., Jagadish, D. and Amuthasheela, R., “Optimum Distribution of Viscous Fluid Dampers in Structural Systems”, Journal of The Institution of Engineers (India), 2005, Vol. 86, pp. 103-108.

[10] Takewaki, I., Katsura, K. and Ku, N., "Earthquake Input Energy to Two Buildings Connected by Viscous Dampers”, Journal of Structural Engineering, ASCE, 2007, Vol. 133, No, 5, pp. 620-628.

[11] Miyamoto, H.K, Gilani, A.S.J., Wada, A. and Ariyaratana, C., "Limit States and Failure Mechanisms of Viscous Dampers and the Implications for Large Earthquakes", Earthquake Engineering and Structural Dynamics, 2010, Vol. 39, No. 11, pp. 1279-1297.

[12] Armouti, N.S., "Effect of Dampers on Seismic Demand of Short Period Structures”, Jordan Journal of Civil Engineering, 2010, Vol. 4, No. 4, pp. 367-377.

[13] Clough, R.W. and Penzien, J., "Dynamics of Structures”, 2nd Ed., McGraw Hill, New York, 1993.

[14] CSI, “Structural Analysis Program, SAP2000 Nonlinear Version 12”, Computers and Structures, Inc., Berkeley, California, 2008. 